NUREG/CR-5856 PNL-8022

\title{
Identification and Evaluation of PWR In-Vessel Severe Accident Management Strategies
}

Prepared by

J. S. Dukelow, D. G. Harrison, M. Morgenstern

Pacific Northwest Laboratory

Operated by

Battelle Memorial Institute

-

Prepared for

U.S. Nuclear Regulatory Commission 


\section{AVAILABILITY NOTICE}

\section{Availability of Reference Materials Cited in NRC Publications}

Most documents elted in NRC publications will be avallable from one of the following sources:

1. The NAC Public Document Room, 2120 L Street, NW., Lower Level, Washington, DC 20555

2. The Superintendent of Documents, U.S. Government Printing Office, P.O. Box 37082, Washington. DC 20013-7082

3. The National Technical Information Service, Springfield, VA 22161

Although the ilsting that follows represents the majorlty of documents cited in NRC publications, it is not intended to be exhaustive.

Referenced documents available for inspection and copying for a fee from the NRC Public Document Roorn Include NRC correspondence and internal NRC memoranda: NAC bulletins, circulars, information notices, inspection and investigation notices; licensee event reports; vendor reports and correspondence; Commission papers; and applicant and licensee documents and correspondence.

The following documents in the NUREG series are available for purchase from the GPO Sales Program: formal NRC staff and contractor reports, NRC-sponsored conference proceedings, international agreement reports, grant publications, and NRC booklets and brochures. Also available are regulatory guides, NRC regulations in the Code of Federal Regulations, and Nuclear Regulatory Commission Issuances.

Documents availabieg from the National Technical Information Service include NUREG-series reports and technical reports prepared by other Federal agencies and reports prepared by the Atomic Energy Commission, forerunner agency to the Nuclear Regulatory Commission.

Documents available from public and special technical libraries include all open literature items, such as books, journal articles, and transactions. Federal fiegister notices, Federal and State legislation, and congressional reports can usually be obtained from these libraries.

Documents such as theses, dissertations, foreign reports and translations, and non-NRC conference proceedings are available for purchase from the organization sponsoring the publication cited.

Single copies of NRC draft reports are available free, to the extent of supply, upon written request to the Office of Administration, Distribution and Mail Services Section, U.S. Nuclear Regulatory Commission, Washington, DC 20555.

Coples of industry codes and standards used in a substantive manner in the NRC regulatory process are maintained at the NRC Library, 7920 Norfolk Avenue. Bethesda, Maryland, for use by the public. Codes and standards are usually copyrighted and may be purchased from the originating organization or, If they are American National Standards, from the American National Standards Institute, 1430 Broadway, New York, NY 10018.

\section{DISCLAIMER NOTICE}

This report was prepared as an account of work sponsored by an agency of the United States Government. Neither the United States Govemment nor any agency thereof, or any of their employees, makes any warranty, expressed or implied, or assumes any legal liability of responsibility for any third party's use, or the results of such use, of any information, apparatus, product or process disclosed in this report, or represents that its use by such third party would not infringe privately owned rights. 
NUREG/CR-5856

PNL-8022

RK

\section{Identification and Evaluation of PWR In-Vessel Severe Accident Management Strategies}

Manuscript Completed: February 1992

Date Published: March 1992

Prepared by

J. S. Dukelow, D. G. Harrison', M. Morgenstern' ${ }^{2}$

Pacific Northwest Laboratory

Richland, WA 99352

\section{Prepared for}

Division of Systems Research

Office of Nuclear Regulatory Research

U.S. Nuclear Regulatory Commission

Washington, DC 20555

NRC FIN B5996

'Jason Associates, Idaho Falls, ID 83402

2Battelle Human Affairs Research Centers, Seattle, WA 98105-5428 



\begin{abstract}
This reports documents work performed for the NRC/RES Accident Management Guidance Program to cvaluate possible strategies for mitigating the consequences of PWR severe accidents. The selection and evaluation of strategies was limited to the in-vessel phase of the severe accident, i.e., after the initiation of core degradation and prior to RPV failurc. A parallel project at BNL has been considering strategies applicable to the ex-vessel phase of PWR severc accidents.
\end{abstract}





\section{Contents}

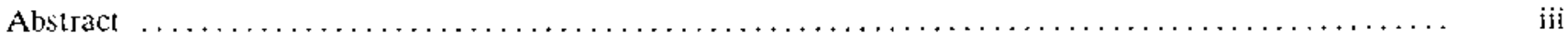

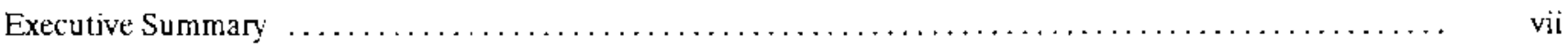

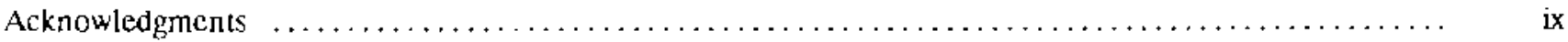

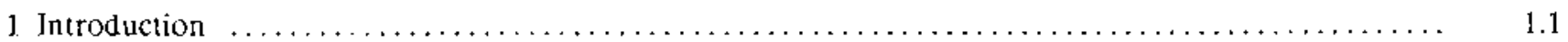

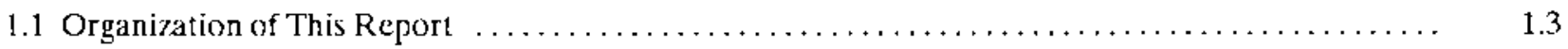

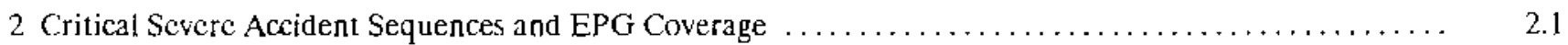

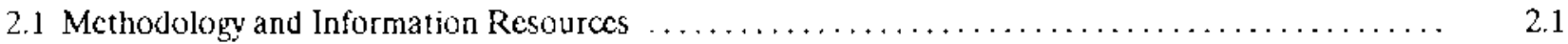

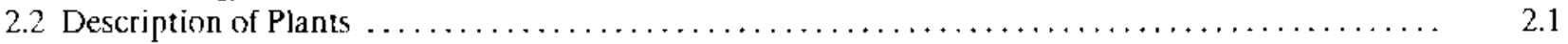

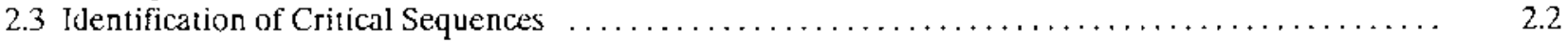

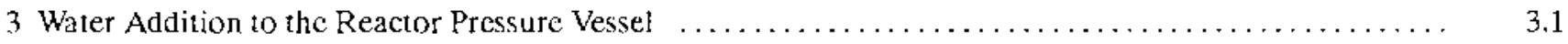

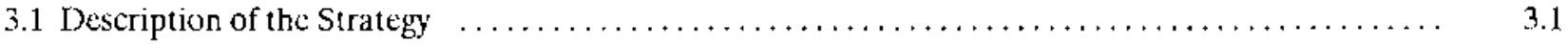

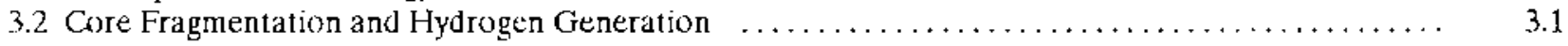

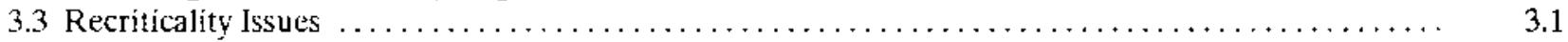

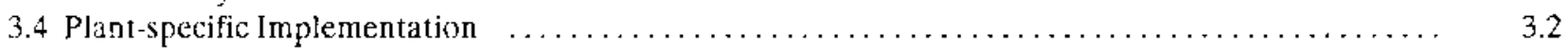

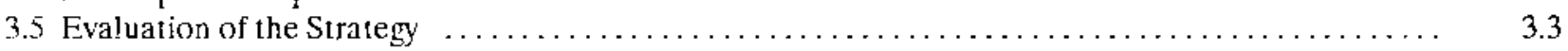

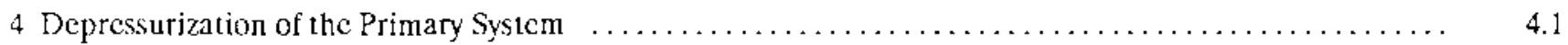

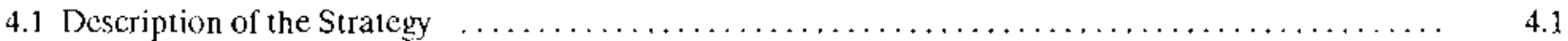

4.2 Use in Steam Generator Tube Rupture and Interfacing System LOCAs ....................

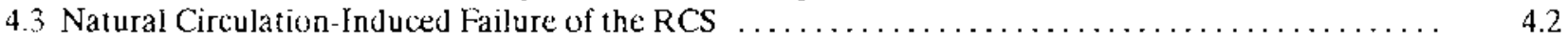

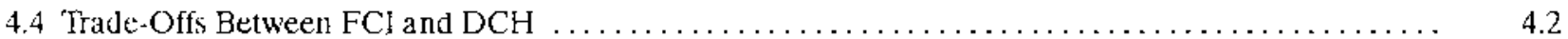

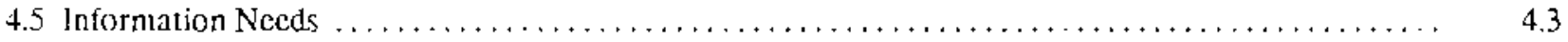

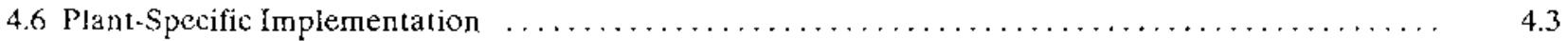

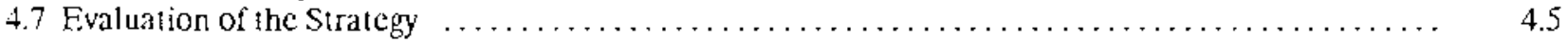

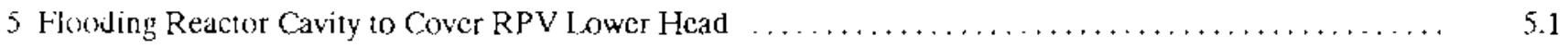

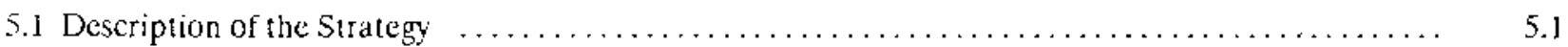

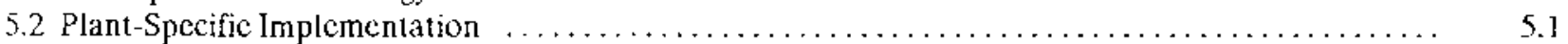

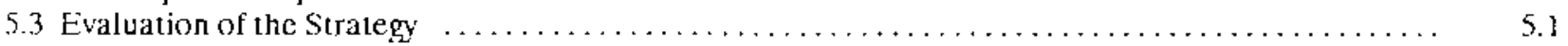

6 Restoration of AC Power and Provision of Portable Pumping Capacity $\ldots \ldots \ldots \ldots \ldots \ldots \ldots \ldots \ldots \ldots \ldots$

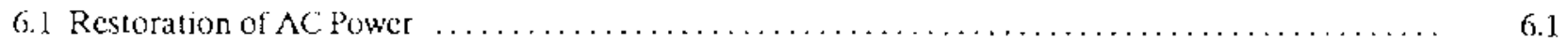

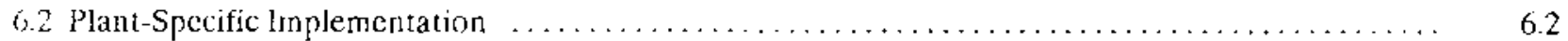

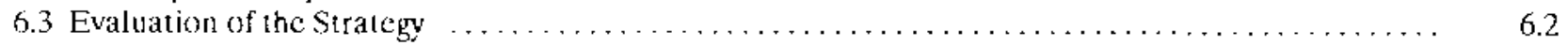




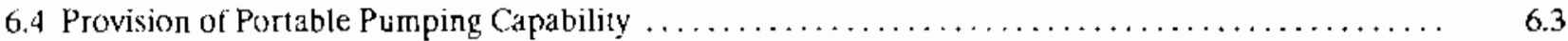

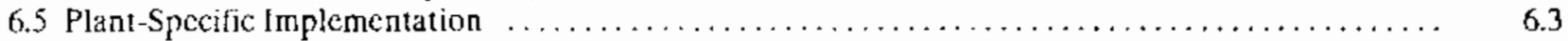

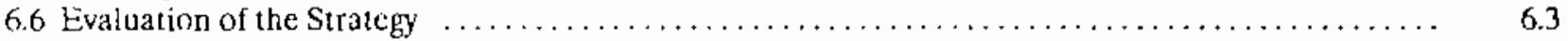

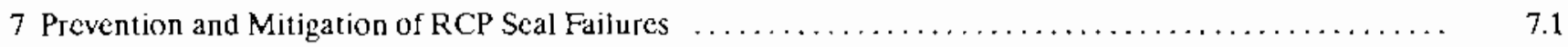

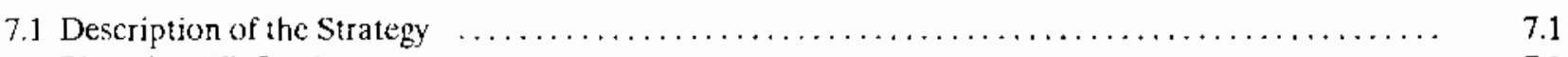

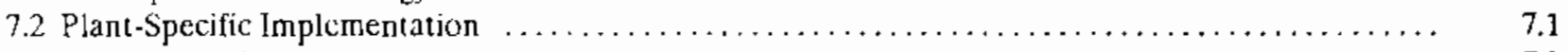

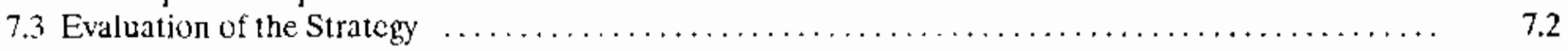

8 Maintaining Forced Circulation Through the Core $\ldots \ldots \ldots \ldots \ldots \ldots \ldots \ldots \ldots \ldots \ldots \ldots \ldots \ldots \ldots \ldots \ldots \ldots$

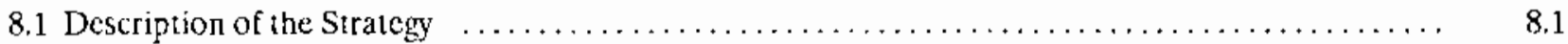

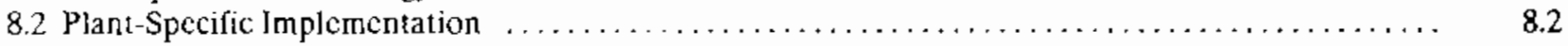

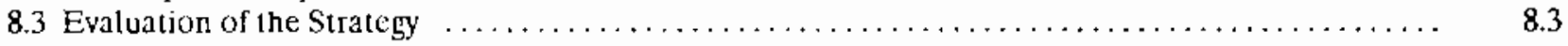

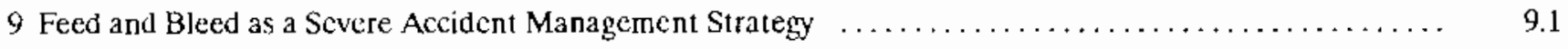

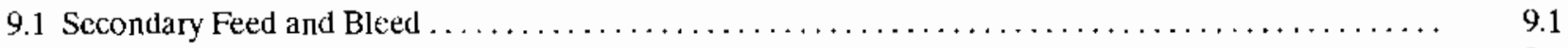

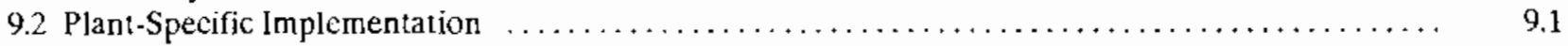

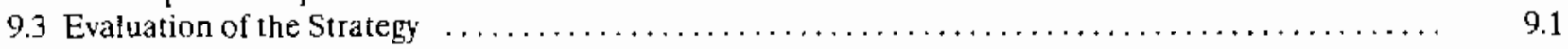

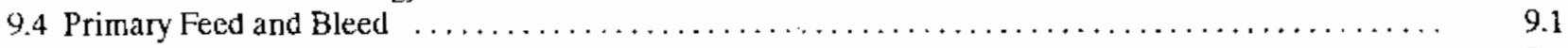

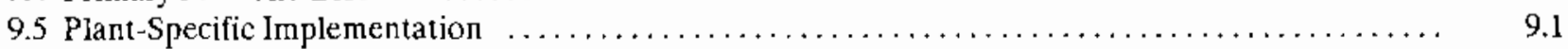

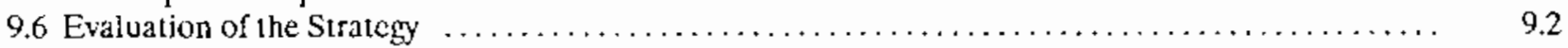

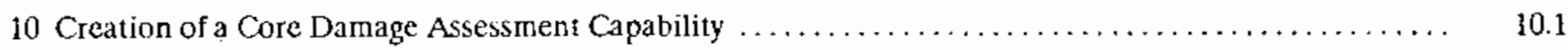

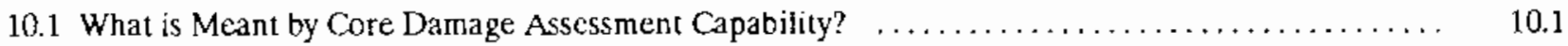

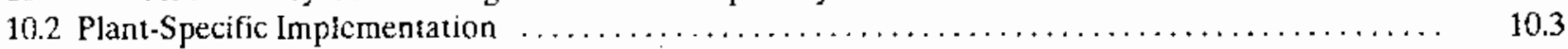

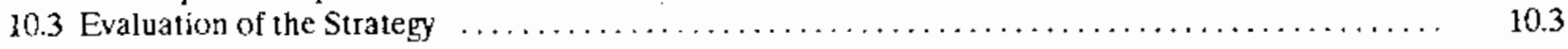

11 Humán Factors Considerations in Severe Accident Management $\ldots \ldots \ldots \ldots \ldots \ldots \ldots \ldots \ldots \ldots \ldots .11 .1$



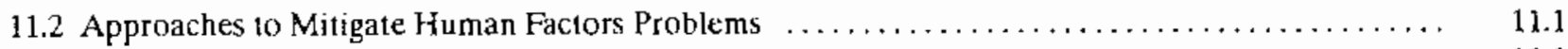

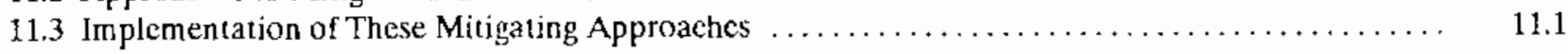

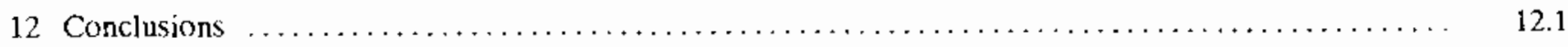

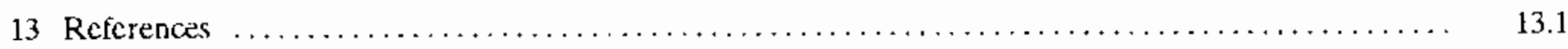

Appendix A: Westinghouse Large, Dry Containment Plant - Zion . . . . . . . . . . .

Appendix B: Westinghouse lee Condenser Containment - Sequoyah ....................... B.1

Appendix C: Combustion Engincering Large, Dry Containment - Calvert Cliffs $1 \ldots \ldots \ldots \ldots \ldots \ldots \ldots \ldots$ C.1

Appendix D: Babcock \& Wilcox Large, Dry Containment - Oconee $3 \ldots \ldots \ldots \ldots \ldots \ldots \ldots \ldots \ldots \ldots \ldots$. $\ldots .1$

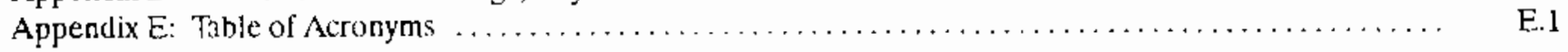




\section{Executive Summary}

The objectives of this report wcre twofold: first, to determine the current understanding and practice in the Pressurized Water Reactor (PWR) Emergency Procedurc Guidelines (EPGs), as it may rclate to severc accident management; and second, to identify and evaluate strategies for mitigating the effects of severe accidents during the in-vessel phase of the accident, which is defined as being after the initiation of core degradation and prior to the failure of the reactor vesscl. It is well-known that the EPGs are success-oriented, and they indeed provide success paths to deal with many of the critical accident sequences discussed in the rcport. In addition, many of the preventive (i.e., tending to prevent the initiation of corc melt) strategies identified in NUREG/CR-5474 have been implemented, either entirely or partially, in the EPGs. However, the EPGs are not designed to provide guidance to the operators in response to the severe core lamage accidents in which nothing works (or not enough things work) and core damage initjates. The functional operating guidelines dealing with inadequate corc cooling and containment integrity do offer some guidance that would be useful during the in-vessel phase of a scvere accident.

The vendor EPGs provide minimal guidance for the evaluation of human factors issues that will impact the ability of control room operators and in-plant operations and maintenance personnel to carry out the actions required under accident conditions; e.g., high temperatures, moisture, and radiation levels, with possibly impaired visibility. The Westinghouse ERGs do note somc of the points at which utilities may have difficult decisions as to the capability of non-control-room staff to implement in-plant actions.

The fact that an accident has progressed to initiation of core damage implies some or all of the following plant conditions:

1. Scveral major plant front-line or support systems are unavailable or degraded.

2. Environmental conditions in containment are degraded, implying difficulty in carrying out some desired plant system manipulations.

3. Quality of the operator's knowledge of plant status, and particularly core status, is deteriorating.

4. The core may still be critical.

5. AC power may bc unavailablc, with DC power degrading.

6. The sitvation in the control room may be chaotic, with personnel present who are not normally in the control room, and plant conditions that have been experienced only during training sessions, if at all.

7. Decision making responsibility and authority may not be clearly defined.

Even with these deteriorating conditions, there are clear actions that operators can take to prevent or mitigate further plant degradation. First and forcrnost, get the reactor subcritical, if it isn't already. Sccond, get water into the vessel by any means possible (aithough there is a hierarchy of preferred means). Third, if possible, maintain the secondary system as a heat sink for the primary system, Fourth, if clectrical power is degraded or unavailable, do everylhing possiblc to testore it. Fifth, if the core is truly endangered, the operators should be prepared to sacrifice any other plant systems to the goal of minimizing the damage to the core and the thrcat to containment. Sixth, a numbcr of relatively modest preventive and mitigative efforts may have a significant impact on plant risk. These inctude the flexibility to use portable AC power generators and portable self-powesed pumps to supply water or power critical equipment. 
Also included is the use of feed and bleed ffow in the service water system to maintain cooling of the centrifugal charging pumps, hence maintaining RCP seal injection and/or RCP seal cooling.

The arguments supporting RCS depressurization prior to vessel breach are persuasive. Early depressurization gets the plant closer to the accident conditions it was designed for, but may accelerate core degradation by comparison with remaining at high pressure. The analysis of Hanson et al. (1990) strongly suggests that late depressurization is preferable to early depressurization. Early or late depressurization should significantly reduce the risk associated with high pressure melt ejection and direct containment heating.

Improved knowledge of the status of a degrading core might improve the quality of accident management. This improved knowledge will requirc calculational toois that can integrate plant data with knowledge of the plant design to choose those descriptions of plant status that are consistent with the data and the time history of the accident -- and do it all in real timc.

Flooding the reactor cavity to the top of the RVP lower head may improve heat removal from the outer surface of the lower head enough to prevent creep-rupture failure of the lower head after relocation of part of the molten corium to the fower plenum.

Continuing to operate RCPs and maintain forced flow through the vessel (under conditions that put the RCPs at risk) may prevent or mitigate core damage or may buy time for actions to recover or protect containment or protect the public. For some LOCAs, this choice may increase the rate of inventory loss from the break, thus requiring increased makcup how.

Thus, this work has identified several strategies, which extend beyond the EPGs into the severe accident regime, that will mitigate the seriousness of events and their consequences during the in-vessel phase of severe accidents. Further work in this area can be expected to better define the feasibility, effectiveness, and potential disadvantages of these strategies in the context of application to specific plants. 


\section{Acknowledgments}

This work has been conducted for the Office of Nuclear Regulatory Research, Division of Systems Research, Reactor and Plant Systems Branch, under the direction and guidance of Dr. James T. Han.

Input to Section 6.0 and plant-specific information about CE reactors was provided in an earlier draft of this report by Rollie D. Warner of PNL.

The authors appreciate the careful review and useful comments provided by a number of reviewers, including: Gary Bair, Portland Gencral Electric; Francis Buck, PNL; Eric Schmieman, PNL; Dr. Bryan Gore, PNL; Dr. Spence Bush, PNL; Peter Cybulskis, Battelle Columbus Laboratory; Professor Bill Kastenberg and his colleagues at UCLA; and Dr. J. T. Han, NRC/RES. 



\section{Introduction}

This report presents the results of work performed by the Pacific Northwest Laboratory (PNL) in support of the Accident Management Research Program (NRC 1989) developed by the U.S. Nuclear Regulatory Commission Office of Nuclear Regulatory Research (NRC/ RES). The Accident Management Research Program is intended to improve "understanding of the physical progression of severe core damage accidents" and to use that improved understanding to "provide insights for accident management, particularly in the area of limiting potential radioactive releases and stabilizing condjtions should the reactor vessel be breached." Further,

"[r]escarch activities will conter on assessing the feasinility of various strategies that might be implemented by utilities to prevent or mitigate scvere accidents, and on jdentifying those which should be considered for inclusion in utility accident management plans... in all cases, the design and operalional requirements for strategy exccution will be evaluated, but emphasis will also be given to examining potential circumsıanees under which certain operator actions could worsen accident consequences or adversely impact the ability 10 achicve a long-term, stable state (NRC 1989)

Specifically, this report documents Tasks 1,2, and 3 of work performed for NRC/RES by PNL in FY 1991 supporting the Accident Management Research Program. The objectives of this report were twofold: first, to determine the current understanding and practice in the Pressurized Water Reactor (PWR) Emergency Procedure Guidclines (EPGs), as it may relate to severe accident management; and second, to identify and evaluate strategies for mitigating the effects of severe accidents during the in-vessei phase of the accident, which is delined as being after the initiation of core degradation and prior to the failure of the reactor vessel. Mitigating strategies for the ex-vessel phase of PWR severe accidents have been considered by a parallel Accident Management Guidance Program project conducted at Brookhaven National Laboratory (BNL).
Task 1 required the identification of critical accident sequences and the extent to which strategies already exist to prevent them or mitigatc their consequences in the EPGs of all three PWR owners groups. For purposes of comparison, a similar review of the EPGs is also made for the 20, largely preventive, strategies that were identificd and evaluated during Fiscal Year (FY) 1989 by $B N L$ and PNL, with that work having been reported in NUREG/CR-5474, Assessment of Candidate Accident Management Srategies.

We understand that the purpose of the EPGs and Emergency Operating Procedures (EOPs) is to address pre. vention of and recovery from inadequate core cooling (ICC) and not necessarily to provide definitive guidance for recovery from severe core damage accidents. Al various points in this report it is concluded that guidance for coping with certain scvere accident conditions is incomplete or nonexistent. This is not intended as a criticism of the EPGs, since their purpose is not to address severe accidents. This conclusion is simply a recognition that coping with severe accidents should properly be addressed in the context of accident management. In certain other cases guidance may exist for ICC recovery which might be appropriate to consider during a severe accident. In those cases, this guidance is identified and may be assessed as a severe accident management strategy in future tasks.

Critical accident sequenees were defined to be those satisfying one of the criteria:

1. Sequences that contribute significantly to the risk of core mett.

2. Scquences that contribute signilicantly to risk characterized by other risk measures. For purposes of this report, the only "other risk measure" we have used is risk to the public, with early risk and latent (cancer) risk lumped logether.

3. Sequences that represent significant challenges to safety functions. 
Introduction

4. Sequences that represent significant challenges to safety systems.

Figure 1.1 shows a top-level logic trec of safety purpose, safety objectives, and safety functions.

The critical accident sequence identification is based on plant-specific information, principally information from planı probabilistic risk assessmcnts (PRAs), for four specific PWRs:

- Zion (Westinghouse PWR with large, dry containment)

- Sequoyah (Westinghouse PWR with ice condenser containment)

- Calvert Cliffs (Combustion Engineering PWR with large, dry containment)

- Oconce (Babcock \& Wilcox PWR with large, dry containment)

These particular plants were chosen because of reasonably good availability of design and operational information and becausc cach was the subject of a recent probabilistic risk assessment (PRA). Zion is the subject of the Zion Probabilistic Safety Study (Pickard, Lowe \& Garrick 1982) and the NUREG-1150 supporting repor1 that rebasclined that study for NUREG-1150 purposes (Wheeler 1986). Calvert Cliffs is the subject of an Interim Reliability Evaluation Program (IREP) PRA conducted for the NRC (Payne et al. 1984). The Sequoyath PRA is documented in NUREG-1150 supporting re. ports (Bcnjamin cf al. 1987; Bertucio et al. 1987). Oconec is the subject of a PRA jointly conducted by Duke Power and the Nuclear Safety Analysis Center (NSAC 1984). These PRAs were used to determine severe accident sequences and the associated risks; additionally, they provide succinct information on plant systems and system interacions in the context of those severe accident scquences.

Since all of the plants are PWRs and the two Westing. house plants arc very similar, except for the containment type, some of the information in this report is necessarily repetitive. Similarly, the FPGs werc Jeveloped by the vendors and the owner's groups under common criteria provided by the NRC. and the same Westinghouse
Emergency Response Guidelines (ERGs) (HighPressure Version) apply to both Zion and Sequoyah.

While the report includes sequences representing early challenges to containment systems, it does not attempt to enumerate sequences threatening containment during the cx-vessel phase of a scvere accident. In this report, wc use the terms "core mcli risk" and "core melt frequency" interchangeably. This common usage can be justified by noting that the risk of an event is usually defined as being the probability of the event times the consequences of the cvent. The probability of a core melt is equal (to a very good approximation) to the corc melt frequency and the consequence of a core melt is taken to be 1 (i.e., one core melt). Thus the core melt risk and the core melt frequency are numerically equal.

Tasks 2 and 3 called for the identification of a list of candidate strategies for management of the in-vessel phase of severe accidents and the evaluation of those strategies according to the critcria of feasibility, cffectiveness, and possible adverse effects. The ilentification is to be based on a revicw of the cxisting litcraturc on severe accidents. The list should include strategies to prevent or mitigate high risk consequences or high corc damage frequency; stratcgies that can increase the availability of pressurized water reactor (PWR) safety functions by using existing equipment and water resources (perhaps in ways not intended by the plant designers); and rel-

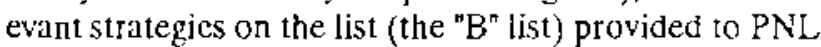
with the Statcment of Work. The " $\mathrm{B}^{\text {tr }}$ strategies referred to above are listed in Table 1.1.

Two additional criteria for the strategy selection were imposed: 1) They should not require major plant modifications, and 2) they should not currently be implemented in the emergency procedures guidelines (EPGs). Since preventive strategies have been previously considered in some detail (Luckas et al. 1990), the primary focus in this report is on strategies intended to mitigate a severe accident in progress (that is, an accident with core degradation) rather than strategies intended to prevent the iniliation of core degradation. It should be noted, howcver, that prevention and mitigation can overlap. Strategies which mitigatc corc degradation may act to prevent breach the reactor pressure vessel (RPV) and thus might bc considered preventive strategies for the ex-vessel phase of the severe accident. 
Table 1.1 " $\mathrm{B}^{*}$ strategies relevant to the in-vessel phose of PWR severe accidents

Procedures and hardware changes, if necessary, to inject water into the reactor to $3.0,4.0,9.0$ terminate the core melt prior to vessel failure (e.g., primary feed and bleed).

Procedures and hardware changes, if necessary, for sccondary side injection to prevent or $4.0,9.0$ terminate the corc melt (e.g., secondary feed and bleed).

Procedures to continue the use of vessel injection after vessel rupture.

Procedures and modifications, as necessary, to cross-conduct corresponding safety injection systems between the units in multiple unit plants

$3.0,6.0$

Procedures to depressurize the reactor system using power operated rclief valves (PORVs), safcty relief valves (SRVs), and/or the high point vents.

Procedures to depressurize the primary sysicm using the steam generator, by opening atmospheric dump valves and providing make up with existing or alternate water sources (i.c., secondary feed and blecd).

Procedures and hardware changes, if necessary, to inject additional borated water from 3.0 alternate source(s) to maintain subcriticality.

The strategies proposed are evaluated on the basis of theoretical and analytical models described in the literature, on reports of experimental results, and on design and operational information on same four PWRs: Zion, Scquoyah, Calvert Cliffs, and Oconce. Figure 1.2 shows how the strategies proposed relate to the safety objeclives and the safety functions. The reader will note that most of the strategies are "integral" in the sense that they impact several different safety functions.

\subsection{Organization of This Report}

Section 2.0 of this report discusses the melhodology used to determine the critical scauences. Appendices A through D document the determination of critical sequences for Zion 1, Sequoyah 1, Calvert Clifls 1, and Oconce 3 , in that order, along with an evaluation of vendor EPG coverage.
The report is organized primarily according to candidate strategies, with subhcadings providing descriptions of the strategies, discussing any related phenomenological or systems issues, and providing generic and plantspecific evaluations of the candidate strategies. The strategies discussed include the " $B$ " List strategies (see Table 1.1 for coverage of the " $B$ " strategies in this repor1) and the following strategies:

- Water Addition to the Rcactor Pressure Vessel (Section 3.0)

- Depressurization of the Primary System (Section 4.0)

- Flooding the Reaclor Cavily to Cover RPV Lower Head (Section 5.0)

- Reestablishment of AC Power (Seclion 6.0) 
- Provision of Portable Pumping Capability (Scclion 6.0)

- Prevention and Mitigation of Reaetor Coolant Pump (RCP) Seal Failures (Sccion 7.0)

- Maintaining Forced Circulation through the Core (Section 8.0)

- Secondary Feed and Bleed (Section 9.0)

- Primary Feed and Blecd (Section 9.0)

- Creation of a Core Damage Assessmenı Capability (Section 10.0)

Section 11.0 contains a discussion of generic human factors issues which impact the implementation of alf of the strategies discussed and evaluated in the report.
Some strategies are not discussed in detail because they are already the subject of exiensive rescarch under the Severe Accident Rescarch Program or they seem to be adequately covered by the vendor EPGs and plant emergency operating procedures (EOPs).

The report identifics situations where phenomena are not well understood, but where a belter understanding of the phenomena is not likely to have any impact on decisions made by operators or Technical Support Center staff during a severe accident. It will also consider generic human factors issues, including the training of operators and others with severe accident manasement responsibilities, personnel performance under severe accident conditions, and the ability of the operating crew to carry out in-plant actions under severe accident conditions. 


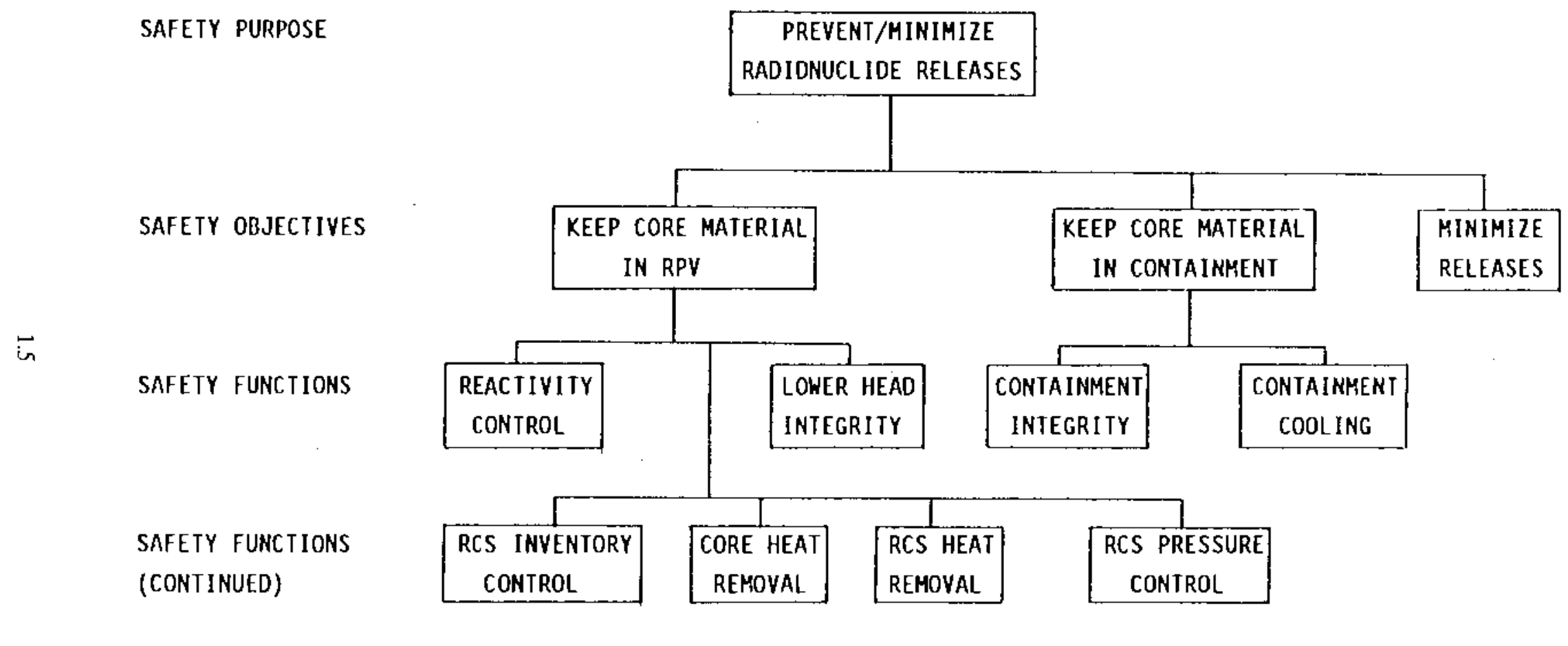

FIGURE 1.1. Reactor Safety Top Level Logic Tree 


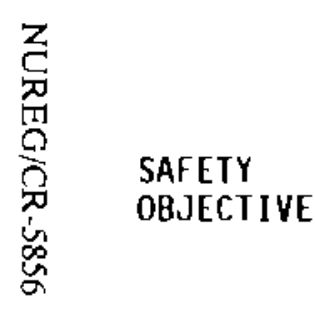

5

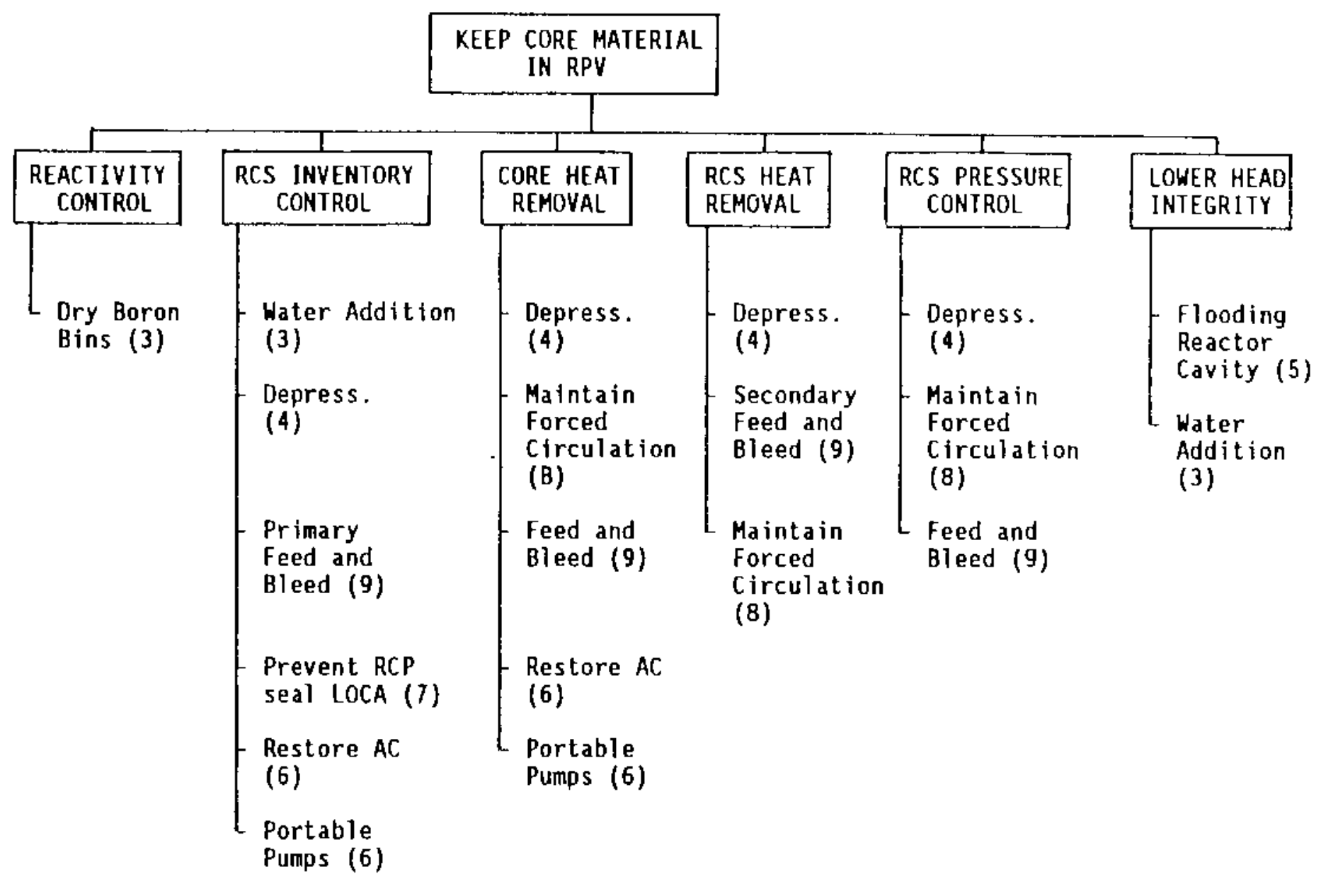




\section{Critical Severe Accident Sequences and EPG Coverage}

\subsection{Methodology and Information Resources}

This report is based upon available documentation of generic rescarch on scverc accident phenomenology, available documentation of design and operational dctails of the four specific plants considered in cvaluating the proposed accident managcment strategics, and the operations and plant systems expcrience of the authors and some of their colseagues. Information sources specifically relied upon include:

- NUREG-1150 and its supporting reports, particularly those directly relevant to Zion and Sequoyah,

- the plant-specific PRAs described in the previous section,

- initial submittals of the Final Safcty Analysis Reports (FSARs) for the four plants, including consideration of later amendments for some of the plants,

- vendor emergency procedures guidelines,

- portions of the piant Emergency Opcrating Procedures for the four plants,

- many of the papers on the Threc Mile Island, Unit 2 (TMl-2) accident in special Volume 87 of Nuclear Technology, August, October, November, and December 1989, and

- other open literature papers and reports on severe accident phenomenology, accident management policy, and plant systems responses to specific accidents.

This was a lot of material for the time and resources available for this project; the authors would appreciate being informed of any omissions or errors in the descriptions, evidence, and conclusions in this report.

\subsection{Description of Plants}

The four plants (by threc vendors) are similar in many ways. This section will note some of the differences between the plants that have an impact on the selection of critical accident sequences and on the extent 10 which a particular strategy might be implemented successfully at a given plant.

Zion is a Westinghouse "high pressure" plant with a targe dry containment. The term "high pressure" means that it has a fully qualified, satcly-related charging system. The charging system is designed to provide rclatively small amounts of conlant makcup flow to the reactor coolant system (RCS) during normal operation With a safcty-related charging system, Zion can takc credit for the ability of the charging system to supply makeup flow to the RCS during small-break loss of coolant accidents (LOCAs) procceding at pressures higher than the shutoff head of the high pressure injection system (HPSl). At the time of performance of the Zion PRAs, Zion was unusually sensitive to the effects of common-causc failures in the Scrvice Water (SW) and Component Cooling Water (CCW) system, with almost $80 \%$ of the corc mclt tisk being related to failures of the CCW system.

The Sequoyah plant is also a Westinghousc "high pres. sure" plant, but one with an icc condenser containment. These containments are smalker than the large, dry containment and have a lower design pressure. They depend on a large collection of baskets of ice to condense steam released from a LOCA, thus protecting the containment from the full effect of the LOCA blowdown. This is a pressurc suppression containment, similar in intent to the BWR pressure suppression pool containments. Ice condenser containments are generally considered to more vulnerable to containment failure in a varicty of accident sequences than large, dry containments. Since this report is dealing with the in-vesset phase of severe accidents, that vulnerability doesn't have much impaci on our work. 
Critical Sequence

The Calvert Clifis plant is a Combustion Engincering PWR with a large, dry containment. It has a non-safetyrclated charging systcm; one effect of this is that the Calvent Cliff IREP PRA (Payne 1984) did not give any credit for the ability of the charging system to provide high-pressurc makeup flow during small-break LOCAs and similat accident sequences. In addition, the shutofI head of the high pressure injection pumps is lower than usual for PWRs (1275 psi versus 1600 psi) and the pressurization of the accumulators is also lower than usual (200 psi versus $600 \mathrm{psi}$ ). The net effect of these design features and the lack of credit for the charging system is that the Calvert Cliffs PRA is dominated by accident sequences remaining at so high a pressurc that no make. up coolant can be provided, leading to eventual uncovery of the core and core melt. Calvert Cliffs was also sensitive to Vital DC bus failures, with these failures causing a plant trip, a demand for safety system functioning, and at the same time degrading several of the safety systems (making them more vulncrable to additional independent failures).

The Oconce plant is a Babcock \& Wilcox PWR with a large, dry containment and a non-safety-related charging system. By contrast with the other two vendors, $B \& W$ uses once-through steam generators (OTSGs), which have a significantly smalter inventory of water on the shell side (secondary side) of the steam gencrator than the U-tube steam generators (SGs) used by Westinghouse and Combustion Engineering. Without the thermal incrifa provided by larger mass of water in the SG shell, OTSGs allow less time for opcrator response to accident sequences involving loss of feedwater. On the other hand, Oconee has a more robust emcrgency electrical power system than most plants and has a Standby Shutdown Facility (SSF) which provides a completely redundant and independent means of injecting coolant into both the steam generators and the core.

\subsection{Identification of Critical Sequences}

Identification of critical accident sequences was affected by both plant differences and differing assumptions and methodologies used in performance of the PRAs. The Zion PRA was performed by Pickard, Lowe, $\&$ Garrick using the Large Event Trec/Small Fault Tree methodology. The resulting accident sequences have a somewhat different flavor than the sequences from the other three PRAs, performed using the Small Event Trec/Large Fault Tree methodology. Each niethodology has advantages and disadvantages; in theory, although the description of accident sequences will be different, the bottom-linc assessments resulting should be equivalent. Tabies 2. 1, 2.2, 2.3, and 2.4 sunmarize the critical accident sequences identified for the four plants. Full descriptions of the sequences, of the EPG coverage of the sequences, and of the EPG coverage of the " $A$ " list sequences from NUREG/CR 5474 are provided in Appendices A, B, C, and D. 


\section{Table 2.1 Summary table of coverage of Zion critical accident sequences by Westinghouse Emergency Response Guidelines}

\begin{tabular}{|c|c|c|c|c|c|}
\hline Sequence & Description & $\begin{array}{c}\text { Full } \\
\text { Covernge }\end{array}$ & $\begin{array}{l}\text { Partial } \\
\text { Coverage }\end{array}$ & $\begin{array}{c}\text { No } \\
\text { Coverage }\end{array}$ & Comments \\
\hline$Z \cdot 1$ & I oss of CCW; induced RCP seal L.OCA & & $\mathrm{X}$ & & AOPs probably cover loss of CCW \\
\hline $\mathrm{Z}-2$ & $\begin{array}{l}\text { Small-break LOCA; failure of high pressure } \\
\text { recirculation corc cooling }\end{array}$ & $\mathrm{x}$ & & & \\
\hline$z .3$ & $\begin{array}{l}\text { Large-break LOCA; faiture of low pressure } \\
\text { recifculation }\end{array}$ & $\mathrm{x}$ & & & \\
\hline $7-4$ & Same as $Z-3$ with medium-break I.OCA initiator & $\mathrm{X}$ & & & \\
\hline Z-5 & $\begin{array}{l}\text { Degraded AC power; AFW failure; failure of primary } \\
\text { leed and bleed; } A C \text { recovery }<4 \mathrm{hr}\end{array}$ & & $\mathrm{X}$ & & \\
\hline $\mathrm{Z} \cdot 6$ & Large-break LOCA; failure of LP] & $\mathrm{x}$ & & & \\
\hline$Z-7$ & Same as $Z-5$ but $4 \mathrm{hr}<\mathrm{AC}$ recovery $<8 \mathrm{hr}$ & & $\mathrm{x}$ & & \\
\hline$Z-8$ & $\begin{array}{l}\text { Degraded } A C \text { power; loss of CCW and SW until } A C \\
\text { recovered between } 1 \text { hr and } 4 \text { hrs }\end{array}$ & & & $\mathrm{x}$ & \\
\hline$Z-9$ & Same as $Z-8$ but with unrecoverable failure of $S W$ & & & $\mathrm{X}$ & \\
\hline$Z-10$ & $\begin{array}{l}\text { Degraded AC power; foss of } C C W \text { and } S W \text { no } A C \\
\text { power recovery in } 8 \mathrm{hr} \text {; failure of containment systems }\end{array}$ & & & $\mathrm{x}$ & \\
\hline Z-11 & $\begin{array}{l}\text { Same as Z- } 8 \text { but with } A \text { c recovery betwcen } 4 \text { hrs } \\
\text { and } 8 \mathrm{hrs} \text {; containment systems succeed }\end{array}$ & & & $x$ & \\
\hline $\mathrm{Z}-12$ & Degraded AC power; l oss of SW; RCP scat LOCA & & & $x$ & \\
\hline $2 \cdot 13$ & $\begin{array}{l}\text { Same as Z-12 but fan conolers fail direcily duc } \\
\text { to loss of AC Power }\end{array}$ & & & $x$ & \\
\hline 214 & Interfacing System I.OCA & & $x$ & & \\
\hline 2.15 & $\begin{array}{l}\text { Loss of DC bus } 112 \text { causing loss of secondary heat } \\
\text { sink and faiture of primary feed and bleed }\end{array}$ & & $\mathrm{x}$ & & \\
\hline$Z .16$ & $\begin{array}{l}\text { Same as } Z-11 \text { with the SW system common-caluse } \\
\text { portion of Z-12 }\end{array}$ & & & $\mathrm{x}$ & AOPs probably cover loss of SW \\
\hline$Z-17$ & $\begin{array}{l}\text { Degraded AC power which lails CCW and induces } \\
\text { RCP seal LOCA; wailable AC allows SW and } \\
\text { containment systems to succeed }\end{array}$ & & & & AOPs probably cover loss of CCW \\
\hline $7 \cdot-18$ & Pressurized thermal shock & $\mathrm{x}$ & & & \\
\hline $7 .-19$ & Anticipated transients without SCIRAM & $\mathrm{x}$ & & & \\
\hline$\angle-20$ & Steam Generator Tilbe Ruplure & $\mathrm{x}$ & & & \\
\hline
\end{tabular}




\section{Critical Sequence}

Table 2.2 Summary table of coverage of Sequoyah critical accident sequences by Westinghouse Lmergency Response Guidelines

\begin{tabular}{|c|c|c|c|c|c|}
\hline Sequence & Descripition: & $\begin{array}{c}\text { Fuil } \\
\text { Coverage }\end{array}$ & $\begin{array}{c}\text { Partial } \\
\text { Coverage }^{(b)}\end{array}$ & $\begin{array}{l}\text { No } \\
\text { Coverage }\end{array}$ & Comments \\
\hline S-1 & $\begin{array}{l}\text { Small-break L OCA; failure of recirculation phase } \\
\text { core cooling }\end{array}$ & $\mathrm{x}$ & & & \\
\hline$S-2$ & $\begin{array}{l}\text { Loss of CCW; induced RCP seal LOCA fatlure of } \\
\text { ECC and containgent spray }\end{array}$ & $\mathrm{x}$ & & & $\begin{array}{l}\text { AOPs probably cover kss } \\
\text { of CCW }\end{array}$ \\
\hline S-3 & $\begin{array}{l}\text { Smalt-break L_OCA; failure of recirculation phase } \\
\text { core cooling (due to I.P pump [aslures) }\end{array}$ & $\mathrm{X}$ & & & \\
\hline$S-4$ & 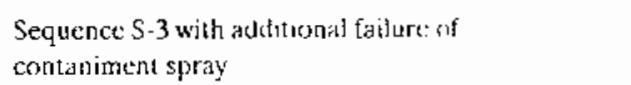 & $\mathrm{x}$ & & & \\
\hline S.5 & $\begin{array}{l}\text { Station blackout; indured } \mathrm{RCP}^{2} \text { seal I.OCA; no ECC } \\
\text { or containment systems available }\end{array}$ & $\mathrm{x}$ & & & \\
\hline S-6 & $\begin{array}{l}\text { Intermediate-break LOCA; loss of I IP recirculation } \\
\text { phase core coning }\end{array}$ & $\mathrm{x}$ & & & \\
\hline S-7 & $\begin{array}{l}\text { Loss of } D C \text { bus } I_{\text {; independen }} \text { fillure of } A \text { liw; } \\
\text { failure of feed and bleed (due to DC bus toss) }\end{array}$ & & & $\mathrm{x}$ & $\begin{array}{l}\text { AOP's probably cover loss } \\
\text { of Vilal DC }\end{array}$ \\
\hline S-8 & I.oss of DC bus II; the rest iderntical to S.7 & & & $\mathrm{x}$ & $\begin{array}{l}\text { AOPs probably cover loss } \\
\text { of Vital DC }\end{array}$ \\
\hline S.9 & $\begin{array}{l}\text { Intemediate-or large-break l.oCn; failure of jee } \\
\text { condenser: containment failure; the'n core metl }\end{array}$ & & $x$ & & \\
\hline$S 10$ & $\begin{array}{l}\text { Interlacing system LOCA; additional fatlures } \\
\text { leading to core mels }\end{array}$ & & $\mathrm{x}$ & & \\
\hline $5-11$ & SGTR: additional failures leading to core melt & $\mathrm{x}$ & & & \\
\hline$S-12$ & RPV enerpressurizaticon at cold shuldown & $\mathrm{x}$ & & & \\
\hline S. 13 & RCS owercokting transiens al power & $\mathrm{x}$ & & & \\
\hline S-1.1 & Loss ol secondary heat sink & $x$ & & & \\
\hline S.15 & Pressurizer tionding & $\mathrm{x}$ & & & \\
\hline$S-1 \sigma_{1}$ & Anlicipated I ranstents without SCRAM & $x$ & & & \\
\hline S-17 & $\begin{array}{l}\text { 1 aess of SW system, causing eventual Joss of } \mathrm{Nl} \mathrm{W} \text {, } \\
\text { CCW, and containment spray }\end{array}$ & & & $x$ & $\begin{array}{l}\text { AOP's probably cover loss } \\
\text { of SW' }\end{array}$ \\
\hline
\end{tabular}


Table 2.3 Summary table of coverage of Calvert Clifts critical accident seguences by Combustion Engineering Energency Procedure Guidelines CEN-152

\begin{tabular}{|c|c|c|c|c|c|}
\hline Sequence & Descríption & $\begin{array}{c}\text { Full } \\
\text { Coverage }\end{array}$ & $\begin{array}{l}\text { Partial } \\
\text { Coverage }^{(b)}\end{array}$ & $\begin{array}{c}\text { No } \\
\text { Coverage }\end{array}$ & Conments \\
\hline $\mathrm{C}-1$ & $\begin{array}{l}\text { Anticipated transient without SCRAM causing } \\
\text { immediate RCS failure and early containment failure }\end{array}$ & & $\mathrm{x}$ & & \\
\hline $\mathrm{C}-2$ & $\begin{array}{l}\text { Loss of DC bus } 11 \text { degrades secondary heal sink and } \\
\text { safety systems; subsequent } A F W \text { failure leads to core } \\
\text { melt }\end{array}$ & & $\mathrm{X}$ & & $\begin{array}{l}\text { AOPs probably cover lass } \\
\text { of DC bus }\end{array}$ \\
\hline $\mathrm{C}-3$ & $\begin{array}{l}\text { Small-small LOCA; failure of I IP' recirculation phase } \\
\text { core cooling }\end{array}$ & $x$ & & & \\
\hline$C-4$ & $\begin{array}{l}\text { Sequence C-3 with additional failute of containment } \\
\text { sprays in recire mode }\end{array}$ & $x$ & & & \\
\hline C-5 & $\begin{array}{l}\text { Loss of secondary heat sink; failure of primary } \\
\text { feed and bleed }\end{array}$ & & $x$ & & \\
\hline$C-6$ & ATWS with boration failure or siuck open PORV & $\mathrm{x}$ & & & \\
\hline$C-7$ & Transient folkwed by loss of secondary heat $\sin k$ & $x$ & & & \\
\hline C-8 & $\begin{array}{l}\text { Loss of offsite power; transient-induced LOCA: } \\
\text { HPSI and containment systems fail }\end{array}$ & & $\mathrm{x}$ & & $\begin{array}{l}\text { Plant-specific guidance needed } \\
\text { for I.OSP }\end{array}$ \\
\hline C-9 & Loss of offsite power; AFW failure & & $\mathrm{x}$ & & $\begin{array}{l}\text { Plant-specific guidance needed } \\
\text { for } 1 \text { OSP }\end{array}$ \\
\hline$C-10$ & Stalion blackout; RCS boiloff causes core melt & & & $x$ & $\begin{array}{l}\text { AOPs may provide Station } \\
\text { blackout guidance }\end{array}$ \\
\hline $\mathrm{C}-1 \mathrm{I}$ & $\begin{array}{l}\text { Transient requiring pressure relicf; loss of } \\
\text { secondary heat sink }\end{array}$ & $\mathrm{x}$ & & & \\
\hline $\mathrm{C} \cdot 12$ & Small-small LOCA; loss of HPSI secondary heat sink & $\mathrm{x}$ & & & \\
\hline$C-13$ & $\begin{array}{l}\text { Loss of offsite power; failure of } \mathrm{AI} \cdot \mathrm{W} \text { and } \\
\text { containment systems }\end{array}$ & & $\mathrm{x}$ & & $\begin{array}{l}\text { Plant-specitic gujdance necded } \\
\text { for IOSP }\end{array}$ \\
\hline$C-14$ & $\begin{array}{l}\text { Interfacing systens I.OCA; adcitional failures } \\
\text { resulting in core melt }\end{array}$ & $\mathrm{x}$ & & & $\begin{array}{l}\text { No caution agajinst initiating } \\
\text { recirc cooling when LOCA is } \\
\text { outside containmenl }\end{array}$ \\
\hline$C-15$ & SGTR; additional faitures resulting in core mclt & $\mathrm{x}$ & & & \\
\hline$C \cdot 16$ & Overpressurization at cold shuidown & $\mathrm{x}$ & & & \\
\hline$C-17$ & RCS overcooling Iransient at power & $\mathrm{x}$ & & & \\
\hline$C-18$ & Pressurizer Пroding & $x$ & & & \\
\hline $\mathrm{C}-19$ & I oss of SW train 12 ; trips plant; لegrades safety system & & & $\mathrm{X}$ & AOPs probably cover ioss of SW \\
\hline$C-20$ & $\begin{array}{l}\text { Loss of Salt Water system; degrades CCW, SW, and } \\
\text { ECC pump room c(xolers }\end{array}$ & & & $\mathrm{X}$ & $\begin{array}{l}\text { AUPs probably cover loss of } \\
\text { of Sall Water System }\end{array}$ \\
\hline
\end{tabular}


Table 2.4 Summary table of coverage of Oconee critical accident sequences by Babcock \& Wilcox Abnormal Transient Operating Guidelines

\begin{tabular}{|c|c|c|c|c|c|}
\hline Sequence & Description & $\begin{array}{c}\text { lull } \\
\text { Coverage }\end{array}$ & $\begin{array}{l}\text { Partial } \\
\text { Coverage }\end{array}$ & $\begin{array}{l}\text { No } \\
\text { Coverage }\end{array}$ & Comments \\
\hline $\mathrm{O}-1$ & $\begin{array}{l}\text { Loss of I.J Service Water; degrades HPl pumps } \\
\text { and }(C W \text { : induced RCP seal } 1.0 \mathrm{CA}\end{array}$ & & $\mathrm{X}$ & & \\
\hline 0.2 & $\begin{array}{l}\text { I arge-break LOCA; failure to transfer to LP } \\
\text { recirculation phase core cooling }\end{array}$ & $x$ & & & \\
\hline $0 \cdot 3$ & $\begin{array}{l}\text { ATWS followed by inmediate LOCA and failure } \\
\text { to reach long-term stable colling mode }\end{array}$ & $x$ & & & \\
\hline $0-4$ & $\begin{array}{l}\text { Small-break t.oCA; depletion of BWSI followed } \\
\text { by failure to transfer to recite conling }\end{array}$ & & $\mathrm{X}$ & & $\begin{array}{l}\text { Partial guidance on need to } \\
\text { preserve BWST inventory }\end{array}$ \\
\hline 0.5 & $\begin{array}{l}\text { I arge FW or Condersate line break causes loss of } \\
\text { secondasy heat sink; feed and bleed fails; emergency } \\
\text { FW from Standby Shutown Facility fails }\end{array}$ & $\mathrm{x}$ & & & \\
\hline $0-6$ & $\begin{array}{l}\text { Loss of Instrument air causes partial loss of } \\
\text { secondary beal sinki HPl and Iimergency lW art } \\
\text { not initiated }\end{array}$ & $x$ & & & \\
\hline $0-7$ & SGTR followed by HPI faiture & $\mathrm{X}$ & & & \\
\hline $0-8$ & $\begin{array}{l}\text { Loss of main FW; failue of EFW; operators fail to } \\
\text { isitiate primary feed and bleed or recover EFW }\end{array}$ & $\mathrm{X}$ & & & \\
\hline 0.9 & $\begin{array}{l}\text { SGTR with stuck-open SG relief valve; BWST } \\
\text { inventory is not maintained }\end{array}$ & & $\mathrm{x}$ & & $\begin{array}{l}\text { Paniát guidance on need to } \\
\text { preserve BWST inventory }\end{array}$ \\
\hline $0-10$ & RPV' rupture precludes ore retlooding & & & $x$ & \\
\hline $0-11$ & Intertacing system LOCA & & $x$ & & $\begin{array}{l}\text { No clear guidance on jenti- } \\
\text { fying and responding to } \\
\text { interfacing system LOCAs }\end{array}$ \\
\hline 0.12 & $\begin{array}{l}\text { Starion blackout; failure steam-driven EFW pump } \\
\text { stuck-open reliet valve }\end{array}$ & $\mathrm{X}$ & & & \\
\hline
\end{tabular}




\section{Water Addition to the Reactor Pressure Vessel}

\subsection{Description of the Strategy}

At almosi all stages of aimost all conceivable severc accidents, addition of water to the core is beneficial. In a few accident sequences, however, particularly when the capability of adding water to the core is regained after a period of zirconium burning and other corc degradation processes, the negative effects of water addition (massive hydrogen generation and structural degradaiion of the core) may be substantial. However, the operators will rarcly have enough information about the state of the core to identify those exceptional situations. On balance, the operators should always add as much water as possible to a degrading core whenever they can, as the likely bencfits outweigh the more speculative possible disadvantages. For operators to choose not to add water because of potential negative impact, is to give up the opportunity to terminate the core Jegradation processes of an ongoing accident. The issue of how the operators can know the status of a degrading core is discussed in more detail in Section 10.0.

There are situations, particularly early in an accident, when the operators may want to throttle or terminate containment spray in order to preserve inventory in the refucling water storage tank for injection into the core. This will postpone the need to switch over to recirculation mode cooling of the core and containment. These situations are easier to identify; if the containment environment can be maintained in the acceptable rangc with the containment fan coolers alone or with the fan coolers and throttled spray flow, then it is desirable to do so. Operators may also need to throttic or terminate water addition to the core in the event of overcooling or overfilling of the RCS. The controlling concern is the prevention of pressurized thermal shock ( $P \Gamma S$ ), which may threaten the integrity of the RPV. If PTS is a conccin, then the operators have at least managed to cool the core and maintain RCS inventory.

Other issues related to water addition are discussed in Sections 4.0, 6.0, 8.0, and 9.0.

\subsection{Core Fragmentation and Hydrogen Generation}

If the core has been uncovered, has dried out, and portjons of it heated up to more than $1700 \mathrm{~K}$, then addition of water may, as it did at TMI-2 (starting at minute 174 of the accident), cause massive zirconium burning, hydrogen generation, and the creation of a large porous rubble bed (Broughton ct al. 1989; Kuan ct al. 1989). This is one of the situations in which the rate of water addition can affect the course of the accident. Small amounts of water will cause only limited zirconium burning, since the process will be steam-starved. Large amounts may limit the amount of zirconium burning by quenching the hot cladding and reducing its temperaluse below $1200 \mathrm{~K}$ In-between amounts of water offer the worst of all possibilitics, enough steam to burn all of the available zirconium, but not enough water to quench the reaction (Kuan and Hanson 1991). As beforc, operators will have difficulty identifying this condition and determining that a given amount of water addition in that situation is too much or too little. On balance, the appropriate operational decision in this situation is to add as much as possible.

The resulting fragmentation of fuel rods and fuel pellets is likely to create a rubble bed, as in the TMl-2 accident, situing atop a consolidated pool of molten corium (corium is a molten or previously molten mixiuse of steel, control rod materials, zirconium, uranium, and oxides of all of these materials). Depending on the size and porosity of the rubble bed and depcnding on the availability of water, the rubble bed may or may not be coolable. If not, then it will gradually melt, cnlarging the underlying corium pool. This process may be terminated by one or morc relocations of molten corium to the lower picnum of the vessel.

\subsection{Recriticality Issues}

In the situation described in Section 3.2, control rod matcriais will have been removed from the rubble bed 
by melting and relocation, lcading to incorporation of these materials into the consolidated pool or the corium crust supporting the molten corium pool. If the water added to the vessel percolates through the rubble bed, providing moderation, then recriticality may be an issuc (Cokinos and Diamond 1979). On the other hand, an unmoderated recriticality of the molten, consolidated portion of a degrading core cannot occur at U.235 enrichments characteristic of a PWR.

Just as with an anticipated transicnt without scram (ATWS) sequence (in which control rod materia! is also missing from the core region), if sufficiently borated water is added, the rubble bed can be maintained subcritical. Problems might arise if the operators find it necessary to add unborated water directly to the RCS or if, during recirculation phase core cooling, borated water in the containment sump has been diluted by the addition of unborated water. At present, there appears to be no consensus as to whether opcrators should add water to a degrading core if their only source of water for that purpose is unborated or borated but diluted to lower than desired horon concentrations. How might borated water in the containment sump become diluted? The physical process of loss of RCS waler from a break with flashing of some or all of the RCS coolant lost followed by condensation of the resulting steam on containment structures or containment spray droplets is equivatent to distillation of the RCS coolant. The boron and other chemicals in the RCS coolant may be partially removed from the RCS coolant by this process and precipitated out somewhere in containment. Unless the boron is re-entrained by containment spray flow on its way to the sump, the net result may be gradual removal of boron from the recirculating coolant. Once precipitated out, the boron is difficult to put back in solution. Keeping it in solution in the borated water storage tanks requires heating.

In the event that it was necessary to add unborated water to containment during the recirculation phase of core eooling or that recirculating coolant has becomc diluted by flashing and condensation, a possibie mitigating stratcgy would be the pre-emplacement of open bins of dry borated chemicals in the neighborhood of the containment sump. As water levels around the sump flood the bins during recirculation-phase cooling, dis- solving the solid boron, soluble horon will be added to the recirculating coolant.

Finally, the encrgetics of a recriticality need to be considered. Recriticality transicnts in a degrading core would be unconstrained, that is, subject to mote or less free expansion as the transicn deposits energy in the critical array. This expansion and Doppler fcedback will introduce negative reactivity and terminate the transient. The total energy deposited by the transient is a function of the rate of positive reactivity addition that initiates the transient. Recriticalities in fuel or wastc process plants are typically unconstrained and initiated by the addition of material to a vessel or by gravitation assembly of a critical mass. Neither process produces very high rates of positive reactivity input; such criticalities have typically been limited to between $10^{17}$ and $10^{19}$ total fissions, released in one or a serics of pulses. This is a relatively modest amount of energy; $10^{19}$ fissions is equivalent to 320 MJoules (i.c., $3.2 \times 10^{8} \mathrm{Joules}$ ) of energy, which is 700 times smalker than the 200 GJoules (2.0 $\times 10^{11}$ Joulcs) of energy deposited in fucl in the first Chernobyl reactivity transient. Approximately a second later 1000 GJoules $\left(10^{12}\right)$ was deposited in the second Chernobyl transient. Lucas, et al. (1987d) estimate 473 MJoules and 662 MJoules as the $5 \%$ and 95\% confidence limits for the steam explosion energy release required to fail the upper head bolts of a U.S. vendor $P W R$ reactor vessel. The Chernobyl accident (which was a reactivity-driven accident, as opposed to the decay-heat-removal-driven T.MI-2 accident) inspircs caution. in that the first pulse was shut down by introduction of negative reactivity feedback (mainly Doppler), but as the power dropped, a combination of cooling of fuel fragments by rapid transfer of heat to reactor coolant together with expulsion of coolant proJuced a large positive reactivity insertion that led to the larger (Iive times larger) second power spike. Similas two-stage processes seem possible in the context of scverc accjdent recriticalities. A modest recriticality transient might disperse corium exposing the corium array to eoolant and leading to positive rcactivity inserirons due to improved moderation and Doppler effecl (i.e., cooling fuel fragments reduces the Doppler broadening of uranium ncutron absorption resonances). It appears this possibility has not been investigated in any detail. 


\subsection{Plant-specific Implementation}

Piant-specific detaiis impact the implementation of this strategy primarily in determining the ability to usc primary feed and bleed cooling and the ability to depressurize the RCS. For instance, at Calvert Cliffs, the low shutoff head of the high pressure injection pumps (1275 psi) and the low pressurization (200 psi) of the plant's safety injection tanks (i.e., accumulators) make it somewhat more difficult to add water to the core in high pressure accident sequences than at other plants.

At Zion, if the plant can be depressurized below $600 \mathrm{psi}$, water can be added to the vessel from the accumulaturs, using the blanket gas to provide the driving pressure. Zion has four accumulators with a capacity of approximately 10,000 gallons each. In addition, the RWST can provide water by gravity feed and has a capacity of approximately 389,000 gals. Procedures now cxist that allow the operators to refill the RWST from ousside water sources.

Both of thesc water sources can be treated with boric acid through the Make-up Water System. 'Therc are three boric acid tanks each with a capacity of approxitnately 11,000 gallons. The boric acid is transfersed via two boric acid transfer pumps each with a capacity of $75 \mathrm{gpm}$. Thesc pumps can be diescl-driven. If the plant emergency diesel gencrators were not working, the transfer pump could be driven by a relatively small portable gencrator if the proper interface were available.

At Oconce, unit cross-connections can have both positive and negative impacts. The ability 10 obtain emergency feedwater, service water, and electric power from other units provides valuable opportunities for recovering vital safety functions (tbere do not appear to be any unit interconnections for safety injection). However, sharing turbinc and auxiliary buildings could allow an internally initiated flood of one unit to affect another unit.

The Standby Shutdown Facility (SSF) at Oconec does provide a unique and independent capability to maintain sufficient inventory in the rcactor coolant system (RCS) to sustain natural circulation. The SSF reactor coolant volume control system (RCVCS) is designed to provide makeup waicr to the RCS and provide reactor coolant pump (RCP) seal injection. The spent fucl pool can be used as a suction source of makeup water if the normat makeup system is not available. There is sufficient boratcd water available in the spent fuel pool to allow the SSF to maintain hot shutdown conditions for all thrce units for approximately three days. The spent fuel pool water level would be drawn down to approxjmately 1 foot above the top of the spent fuel racks after this 3 day period. The RCVCS components are provided motive and control power via an independent electrical power system, which uses a dedicated diesel generator.

\subsection{Evaluation of the Strategy}

As indicated above, adding water to the vessel as soon, as often, and in as great a quantity as possible should be the operator's primary strategy for responding to severe accidents. Feasibility of the strategy is an issue; with the exception of some ATWS sequences, inability to add water to the core at some critical juncture is what turns a transient or a loss of coolant accident (LOCA) into a severe accident. Many of the other strategies discussed in this report and most of the strategies discussed in Luckas et al. (1990) represent attempts to prevent the loss of RCS inventory or to find some functioning makeup water source and delivery system that can replace lost RCS inventory.

Effectiveness of the strategy will depend on when and how the water is added and on the previous course of the accident. In a degrading core, when the pool of molten corium reaches a certain mass, its size and the sursounding crust of frozen coriun and metal will render it effectively impervious to quenching and conldown by water added to the core region. However, the watcr added to the vessel at this juncturc can still have beneficial cffects: slowing the core melt progression, scrubbing frssion products, and perhaps mitigating the fuel-coolant interaction $(\mathrm{FCl})$ at the time of relocation of the motten corium to the RPV lower plenum. Finally, presence of water at the time of core relocation to RPV lower plenum may permit quenching of a sufficiently porous rubble of fragmented corium, as appears to have happened at TMI-2. 
Water Addition

As indicated above, the potential adverse effects of water addition are speculative. In addition, the operator would seldom have sufficient information on the slatus of core degradation to identify those precise situations in which watcr addition (or addition of the wrong amount or wrong kind of water) will exacerbate the accident scquence. Consequently, whenever possible, water should be added to the vessel, as soon and as rapidly as possible. 


\section{Depressurization of the Primary System}

\subsection{Description of the Strategy}

Depressurization of the primary system during a degraded corc accident or a potentially degraded core accident carries four major potential bencfits:

1. During the depressurization transient, flashing of water to steam in the core region will cool fuel, cladding, and core internals,

2. depressurization may permit addition of water to the core using low pressure water sources,

4. depressurization should reducc the threat of induced LOCAs or steam generator tube ruptures due to natural circulation within the RCS of high pressure, supcrheated steam,

3. and it may prevent or mitigate direct heating of the containment atmosphere upon meli-through of the RPV.

Depressurization also has two major potential disadyantages: after the flashing transient is complete, core dcgradation will proceed essentially adiabatically (sec the note in Section 4.3 below) and hence more rapidly. Depressurization may also significantly increasc the probability of an energetic $\mathrm{FCl}$ (at the timc of relocation of molten corium to the lower head of the RPV).

Depressurization as an accident mitigation strategy is bcing extensively investigated at the Idaho National Engineering Laboratory as part of the NRC Sevcrc Accident Rescarch Program (Chambers et al. 1989; Golden et al. 1989; Hanson et al. 1990). Hanson et al, (1990) considered (i.e., by modelling the events using SCDAP/ RELAP5) two different depressurization strategies applied to the Surry TMLB' accident (station blackout with AFW failure). The first strategy required (early) depressurization at the time of SG dryout. The second required (late) depressurization after corc dryout and heatup (operators latch open the PORV $V_{S}$ when core exit temperatures indicate $922 \mathrm{~K}$ ). Both strategies successfully depressurized the RCS to around 1 MPascal (approximately $150 \mathrm{psi}$ ), considered low enough to prevent direct containment heating. Early depressurization accclcrated the time of core melting and RPV failure, becausc of earlier core uncovery and the ineffectiveness of low pressure steam as a heat transfer agent (see the note in Section 4.3). Because the RCS was essentially full at the time of depressurization, the depressurization transient took longer and cladding got hot enough at the time of accumulator injection to cause significant zirconium burning, hydrogen generation, and relocation of clad and fucl. For late depressurization, the RCS inventory at the time depressurization bcgins is much smaller, lcading to a shortcr transient and lower clad temperatures at the time of accumulator injection. As a result, accumulator injection quenches the core, delaying corc degradation and minimizing hydrogen production. On the basis of thcir analysis, Hanson et al. recommend late depressurization.

Liccnsing authorities in the Federal Republic of Germany have adopted depressurization as a severe accident management tool, basing their decision partly on the domination of core damage risk by high pressure core melt and vessel failure sequences ( $98 \%$ of the corc damage risk, as determined in PRAs). In addition, the high pressure sequences are considered to increase the risk of carly containment failure (Kersting 1990). A review of PRAs for the Sequoyah, Zion, Calvert Cliffs, and Oconce plants suggests a similar, if not as overwhelming, preponderance of risk-significant high pressure vessel breach sequences (Payne et al. 1984; Benjamin et al. 1987; Wheeler 1986; NSAC 1984).

\subsection{Use in Steam Generator Tube Rup- ture and Interfacing System LOCAs}

Certain types of severe accidents essentially require depressurization. For stcam generator tube ruptures (SGTRs) and interfacing system LOCAs (Event $V$ ) which threaten to proceed to corc degradation, depressurization is a major strategy for reducing thc leakage from the primary system to the secondary system (during an SGTR) or to the auxiliary building (during Event $V$ ) by reducing the pressure difference driving the leakage. Indeed, for an SGIR, primary system pressure miay be 
reduced below secondary system pressure in order to backfill the primary system from the secondary; this also stops the leakage from primary to secondary, with the disadvantage of introducing unhorated water into the primary system.

\subsection{Natural Circulation-Induced Fail- ure of the RCS}

For severc accidents proceding at high pressure, such as small-break LOCAs or transient-induced accidents, the volumetric enthalpy of stcan is high enough that significant amounts of heat can be removed from the corc by natural circulation of steam. [Note: As pressurc increases, steam density, thermal conductivity, Reynolds number, and Prandtl number all increase, swamping small decreases in dynamic viscosity and mass-specific enthalpy. The net effect is an approximately 85 -fold increasc in the elfectiveness of steam as a heat transfer medium as pressure increases from 1 bar (approx. one atmosphere) to 150 bars (El-Wakil 1971, p.244)]. In this event, natural circulation loops may transfer enough heat to the higher elevation portions of the primary systcm to cause a breach of the primary system (probably at the pressurizer surge line) large cnough to depressurizc the primary system. This scenario is speculative, but has becn supported by small-scalc experiments and detailed code analyses (Cha et al. 1989; Bayless 1988; NRC 1987). Cha ct al. investigated the sensitivity of natural circulation flows in a high pressure degrading core accident in order to try to understand why the TMI-2 accident showed little evidence of this phenomenon. Their models suggested that pressure variations and evaporation rates during the course of the accident had no impact on the natural circulation flows predicted by the codes, while higher water levels tended to reduce the strength of the flow, but not eliminate it entirely.

Analysis of a Surry TMLB' accident sequence (station blackout with loss of AFW) by Bayless (1988) using SCDAP/RELAP5 Support the conclusions:

1. Natural circulation of superheated stean is likely 10 occur in the TMLB' sequence;

2. its occurrence is relative insensitive to modelling uncertaintics;
3. it extends the core heatup transient by transporting heat from the core to struclures high in the RPV and (perhaps) to piping high in the RCS;

4. it leads to creep-rupture failure of the pressurizer surge line or one of the hot legs prior to RPV failute;

5. the RCS depressurization induced by surge line or hot leg failure leads to accumulator injection which quenches the core.

From the accident management viewpoint, the importance of the high pressurc superheated steam natural circulation phenomenon is that, even if the operators wanted to implement a stratcby of maintaining high RCS pressure (say, with the goal of preventing a stcam explosion when the molten core relocates to the lower plenum), it might not be possibic.

\subsection{Trade-Offs Between FCI and DCH}

Direct containment heating (DCH) is postulated to occur when a reactor vessel fails while the primary system is at high pressure. The high delta-p driving the flow of molten corium through the brcach causes it to fragment into an aerosol. The large surface area of the acrosol en hances heat transfer to the containment atmosphere and (exorhermic) oxidation of the metallic components of the corium. An obvious mitigating strategy is to depressurize the core to reduce the pressure driving the dispersal and fragmentation of the corium.

On the other hand, some rescarchers believe that energetie fucl-coolant interactions (FCI) are significantly more likely at low pressure than at high pressure (Bcrman 1988). The partial core relocation at TMI-2 oecurred at high pressure and produced only a mild FCI. For the in-vessel phase of a scverc accident, this is mainly an issue at the time of relocation of molten corium to the fower plenum. The concern is that an encrgetic FCI could fail the RPV in such a way as to create a missic that dircctly penctrates the containment, causing a large radiation rclease. This sccnario, called alpha-failure of containment, and fuel-coolant interaction in general, have been extensively studied for a variety of fuels and conlants, both experinentally and 
theorctically. Papers by Theofanous et al. (Theofanous et al. 1987; Abolfadl and Theofanous 1987; Amarasooriya and Theofanous 1987; Lucas et al. 1987) review the evidence for and against creation of a sufficiently energetic missile, reaching the conclusion that the probability of alpha-failure is acceptably low. Numerous Letters to the Editor responding to the Theofanous et al. papers (Berman 1988; Marshall 1988; Corradini 1988; Hopenfeld 1989; Fletcher and Thyagaraja 1989; Corradini 1989; Young 1989) and Theofanous et al. responses to those letters (Theofanous 1988a; Theofanous 1988b; Theofanous 1988c; Theofanous 1989a; Thcofanous and Amarasooriya 1989; Theofanous $1989 \mathrm{~b}$; Theofanous 1989 c) suggest that scientific consensus has not yet been reached on these issucs.

It should be noted that Theofanous et al. limit their consideration to single FCI events and consider only the probability of alpha-failure of containment. Thus, they do not consider the possibility that a sma!l FCI might disperse the remaining molten corium, providing the mechanism for both significant premixing and the triggering of a second and larger FCl. Also, their calculation of the probability of alpha-failure involves stcadily decreasing quantitics of FCI energy available to be directed upward in the vessel, to cause failure of the upper head, and to invest the upper hcad with sufficient upward-directed kinetic energy to fail containment. Finally, left out of consideration is the possibility that an FCI sufficiently energetic to fail the lower and/or upper heads may also disperse molten corium into containment as fine aerosol with the potential to cause direct containment heating.

\subsection{Information Needs}

An "ideal" strategy for dealing with a degraded core night be to maintain the primary system at high pressure while the core degraded, somehow avoid a natural circulation-induced failure high in the primary system (which would quickly depressurize the RCS), juentify when the core had relocatcd to the lower plenum, and then depressurize prior to breach of the lower head so as to mitigate DCH. By dropping the core into the lower plenum while the RCS is at high pressure, the probability of an energetic FCI is minimized. However, therc are some problems with this scenario. Natural circulation of superheated steam may depressurize the primary system independently of the operator's intent. Even if unintended depressurization doesn't occur, the operator may not have enough information about the state of the degrading core to know what actions to take and when. Finally, even if the operator could identify the moment of core relocation, there might not be sufficient time to depressurize the RCS prior to vessel failure. These problems scriously compromise this "ideal" strategy.

There is a lot of information available to the operators during a severe accident; the problem is that it's not necessarily the information the operator really needs. However, the information is tied together by the fact that all of the measurements are of a system of known dimensions and compositions undergoing a more or less understood evolution subject to the laws of physics and chemistry. The appropriate calculational tools would permit the comparison of plant data against predictions calculated from possible plant damage configurations and significantly improve the operators' understanding of the severe accident progression. These questions are considered in more detail in Section 10.0.

\subsection{Plant-Specific Implementation}

The potential tools for deprcssurizing the RCS are 1) heat removal through the stcam generators, 2) emergency core cooling system (ECCS) hows, 3) PORVs, 4) letdown how, 5) RPV head vcnts, 6) charging pumps, and 7) pressurizer spray. The difficulty is that if the operators are considering depressurization of the RCS during a severe accident (with the core degrading), most likely the plant reached this state because of the unavailability or ineffectiveness of some or all of these tools.

Depressurization using normal pressurizer spray will only be effective if water in the cold leg is subcooled and there is a sufficient pressure difference between the cold leg and pressurizer dome to drive the how in the spray line (i.e., the RCP in that loop is running). if not, therc will be an auxiliary spray flow path, most likely from the charging pump discharge header, which may be able to supply sub-cooled water to the spray valves. The reactor head vents are quite small, intended only for bleeding non-condensible gases from the RCS. The normal 
charging and fetdown flows are also relatively small, but can be increased several-fold by starting additional charging pumps or opening the letdown how control valves. The letdown flow reduces both mass and enthalpy in the RCS, thus tending to depressurize the system. The charging pumps add water to the RCS, increasing the inventory in the RCS. However, the water added is significantly subcooled, thus tending to lower the average enthalpy. 'The ECCS systems can add significant amounts of subcooled water to the RCS, combining the benefits of depressurization, makeup of RCS inventory, and quenching of hot components. The PORVs remove water mass and enthalpy from the RCS, thus depressurizing the RCS, but also tending to uncover or further uncover the cure becausc of the reduction in RCS inventory. Hanson et al. (1990) note a relatively high probability (on the order of $\mathrm{p}=0.3$ ) that a PORV block valve will be closed, because of problem leakage through the PORV. In the event of a station blackout, such closed PORV block valves cannot be opened, preventing use of that PORV as a relief and dc. pressurization pathway. In addition, Hanson et al. note that thcir late depressurization stratcgy might reqnire air system modifications to support the frequent cycling of the PORVs prior to initiation of depressurization.

If available. the steam generators are the preferred tool for depressurizing the primary systcm. The steam gencrators and the secondary system are designed to renove enthalpy from the primary system; this can be done without some of the disadvantages of Jumping large quantities of primary system mass and enthalpy to containment (through PORVs and head vents) or through the letdown flow.

The Calvert Cliffs IREP PRA assumes throughout that, in transicnt-initiated and small break LOCA accidents, the PORVs are not capable of lowering the RCS pressure below the shutoff head of the high pressure safety injection/recirculation (HPSI/R) pumps (1275 psi) soon enough to prevent core damage. For this reason, most of the core melt risk-significant accident sequences arc high-pressure sequences involving the inability to implement primary fecd and blced cooling. Since the time window for action is wider, the Calvert Cliffs PORVs should be adequate to depressurize the RCS during core degradation.
If it is decided that depressurization is necessary and all of the tools discussed above are unavailabic or have been unable to cffect depressurization, then operators can attempt 10 create a hoic in the primary system pressure boundary. A speculative possibifity, if $A C$ power is available, would be to attempt to run an RCP to destruction, thus creating a seal LOCA or some other disruption of the pressure boundary near the RCP. The actual or potential disadvantages of this action include the destruction of a valuable picce of equipment, creation of a LOCA or other damage to the RCS, and possibly providing an ignition source for hydrogen in containment. As such, this action would be taken, if at all, only afier careful consideration by the emergency staff in the Technical Support Center.

For the Zion plant, the procedure recommended in the EOP to depressurize the RCS is to use normal pressur izer spray. If pressurizer spray is not available then the RCS should be depressurized using a PORV. If no PORV is working, pressure can bc reduced using auxiliary spray, combined with letdown to prevent overfilling the RCS. Since procedures for refitling the RWST are in place at Zion, normal or auxiliary spray should be available. Note that the RCS cannot be depressurized quickly using the pressurizer spray alonc, since it only gradually reduces the average enthalpy of primary sys. tem inventory.

For the Oconee plant, decisions on operator actions to deat with inadequate core cooling, including depressurization, are based upon fuel cladding temperature, as measured by the core exit thermocouples. If the temperature of the cladding $\left(\Upsilon_{\text {clad }}\right)$, based on the average of the five highest reading core exit thermocouple tempcratures, is greatcr than $1800^{\circ} \mathrm{F}$, the operator is directed to depressurize the once-through sicam generators (OTSGs) as quickly as possible and to depressurize the RCS using the PORV until low pressure injection (LPI) is able to restore core cooling and the core exit thermocouplc tcmperatures indicate a return to saturation temperature.

If a $\mathrm{T}_{\text {clad }}$ greater than $1400^{\circ} \mathrm{F}$ but less than $1800^{\circ} \mathrm{F}$ is indicated by the core exit thermocouple temperatures and primary to secondary heat transfer has not been es. tablished, direction is given to open the pressurizer 
PORV and depressurize the RCS until the high pressurc injection (HPI), LPI, and core flood tanks (CFTs) return the core exit thermocouple tempcratures to saturation temperature. If primary to secondary heat transfer is established, direction is given to maintain this heat transfer mode by cycling the pressurizer PORV to kecp the RCS pressure 25-60 psi greater than the OTSG pressure.

The OTSG sheli-side pressurc can be lowered by adjusting the turbine bypass valves (TBVs), while maintaining SG level, until secondary $\mathrm{T}_{\text {sat }}$ is 40 to $60^{\circ} \mathrm{F}$ lower than the core exit thermocouple temperature. If primary-tosccondary heat transfer cannot be establishod, the OTSGs can be further depressurized until the secondary $\mathrm{T}_{\text {sat }}$ is 90 to $110^{\circ} \mathrm{F}$ lower than the core exit thermocouple temperature.

For an SGTR with the RCPs running, the RCS is depressurized using the pressurizer sprays. Cooldown is accomplished using the TBVs. Steamiug is initiated on the fauited OTSG until the sccondary pressure is below 1000 psig and the OTSG level is below $95 \%$. If steaming is not possible, the faulted OTSG can be drained to the condenser to avoid ovcrilling. The RCS is aiso depressurized, while maintaining subcooling, to minimize the tube leak ratc driving forcc.

\subsection{Evaluation of the Strategy}

Reactor Coolant System depressurization involves potential disadvantages and uncertainties:

- Bccause steam at low pressures is a much less effective heat transfer medium than high-pressure steam, depressurization will causc uncovered core heat-up to procecd essentially adiabatically.

- Available evidence suggests depressurization may increase the probability of "iriggering" a steam explosion (cnergetic FCI) (Berman 1988) at the timc of molten corc relocation, although it may reduce the amount of "pre-mixing" and, hence, the sizc of the resulting FCI (Abolfadl and Theofanous 1987).
- Depressurization of the RCS using PORVs whitc the core is degrading is likely to degrade conditions in containment, which will increase pressure, temperature, hydrogen content, and radionuclide contamination. This may prevent the operating staff from entering containment.

- If containment integrity has been compromised, RCS depressurization may also degrade conditions in the Auxiliary Building or causc releases to the environment.

and potential advantages:

- Depressurization below the shutoff head of ECCS pumps or below the nitrogen pressure in the accumulators may allow addition of water to the RPV using these sources.

- Deprcssurization will reduce the thermal and pressure challenges to the RCP seals.

- Depressurization will feduce the loss of RCS inventory out any breaches in the RCS pressure boundary.

- Depressurization may prevent or mitigatc high pressurc melt ejection (HPME) and DCH. This can be particularly important at plants with lower containment designs pressures, such as Sequoyah (ice condenser containment).

- Depressurization will reduce the structural challenge to an RPV weakened by high temperature crecp, potentially avoiding RPV breach.

On balance, the potential for early failure of a highly contaminated containment, duc to the likelihood and potential consequences of HPME and DCH, strongty recommends dcpressurization as a strategy for mitigating a degrading core. This is particularly true in cases where depressurization will allow water to be injected into the reactor vessel. 



\section{Flooding Reactor Cavity to Cover RPV Lower Head}

\subsection{Description of the Strategy}

Flooding the reactor cavity up to the level of the top of the RPV lower head might prevent breach of the RPV after relocation of the molten corium to the lower plenum. Failing that, this strategy might mitigate DCH by quenching and scrubbing the relcase of molten corium to the cavily.

This strategy would work to prevent RPV breach, if it worked, by changing the outside surface of the RPV from an adiabatic boundary to one with boiling and natural convection heat removal. With an adiabatic boundary (due to the reflective metal insulation on the outside of the vesscl), heat will accumulate in the metal of the lower head, raising its temperature and lowering its strength. With heat removal at the outside surface, a frozen corium crust should tend to grow at the vessclcorium interface. This corium crust will tend to insulate the vessel from the high temperatures of the molten corium mass.

If the lower head failed anyway, the mass of water in the cavity would tend to quench the corium cjected through the brach. The phenomenology is complex, however. High pressure melt ejection into a pool of water may result in an energetic fuel-coolant interaction combined with substantial generation of hydrogen from oxidation of metals in the corium.

\subsection{Plant-Specific Implementation}

Some of the factors affecting the feasibility of this strategy in preventing RPV breach are:

- The amount of erosion of the vessel by a jet of molten corium impinging on the lower head as the molten corium relocates to the lower plenum.

- The heal transfer coefficient between the molten pool, the inside surface of the RPV, and the reactor vessel internals.
- The amount of quenching and fragmentation of the corium when it relocates and the resulting porosity of the mixed molten/frozen corium mass.

- The thermal conductivity of the molten corium, frozen corium, and RPV metal.

- The heat transfer mode (nucleate boiling, film boiling, ecc.) at the outside RPV surface and the resulting surface heat transfer coeffjcient.

- Access of water in the looded reactor cavity to the surface of the RPV and pathways for removal of the steam generated at the RPV surface (i.e., how tight is the RPV insulation?).

- Ability of the operators to successfully flood the reactor cavity to the level of the lower head of the RPV.

For the Zion plant, the best way to flood the cavity is to use containment spray, drawing water from the RWST tank. This method can supply water over an extcnded period of time since the RWST can be refilled. One of the containment spray pumps is driven by its own diesel driven pump. As of 1986, it was still dependent on AC for SWS cooling of the diesel and for control. The NRC has recommended that the system be modified to make the diesel and pump independent of $\mathrm{AC}$ power. If the RWST has been refillcd with unborated water, it can be borated through the make-up water system from three boric acid tanks via boric acid transfer pumps. This system is AC dependent. This strategy is relatively simple to impicment as Zion.

\subsection{Evaluation of the Strategy}

Although the factors described in the previous section are complex, they should be amenable to quantitative analysis. Henry et al. (1991a, 1991b) have performed scoping experiments using small-scale vessels of two different thickness, both with and without reflective metal 
insulation, to assess some of the phenomenological issues. The heat source was molten iron thermite dropped into the bottom of the vessel. For their experimental setup, heat removal at the outside vessel surface procecded by nucleate boiling and there was a sufficient supply of water inflitrating through the insulation seams that the heat flux was limited by thermal conduction through the vessel wall and not by the boiling heat transfer processes on the outside surface of the vessel. M. Saito et al. (1990) developed a mathematical model for the melt/freeze phenomena occurring when a stream of motten metal falls onto a stecl plate and compared the predictions of their model with experimental results. They compared predictions assuming 1) meiting of the steel plate combined with crust formation as the molten metal froze against it and 2) the model assuming no crust formation. Experimental results wcre better predicted by the crust formation model. The crust will form an insulating layer tending to retard melting of the plate. They calculated a threshold temperature for the molten metal above which no crust would form, implying more rapid melt attack on the platc. For a molten $\mathrm{UO}_{2}$ jet, a temperature well above $4000 \mathrm{~K}$ was required to inhibit crust formation. A recent UCLA preprint (Park and Dhir 1991) Jescribes two-dimensional transient and steady-state analyses of this strategy, including the heat loss by radiation to the upper regions of the reactor vesscl and the unwetted portions of the vessel lower head. They concluded that: 1) melting of the unwetted portion of vessel wall is predicted for vessel wall emissivities greater than 0.2 (however, the melting is not expected to propogate further than half the vessel thickness) and 2) for a range of parameters studied, fooding of the cavity may provide an effective means of retaining the core in the vessel.

The issue of whether ejection of the molten corium into a pool of water in the reactor cavity would have unacceptabte consequences shares the complexity of $\mathrm{FCl}$ issues in general. A potential disadvantage of the stratcgy, if it succeeded in preventing failure of the lower head of the RPV is that maintenance of the molten core within the RPV might lead to late failures of steam generator tubes, with concommitant contamination of the secondary system.

Flooding the reactor cavity to some depth (perhaps less than the level of the lower head) is widely cited as a potential or settled strategy for the mitigation of HPME and DCH (Hanson et al. 1990; Kastenberg et at. 1990; Kersing 1990; Espefalt 1989; Lehner et al. 1988). 


\section{Restoration of AC Power and Provision of Portable Pumping Capacity}

\subsection{Restoration of AC Power}

For station blackout accidents, and to a lesser extent for loss of AC powcr transients that have proceeded to core degradation, almost all potentialiy beneficial strategies require electrical power. Thus, strategies to restore either offsite $\mathrm{AC}$ power or emergency $\mathrm{AC}$ power (or in the loss of offsite $\mathrm{AC}$ power transient, protecting against subsequent loss of the emergency diesel generators [EDGs]) are of the highest urgency.

Strategies to restore $\mathrm{AC}$ power will depend on the nature of the original transient and the estimated time to recovery (taking into account the uncertainties in timc to recovery). It is important to recognize that each faiture reduces safety margin and raises the conditional probability that additional faitures will cause core damage, core melt, and/or containment failure. This means that a plant suffering a loss of offsitc AC power with successful start and operation of the emergency diesel generators may want to arrange for delivery of backup generating capacity as insurance against subsequent failure of the diesel generators. The expected duration of the loss of offsite AC power would obviously figure in this decision.

A utikity with multiple nuclear units could purchase a single, centraily locatcd skid-or truck-mounted diesel or gas turbine generator to provide last-resort AC power backup to all of its plants. This generator should be able to reach any plant in the system within a couplc of hours. Single unit utilities might join with neighboring nuclear utilities to cooperatively purchase such emergency gencrators. At least one company (in the Chicago area) maintains sizeable inventoties of dicscl generators, gas turbine generators, and package boilers. These arc available on a 24-hour basis for rent, with delivery by truck or air freight. With appropriate planning this implies availability at any plant in the East within 12 hours and at any plant on the West Coast within 16 hours. A recent call to this company established availability of 18 rental gas turbine generators light enough tor airlifting, ranging in power from $900 \mathrm{~kW}$ to $3250 \mathrm{~kW}$, and 9 diesel generators, from $500 \mathrm{~kW}$ to $2500 \mathrm{~kW}$.
Much smaller portable generators woułd be capable of supporting critical tasks, such as maintaining DC power to the auxiliary feedwater pump and turbine or maintaining reactor coolant pump seal injection and cooling.

Finally, commercially available uninterruptible power systems (UPSs) and power conditioning systems, could help the essential plant systems ride oui short outages and bus failures. Essential $\mathrm{AC}$ power systems, which use inverters to produce $\mathrm{AC}$ power from Essential DC power busses, serve the same function. Some critical cquipment and instrumentation might be protected using commercially available UPSs, which can protect against both elcctrical line transicnts and short outages. The protection against line transients is important; without it, operators may restore $\mathrm{AC}$ power and discover that critical plant equipment was damaged by the initiating clectrical transient and is still unavailable, even though $\mathrm{AC}$ power has been restured. An example of critical instrumentation deserving of such protection are the steam gencrator level sensors. In a station blackout, after depletion of the batteries, it should still be possible to manually operate the iurbine-driven auxiliary feedwater (AFW) pump, but knowledge of the steam generator level will be required to manually control that level using the turbine-driven AFW pump.

To assure the fcasibility of such backup generation, a utility would need to inventory available portable backup generation; this would include the sources described in the previous paragraph, as well as skid-, truck-, and trailer-mounted generators used by industrial, commercial, and institutional organizations in the utility's service area. A utility might even offer incentives to organizations that generate part or all of their own clectricity to use portable generators that would be available to the vtility in an emergency. Additionally, the utility would need to plan how to tie such capacity into the plant's AC distribution systcrn, including provi. sions for bypassing failed switchyard equipment or failed busses in the plant. If the accident has resulted in (or may result in) releases to the environment, the contingency planning should permit operation of the emergency generator at some "stand-off" distance from the plant. 


\subsection{Plant-Specific Implementation}

For the Zion plant, the opcrators will first attempt to load the emergency AC bus to the EDGs from the controt room. If the EDGs start but the emergency $A C$ bus cannot be loaded from the control room, personnel would attempt to load the bus locally. If the EDGis do not start automatically, interlocks must be defeated and the diescls started manually. If the diesels do not start, the operators would attempt to power the emergency $\mathrm{AC}$ bus from any available and appropriate $\mathrm{AC}$ power supply.

The DC power systems of the three Oconee units are linked through an isolating diode arrangement so that each unit provides a DC power backup for the other units. The DC power sysiems supply instrumentation and control power through an inverier and are backed for essential loads by the $120-\mathrm{V}$ AC regulated power system. The availability of DC power aids in the recovery of $A C$ power. The wider variety and higher reliability of $A C$ power sources at the Oconee plant render station blackout accidents significantly less likely than at other plants.

Al Oconec, emergency AC power can be furnished from several sources, including:

- for certain koss of load transicnts, turbine runback will allow the Oconee plant's own generator to continue to supply plant auxiliary loads,

- six 230-kV transmission lines serving Oconec from three directions,

- either of the other two nuclear units,

- 100-kV transmission line from the two conbustion turbine generators at the Lec Steam Station,

- 13.8-kV underground line from a quick-starting on. site Keowee Hydroclectric 87,50)-kVA Gencrating Unit, and

- 230-kV overhead line from another Keowee Hydro. electric Generaing Linit.
The primary energency AC power source at Oconce is the two hydroelectric units rather than by dicsel gencrator sets. These hydroclectric units are more reliable than dicsel generators. Morc importantly, their large capacity makes it possible to provide emergency power to virtually any load. Thus, load shedding is much more limited and load sequencing is unnecessary. The reliability of the emergency $A C$ power system is futther $\mathrm{cn}$ hanced by the availability of the two Lec Steam Station combustion turbine gencrators dedicated to Oconee, with separate supply lines to a separate standby transformer.

\subsection{Evaluation of the Strategy}

Taking action to increase the flexibility and reliability of clectrical power supply sources is clearly feasible. The decision on whether and how to implement it in a specific case will need to balance bringing in backup gencrating capacity from out of town at great expensc against the downside risk of continuing to operatc with degraded electrical power supply. The probability of additional failures or slow recovery of the lost offsitc power may be quite small but the downside consequences are quite targe. There are no obvious disadvantages, other than cost, to this stratcgy, although proccdural modifications and additional training would be necded to implemont the strategy effectively.

For the Zion plant, the restoration of AC power has a major impact on a number of recovery sequences, as described in the Zion PRA rebaselining report (Wheeler 1986). The impact of restoration is highly time dependent. For cxample, in one scenario, loss of offsite power followed by loss of Auxiliary Fcedwater results in loss of secondary cooling, which is followed by an independent loss of fced and blecd capability due to human error. The restoration of $\mathrm{AC}$ power within four hours results in the successful functioning of the containment systems. Restoration later than four hours results in degraded performance of containment systems and higher probability of containment failure. Timcly restoration of AC power in certain scenarios increases the probability of containment success by two orders of magnitude. 


\subsection{Provision of Portable Pumping Capability}

Another potential approach to mitigation of station blackout and loss of of fsite $\mathrm{AC}$ power accidents is the use of portable pumps that are not powered from the plant electrical busses. These pumps could pump water from plant water sources or from offsitc water sources (i.c., lakes, rivers, etc.). There is no shortage of portable pumps at or near most nuclcar plant sites, so what is needed is pre-planning of access to the pumps and contingent connections to plant piping systems.

For accidents, such as loss of offsite $\mathrm{AC}$, station blackout, loss of main and auxiliary fecdwater, what has been tost is not access to water but pumping capability. Provision of portable, independently-powered, pumping capacity can prevent or mitigate severe accident scenarios arising from these initiators. It is necessary to:

1. ensure that the needed motive force is available-even under station blackout conditions, and

2. pre-stage the equipment necessary to allow previously anafyzed cross-connections $10 \mathrm{bc}$ implcmented quickly enough to be useful in an emergency, and

3. implement appropriate changes to procedures and training

4. assure that the connection of these pumps does not violate containment at a time of potential core degradation.

Equipment needed includes:

Piping - Fire hoses or equivalent (mostly pre-staged at the required locations)

Pumps - Fire trucks (pumper trucks) or pre-staged portable pumps

Connectors - Manifolds or "spiders" on appropriate tanks, pump suction headers, or at natural bodics of water, with connectors appropriatcly matched to the hoses and pumps to be used.
This strategy will tend to provide only low pressure pumping capacity, limited by the pumps available and the pressure linits of the flexible hoses. Higher pressures and higher hows would imply bigger purnps, bigger drivers, and pre-positioned hard piping. Thus, utilization of this strategy will primarily address supporting systems. It would tend to require depressurization of the RCS or the steam generators. Nevertheless, even in high-pressure scenarios, these portablc low pressure pumps could be used to refill water tanks and to provide cooling to ECCS equipment and RCP seal injection flow, etc.

\subsection{Plant-Specific Implementation}

Some plants have already implemented some aspects of this strategy. A1 Zion, along with extensive provisions for utilization of cross-connections between the two units, there are two fire system connections. The first is a hard-piped connection betwecn the Fire Protection (FP) system and the emergency diesel generator jacket water cooling system. Upon loss of Service Water, this backup system can be valved in from the control room. The second FP system cross-conncct allows FP system now to the centrifugal charging pump cooling systcm. This second application uses pre-staged fire hose and connectors and is incorporated into the Abnormal Operating Procedures (AOP-4.1, Rev. 3,7/31/90). Ample quantities of water are available and the ability to refill the RWST makes this strategy very attractive at Zion.

This strategy can be very useful even if only a limited pumping capability is provided. For examplc, portable purnss might be used to provide cooling for the diesel generators and/or the diesel powered containment spray pump. The ability to kcep the diesels operating might make it possible to restore the service water system (SWS) or continuc containment spray.

\subsection{Evaluation of the Strategy}

Prc-slage portable pumping capacity with judiciously planned cross-connections between plant systems and water sources result in: 
1. A relatively inexpensive upgrade of plant safety and flexibility.

2. Pumping power that is independent of offsite $A C$ and emergency $\mathrm{AC}$.

3. Increased flexibility, which could mitigatc other offnormal plant conditions:

- spent fucl pool tevel loss

- refucling cavity scal loss

- outage and maintenance activitics that requirc unusual systcm isolations

- increase relundancy for existing safety systems (e.g., jacket water cooling for the EDGs)
Other than the pressure limitations, there are no obvious disadvantages to implementing this strategy. It should be possible to use cxisting piping with fully qualified containment penetrations as the pathway for delivering water to the target systems inside containment. The piping connections needed to assure quick connection of the portable pumps are relatively modest. Certainly any such changes increase the complexity of the plant and would require changes in procedures and additional training. In addition, each added connection to plant piping systems and each ncw cross-connection beween plant systems may introduce possible plant evolutions with un-analyzed safety impacts. These potential probicms can be minimized by assuring that these crossconnects will be used only under clearly identifjed and specified circumstances, which can include severe accidents in which the potential consequences of the accident swamp the unccrtainties involved in using the cross-connect. 


\section{Prevention and Mitigation of RCP Seal Failures}

\subsection{Description of the Strategy}

This section describes some strategies from a paper by Cheng (1989) for preventing RCP seal failures subsequent to loss of Component Cooling Water (CCW) or loss of service water. If seal injection is still available (i.c., the centrifugal charging pumps are still available), fecd and bleed operation of the CCW may maintain suffjcient cooling of the centrifugal charging pumps (CCPs) to protect the seals. If not, alternate cooling water for the CCPs needs to be established. If neither of the above is possible, then an emergency cooldown of the primary system wili mitigate the effects of RCP seal failure.

\subsection{Plant-Specific Implementation}

Cheng's paper describes analysis of preventive and mitigative strategies implemented for the Taiwanese Maanshan plant, a 3-loop Westinghouse PWR. The niethods described should be generally applicable to oiter Westinghouse plants and to other PWRs.

Cheng notes that experiments and analyses by Westinghouse, the Energy Technology Enginecring Center, Atomic Energy of Canada Limited, and Electricite dc France all suggest that RCP seal failures under toss of seal injection or seal cooling will occur later and result in lower LOCA flow rates than generally assumed in safcty analyses and PRAs. Hc also discusses potential recovery actions discovered while performing a Level-1 PRA on the Maanshan plant.

If the initiating event is loss of service water (i.e., CCW pumps arc still available), causing loss of shell sidc heat removal in the CCW system heat exchangers, then feed and bleed operation of the CCW may remove enough heat to keep the CCPs operating, hence maintaining $\mathrm{RCP}$ seal injection fow. This is accomplished by fecding coll water from the condensate storage tank into the CCW surge tank, where it mixes with the hot CCW system inventory. The mixed water is pumped through the hcat exchanger where some is drained off througb the shell vent valve and the rest continues to the various emergency loads, particularly the charging purnps.

If there is not a CCW pump avaliable, or if the CCPs begin to overheat, then the operator should try to establish alternate sources for cooling water to the CCPs. At Maanshan, water from a demineralized water storage tank (DST) can be lined up by hose to supply cooling water to the ECCS pumps and the containment spray pumps. If opcration of the CCPs can be maintained, no seal LOCA is expected and the operator can proceed to a natural circulation cooldown.

If the CCPs fail (early or eventually), then the operator should initiate depressurization and cooldown of the RCS, cither a normal natural circulation cooldown or an emergency cooldown, as necessary. During the cooldown, the operators can establish alternate cooling of the RHR pumps from the DST and alternate RCP scal injection using the hydrotest pump. The alternate seal injection may prevent or mitigatc development of the seal LOCA Atternate cooling 10 the RHR pumps may allow makeup to the RCS (after the depressurization) even if the seal LOCA develops.

The analysis of core damage frequency in the Zion PRA rcbaselining (Whecler 1986) assumes that a $300 \mathrm{gpm}$ leak will develop per pump onc hour after loss of service water cooling to the seals. Once this seal LOCA occurs it is assumed that the core will be uncovered in one hour.

Reduction of RCS pressure will reduce the leakage through the seals and reduction of temperature will reduce the thermal degradations of materials. The usc of feed and bleed of CCW to protect the charging pumps can in turn protect the RCP seals. That protection cats also extend to the capability to perform primary feed and bleed cooling. At Zion, the $550 \mathrm{gpm}$ chas pumps bave a maximum discharge head of $2670 \mathrm{psig}$. Since the lift setting for the safety relief valves is $2435 \mathrm{psig}$, the feed and blecd capability exists even if mo PORVs are available. Procedures for feed and bleed opcrations are in place at Zion. 
If $\mathrm{AC}$ power is restored after having been lost, flow to the seals should be restored slowly to prevent thermal shock to the seals, bearings and pump shafts. The operators should defeat the automatic loading of the charging pumps onto the AC busses, so that flow to the RCP seals can be controlled by the opcrators.

The Oconee PRA assumed that scal leakage could reach approximatcly $100 \mathrm{gpm}$ per $\mathrm{RCP}$ within about an hour if the RCPs continue to operate without scal injection and either the seal return line is isolated or component cooling fails. If the RCPs werc tripped within 15 minutes, seal leakage is estimated $\omega$ be substantially less, no more than $15 \mathrm{gpm}$ per RCP after about an hour.

Low pressure servicc water (LPSW) provides motor cooling to the RCPs, CCW cools the RCP thermat barriers, and HPI cools the RCP seats. LPSW also provides cooling for the HPI pump motors and the CCW hcat exchangers. In the event of LPSW failure, backup cooling flow could be madc available cither from the LPSW of Units 1 and 2 or from the high pressure service water (HPSW), which supplies the fire protcction headers in all three units. The HPSW normally takes suction from the condenser circulating water crossover linc, but a
100,000 gallon clevated storage tank can provide a backup water supply. The operator recovery actions to provide backup flow to LPSW requirc local manual opcrations of cross-connection and/or isolation valycs.

In addition, the Standby Shutdown Faciity (SSF) can be used to provide RCP seal cooling indepcndent of the above systems. The spent fucl pool can be used as a suc. tion source for RCP seal injection and RCS makcup.

In $C E$ plants, $C C W$ provides conling to the RCP mechanical seals, but not seal injection.

\subsection{Evaluation of the Strategy}

The strategics discussed in this section are mostly preventive strategies, aimed at preventing or mitigating RCP seal LOCAs in accident sequences involving failures of the $\mathrm{CCW}$ system. Their implementation uses existing plant equipment and parts of these strategies are already implemented at the plants considered in this report. The only obvious disadvantage is the potential for damage to the RPV and RCS piping from the emergency cooldown, if it is needed. 


\section{Maintaining Forced Circulation Through the Core}

\subsection{Description of the Strategy}

This section considers the maintenance of forced flow under conditions that might "normally" require shutdown of the RCPs. During the TMI-2 accident, operators shut down the last opcrating RCP at 100 minutes into the accident because of vibrations caused by the two phase tluid it was pumping. Prior to this shutdown, the TMI-2 core was being successfulty cooled by the forced circulation of the two phase coolant. Upon pump shutdown, the core quickly uncovered, started to heat up, and then to degrade. When RCP flow was reestablishcd at 174 minutes into the accident, core degradation had proceeded so far that the consolidated region of molten core was not coolable and the region of the core above it fragmented due to thermal shock and zirconium burning into a porous debris bed.

Compcting critcria affect whether RCPs should continue to operate after a LOCA. The pump head may cause inventory to be lost through the break as a liquid flow, rather than a steam flow. Since steam flow will be limitcd by sonic choking of the flow, liquid break flow will result in greater inventory loss. If the pumps are tripped, then the RCS will be stagnant or naturally circulating. If pressure drops in the RCS to less than the saturation pressure corresponding the average specific enthatpy in the system, then water will start llashing throughout the system. The resulting steam will tend to collect in system high points, perhaps interrupting any natural circulation. If the RCPs ate running, the steam resulting from the flashing will tend to circulate with the rest of the coolant as a two phase mixturc.

In the absence of serious vibration, operators should attempt to maintain some level of forced circulation, if only to buy time for other mitigative strategies. Considcration should be given to "loggling" or "bumping" the RCPs, i.e., starting an RCP, bringing it up to full speed, then tripping it off and leting it coast down. This process should be continued as long as possible, perhaps rotating between severai of the RCPs. As noted, running the pumps may cause the break flow to be liquid, increasing the rate of inventory toss. This will also cause the system to depressurize faster, eventually allowing makcup from the accumulators and the low pressure injection systems.

Karassik (1989) recommends that operators continue running steam-bound boiler feed pumps until proper suction conditions can be re-established. This recom. mendation gocs counter to accepted practice of stopping a steam-bound pump immediately and not restarting it until proper suction conditions exist. He notes that he knows of no authenticaled case of a high pressure boiler-feed pump seizing at full speed beciuse of a flashing suction. When pumps have seized, it has been while coasting down after being tripped. He proposes three theoretical reasons for this assertion. First, with the pump running, there is sufficient driving torque to pull through momentary contacts between shaft and bearing caused by vibration. Second, the continuing presence of fluid (albeit, steam) in the pump body tends to damp out vibrations. Third, as a pump coasts down after being tripped, it may pass throngh a critical frequency, at which the resonance vibration will be worse than usual because it is undamped by liquid in the pump. By continuing to operate the pump under these conditions, it is simply being operated as a steam compressor. In another context, Karassik notes that cavitating flow conditions in a pump can be mitigated somewhat by adding a small amount of non-condensible gas to the pumped fluid (Karassik et al. 1976). In some low-pressure accident scenarios, operators would have access to the nitrogen remaining in the accumulators after the water in the accumulators has been blown-down into the RCS. Karassik notcs that this strategy for mitigating cavitation is rarcly used because of the difficuity in injecting just the right amount of non-condensible gas.

A related consideration is the possibility that continued operation of the RCPs, even just "bumping" them occasionally, may bias the flow and heat transfer regimes in the RCS toward natural circulation and other regimes offering significant levels of heat removal through the steam generators. Recently, di Marzo et al. (1988) described a thermal hydrautic regime occurring in smallbreak LOCAs. This regime, which they call interruption and Resumption Modc (IRM), was demonstrated 
in a test facility prototypical of a B\&W PWR. The authors makc the following observations about this thermal hydraulic regime:

1. It cannot be predicted on the basis of local conditions in the RPV, the loop seals, the OTSG, or the hot and cold legs; the RCS has to be treated integrally.

2. The (how) interruption phase of IRM involves the growth of saturated or superheated steam bubbles in the vessel downcomer or the cold legs that are, temporarily, insulated from subcooled coolant.

3. The (flow) resumption phase of IRM involves the breakdown of that insulation and rapid condensation of the bubbles, with the resulting mild waterhammer causing resumption of flow through the loop seats, the candy cane, and the OTSG.

4. The system shows signs of chaotic dynamics. "Tests repcated at the same initial conditions showed that bifurcations which alter the transicnt trajectory can occur."

5. The resumption phase produces efficient heat transfer in the OTSG, which is capable of removing all of the heat that had built up in the system during the interruption phase.

6. Increased water level in the shell-side of the OTSGs reduces the amplitude and the duration of these oscillatory flows.

Relevance of IRM to the present cvaiuation is speculative. It is possible that continucd operation of the RCPs and continued forced circulation in the RCS (even in "bumping" mode) may bias the system toward flow regimes such as natural circulation, "zeflux" cooling, or IRM which offer effective heat transfer through the stcam generators. Morc work is needed on the true lim. iring conditions for RCP operation and the impact of continued operation on loop thermal hydraulics under accident conditions.

\subsection{Plant-Specific Implementation}

At the Zion plant, RCPs could be manually started and allowed to coast down using normal procedures. There are no specific restrictions in the procedures; however, if seal cooling has been lost and reestablished, it is important to throttle back the charging pumps so that the seal and pump shafts are not damaged by thermal shock. Thermai shock of the RCP shafts could result in shaft deformation which could in turn damage the RCP by causing severe vibrations.

The obvious advantage of this strategy is that it can delay further core degradation and this, in turn, may provide the time to restore other functions that could limit the severity of the accident. Since therc has been no study reporied on the effects of "bumping" the Zion RCPs, it is difficult to assess the trade-off between using this technique to delay further core damage vs. the possibility of disabling the pumps, thus making them unavailablc should plant conditions change so that they could bc restarted. If this stratcgy were implemented on onc pump at a time, rotating among the pumps, the chances that all purnps would be damaged beyond use seems vcry remote.

At the Oconee plant, during a loss of offsite power, the RCPs are load shed. However, with the large capacity of the Keowee hydrocicctric units, load shedding is less extensive than for plants which use EDGs.

The Babcock and Wilcox (B\&W) abnormal transicnt operating guidelines (ATOG) provide directions on the best methods of operating the RCPs. The RCPs arc tripped during a small break loss of coolant accident (LOCA) if the subcooling margin is tost. However, as long as the pumps continue to run the core will be cooled by the steam and water mixture circulating through the core. If the pumps are tripped at a later time, when little liquid remains in the RCS, the stcam and water remaining in the vessel and loops will separate. Steam will collect in the high points and water will collect in low points. If enough water does not collect in the vessel, the core will be uncovered, will not be 
adequately cooled, and core damage will result. Based on the above rationale, the B\&W ATOG states that the RCPs must be tripped immediately when the subcooling margin is lost, but if the RCPs are not tripped immediately (within 2 minutes of loss of subcooling margin) they should not be tripped at a later time and at least one RCP in each loop should be operated. If scvere inadequate core cooling (ICC) conditions exists the B\&W ATOG directs that the RCPs must be restarted even if mechanical damage can occur. The ATOG also suggests "bumping" the RCPs (i.e., start and run a RCP for 10 seconds then shut it off) to start/rcstart natural circulation. If there is enough water in the RCS this should initiatc natural circulation. Under saturation conditions "bumping" may or may not start natural circulation, but it will help depressurize the RCS by condensing reactor coolant steam in the steam generators and allow more HPI to flow into the system. If natural circulation does not start after four "bumps" over an hour period, then the ATOG directs running onc RCP as long as one OTSG is available as a heat sink.

At Scquoyah and Zion, cooling of the pump motor windings is provided by air flow induced by an impeller attached to the pump shaft. This cooling air is cooled by a heat exchanger after it has passed over the windings (thus, the heat exchanger is really keeping the air in the pump enclosure cool). A routine of "bumping" the pumps and letting them coast down would expose the windings to 5-10 seconds of high heating (because of high startup amperage) followed by a couple of minutes of cooling with no electrical current in the windings. It may be possible to continue this routine indefinitely.

The Combustion Engineering EPGs CEN-152 (p. 1-51ff) provides guidance for tripping and restarting RCPs that tends to keep RCPs running in all sequences except the large break LOCA and a specific size range of hot leg LOCA.

The Generic Issue document for RCP Trip/Restart found in the Exccutive volume of the Westinghouse Owners Group ERGs (1983) gives the clearest description of the Westinghouse Owners Group approach to use of the RCPs during severe accidents. Basically, they recommend continuing to operate the RCPs during all upset and accident situations, cxcept for the inilial response to certain SBLOCAs, for which case several possible RCP trip criteria are described. These trip critcria arc preemptive, in the sense that they providc for an early trip of the RCPs in SBLOCA scenarios in which a later, inadvertent trip of the RCPs would lead to rapid core uncovcry and cladding hedup. The criteria are chosen so that they will require an RCP trip in the specific SBLOCA scenarios, but not require an RCP trip in SGTR and non-LOCA transients. The document notes that best estimate analysis shows acceptable peak cladding temperaturc for all LOCAs and transients, without tripping the RCPs, but the conservative Appendix K criteria requirc RCP trip for the specific range of SBLOCAs sequences. In any case, $\mathrm{RCP}$ operation is required in the event of inadequate core cooling (core exit thermocouple readings above $1200^{\circ} \mathrm{F}$ and secondary system dcpressurization not succeeding) or imminent pressurized thermal shock (when the RCPs are used to mix the cold safety inject flow with previously stagnant hot RCS inventory). If the RCPs have been tripped in response to a SBLOCA and the sequence later degrades to inadcquate core cooling, the ERGs require restart of one or more RCPs, even if the $R C S$ is highly voided.

\subsection{Evaluation of the Strategy}

The rapidity with which the situation at TMI-2 deteriorated after minute 100 of the accident when the last RCP was trippeds off, suggests careful consideration of RCP operation guidelines that focus more on protecting the core than protecting the RCP. The worst thing that can happen from continuing to operate the RCPs in cavitating and steam-binding conditions is catastrophic failurc of one or more of the pumps. To the extent that this (or these) failures create LOCAs, they will tend to depressurize the RCS, leading toward the low pressure, large. LOCA sequences that all contemporary PWRs were designed to accommodate.

Certainly, the thought that one or more RCPs were destroyed in an accident that might have been controlled by other means while protecting the RCPs would not be a pleasant one for the utility management. Howcver, as discussed in Section 6.3, accident management decisions should bc made with appropriate consideration of the Jownside risk of the vanious alternatives. If the acciden sequence has led to cavitation or steam binding condi. tions in one or more of the RCPs, then the conditional probability of core melt is already much larger than 
under normat conditions. This higher conditional probability leads to significantly higher economic and public safety risks in the only relevant context, that of the accident situation the operators are facing at that moment. These higher risks should tend to tilt decision criteria away from protection of valuable assets, such as the RCPs, and toward protection of the core, the containment, and the environment surrounding the plant.
The Westinghousc Emergency Response Guidelines, the CE CEN-152, and the B\&W ATOG all reflect a heightened awareness of the need, under some accident conditions, to operate RCPs under conditions of cavitation, flashing, and vibration that would normally require their shutdown. 


\section{Feed and Bleed as a Severe Accident Management Strategy}

\subsection{Secondary Feed and Bleed}

This strategy will not be described in Jetail since it is generally covered adequately by the EPGs and EOPs.

\subsection{Plant-Specific Implementation}

Vendor EPGs and plant EOPs and abnormal operating procedures (AOPs) use secondary fecd and bieed as a strategy for continuing to cool the RCS through the stcam generator, in the event that the main condenser is not available. Secondary feed and bleed, dumping steam to the atmosphere and suppiying feedwater from any available source, is preferred to primary feed and blced, which amounts to an operator-induced LOCA.

Secondary feed and bleed procedures are includect in the Zion EOPs.

At the Oconce 3 plant, the TBVs are used for steaming the OTSGs and feedwater is typically provided by emer. gency fecdwater. Backups to the emergency feedwater system include: 1) cross-connections from Units 1 and 2,2) service water, and 3) SSF auxiliary service water system (ASWS). The SSF ASWS takes suction from the Unit 2 condenser circulating water line and is a completely independent backup source.

\subsection{Evaluation of the Strategy}

As noted previously, RCS heat rejection to the secondary through the steam generators is the preferred strategy. It requires a pathway for RCS heat removal through at least onc steam generator. If possible, this is done with heat removal from the secondary through the main condenser and with normal fecdwater supply. If heat cannot be rejected at the main condenser, then steam is dumped to the atmosphere and secondary inventory is made up using whatever feedwater sources are avaitable (secondary feed and bleed). If secondary teed and bleed is successful, it should prevent core melt.
A potential adverse effect of this strategy is the possibility that feed and bleed cooling of the secondary will subject steam generator tubes to thermal shock causing an induced SGTR sequence, with its implication of containment bypass.

\subsection{Primary Feed and Bleed}

This strategy will not be Jescribed in detail since it is generally covered adequately by the EPGs and EOPs.

\subsection{Plant-Specific Implementation}

The Calvert Cliffs IREP PRA assumes throughout that, in transient-initiated and small break LOCA accidents, the PORVs are not capable of lowering the RCS pressure below the shutoff hedd of the HPSI/R pumps (1275 psi). For this reason, most of the core melt risksignificant accident sequences are high pressure sequences involving an inability to implement primary feed and bleed cooling. One possible way of raising this shutoff head a bit would be to align the discharge of the low pressure injection pumps or the containment spray pumps to the suction of the high pressure pump, which should raise the shutoff head of the HPSI/R pump to around $1425 \mathrm{psi}$. This strategy would appear to be feasible both in the injection phase and the recitculation phase of an accident, but would require complicated opcrator manipulations of cross-connecting lines.

Primary feed and bleed procedures are included in the Zion EOPs. As already noted in Section 7.2, feed and bleed cooling in the CCW system may maintain cooling to the charging pumps, thus maintaining the capability for primary feed and bleed using the charging pumps and the PORVs or the letdown flow.

For the Oconec plant, if sccondary side heat removal is nol established, the Oconee ATOG directs the establishment of HPl cooling. This is accomplished by initiating HPI, opening the pressurizer PORV, and 
Feed and Blced

running one $\mathrm{RCP}$ per loop (as long as adequate subcooling margin is maintained).

Finally, some plants (Combustion Engineering System80 plants) have no PORVs. For these plants, depressurization must bc implemented using heat removal through the steam generators or by means of feed and bleed cooling using the charging pumps, pressurizer spray, and letdown system.

\subsection{Evaluation of the Strategy}

Primary feed and bleed is a major contingent method of removing heat from the primary system. Its feasibility and effectiveness depend on the availability of bleed pathways and sources of inventory makeup. At some plants for some accident sequences primary feed and blecd may be blocked by the inability to depressurize the plant sufficiently to permit sufficient inventory makeup. The major disadvantage of primary fced and bleed cooling is that it amounts to an operator-created LOCA, contaminating, heating, and pressurizing containment, and requiring inventory makeup to prevent core uncovery and core degradation. 


\section{Creation of a Core Damage Assessment Capability}

\subsection{What is Meant by Core Damage Assessment Capability?}

This is intended to be a collection of tools for assessing and drawing conclusions about the state of the core and the RCS by evaluating the available information in its entirety. It is not intended to require extensive modifications or additions to plant instrumentation.

After TMI-2, the NRC requircd utilities to significantly upgrade their ability to identify and evaluate inadequate core cooling. All PWRs were eventually required to have in place redundant, qualified, Class $1 \mathrm{E}$ instrumentation to determine subcooled margin, temperatures at the corc exit, and RPV coolant level. Anderson (1989) has described industry responses to these NRC initiatives. Combustion Engineering developed a heated junction thermocouple (HJTC) instrument for measuring RPV coolant level. Westinghouse developed a differential pressure-based level detector, the Reactor Vesscl Level Instrumentation System (RVLIS). After rcview and lesting by the NRC, these systems were give preliminary, generic approval and have been adopied by many CE and W owners. National Nuclear Corp. developed and tested at the Farley plant a lcvel detector bascd on ex-vessel neutron detector mcasurements. This was reviewed by the NRC and judged not to provide consistent and rcliable measurement of vessel lcvels under all conditions of interest. A few plants have installed level detectors, developed by Technology for Energy Corp., based on strings of gamma thermometers arrayed in a verticat probe, providing indications of liquid or vapor conditions at a number of discretc elevations. This system has been reviewed and approved by the NRC. Babcock \& Wilcox (B\&W) plants are using differential pressure-based detectors to determine both RPV and hot leg/candy cane levels.

Utilities have tended to bring display of these instruments into the control room through the Safcty Parameter Display System. Utilities and vendors have been Icquired to test and modify the lcvel instruments and core cxit thermocouples, as neccssary to assure adequatc reliability and accuracy.
Regulatory Guide 1.97 (NRC 1980) states implementation approaches that the NRC is prepared to accept for the provision of instrumentation to monitor conditions in the plant and its environs during and following an accident. The objectives of this monitoring are:

1. provide information needed for the operators to take pre-planned manual actions to accomplish safe plant shutdown;

2. determine whcther post-accident actions and systems are performing their intended functions;

3. provide information to the operators to permil them to determine is a gross breach of barriers to radioactivity release might occur or has occurred;

4. furnish data on the opcration of important plant systems; and

5. provide information on the release of radioactive matcrials.

The Reg Guide requires that the instruments be designed so that they are always on scale during and after an accident. They are required to survive the accident environment for the length of time their function is required. The Guide identiftes the minimum number of variables to be monitored by control room operating personne: during and after an accident. It classifies instruments into five types and three categories. For the most important variabies, Type $A$ and Category 1 , the Guide requires that the data monitoring function not be susccptible to single failures; that the instruments be cnergized from station standby power; and that continuous indication be provided and recorded. Plants going into operation after June 1983 are required to meet the requirements of the Reg Guide; plants going into operation before that time are required to mect the requirements with some modifications.

Taken together, these post TMl-2 actions are intended to assure that a rich body of information about the plant will be availabic to help operators and Technicat Support Center staff determine the appropriate course of 
action during and after an accident. There remain, however, numerous difficulties with assessing the status of a degrading core. Incore instrumentation is mostly designed to provide information about neutron flux levels and mid-corc or corc exit temperatures; while it is important to know that the reactor is subcritical, these flux levels do not dirccliy tell the operator much about the status of a degrading corc. Thus, the operator is lcft with trying to draw conclusions about corc damage progression from measurements of various parameters taken at some distance from the core.

All is not lost, however. Forensic analysis of signals from the cx-vessel flux detectors during the first four hours of the TMI- 2 accident yielded a picture of reactor vesscl level consistent with that derived from the analysis of other plant data (Wu et al. 1989). This was possible because the ex-vessel detectors responded directly to gamma radiation generated in the shutdown core and to photo-neutrons generated by intcraction of the gamma radiation with dcuterium in the coolant. For both these signals, the source strength and the shielding are affected by coolant level in the core and in the downcomer. Adams and Berta (1980) indicate that selfpowered neutron detectors (SPNDs) can also provide qualitative indication of RCS coolant density and vessel level. These SPNDs, present in the core of some PWRs, will indicate directly if the reactor has not been shutdown. If it has been shutdown, the neutron signal will go off-scale low, although there is some indication that extremely sensilive amplifiers ("pico-amplifiers") can measurc this signal. With the reactor shut down, the SPNDs become much more sensitivc to temperature variation than they are to neutron fluctuations. As with the ex-vessel flux detectors, forensic analysis of SPND signals provided a picture of incore temperatures during the heat-up, dry-out, and melt-down of the TMI-2 core (Broughton et al. 1989) that is consistent with data from the core exit thermocouples.

As indicated above, all plants have core exit thermocouples (CETs). They can provide valuabie information about the condition of a degrading core, atthough Adams and McCrecry (1984) report a substantial time lag and clad temperature under-representation in the detection of cladding heat-up by the core exil thermocouples in the Loss-of-Fluid Tesi (LOFT) facility. They attribute the time lag to a film of water coating the thermocouple, which has to be boilcd away by the supcrheated steam cxiting the corc before the thermocouple can respond. The under-represemation is atrib. utcd to intervening heat transfer from the steam to cladding and core internals high in the core prior to the steam arriving at the CET.

Because of the joint sensitivity of flux detectors to both neutrons and gammas, a llux detector located under the RPV (or a ganma detector low in the reactor cavity) would respond very strongly to relocation of nolten corium to the lower plenum. Prior to relocation, both neutrons and gammas are substantially shiclded from the detector by the water in the lower plenum. After reJocation, there is little shielding for either the ganmas or photo-ncutrons. Ex-vesscl flux detcctors, located outside the vessel (at, above, or bclow the core midplane), show a similar responsc, although much reduced, to core relowation. The source range monitors at $\mathrm{TMI}-2$ showed a doubling of response at 224 minutes into the accident, which correlated with temperature and pressure indications of the relocation of moiten corium to the RPV lower plenum.

Mass and energy accounting conbined with flow rates, pressures, and temperatures throughout the RCS and containment can potentialfy provide a very complete picture of break sizes and RCS inventory. Hydrogen and gamma spectroscopy analysis of RCS coolant sanples can indicate cladding oxidation, clad failure, and fuel pellet temperatures.

Implementation of this strategy would involve the creation of calculational tools allowing the kinds of forensic analyses done after the TMI-2 accident to be completed in real-time during a future aecident. This would be analogous to tomography, in which a detailed picture of plant status is "unfolded" from a collcction of integral measurements. Specific subroutines can be developed to calculate 1) containment pressure and temperature response to LOCA blowdowns, 2) heat transfer to vessel, RCS, and in-containment structures, 3 ) hydrogen generation as a function of clad temperature and steam supply, 4) ex-vessel flux detcctor responsc to neutron and gamma sources and vessel and downcomer level, etc. The results of these calculations and other plant data can be integrated with an expcrt system which incorporates physical, chemical, and temporal relationships that have to be satisfied during any devcloping accident. Use of the expert system would enforce a consistent ifie., 
consistent with the plant design, prior history of the transient or accident, and the laws of physies and chemistry) interpretation of the available data.

For some phenomena, collections of measurements may be determined by the geometric configuration of the corc and the recent history of water leve!, coolant density, pressure, ctc. This would be true of the collection of ex-core and incore flux measurements, for instance. Artificial neural networks (ANNs) bave been used successfully in similar applications of adaptive pattern recognition. Similarly ANNs could be used to create or "capture" functional relationships between plant parameters and measured variables, on the one hand, and output variables descriptive of plant status during an accident. An artificial neural nctwork is "trained" or "learns" these rclationships by exposing its input and output "leads" to the matching input-output data vectors and letting the learning algorithm gradually build the mathematical fit that ties the corresponding input and output logether. This approach has be used successfully to identify patterns in noisy visual data or audio data. Such pattcrns might be, for example, letters in optical character recognition, "targets" in radar or iclevision or sonar signals, or phonemes (or syllablcs) in speech rccognition. In the nuclear plant severe accident context, the types of patterns we would like to be abic to identify include:

1. the type of accident underway, as a function of the set of alarms and the values of basic plant yariables and

2. the condition of the core as a function of flux, thermocouplc, flow, pressurc, and level measurements.

As these words were being wrilten a journal article arrived in the mail (Klopp 1990) discussing industry approaches to Individual Plant Examinations (IPEs) and to accident inanagement planning. On the issuc of calculational tools, Klopp discusses several possible approaches being considered. These include:

1. Placing the Modular Accident Analysis Program (MAAP) codlc at cach on-site and off-site cmergency response lacility.
2. Tying MAAP in with the plant computer, so that the input decks are written automatically to reflect current plant status.

3. Creating a "library" of MAAP runs that would depict the (calculated) plant response to a large number of scverc accident scenarios.

4. Finally, "[w]e are currently conducting feasibility studies on the potential usc of artificial intelligence (AI) systems (including neuron hybrids) as a means of collecting and presenting such a mass of information... The AI system could "learn" the library content, complete with identifiers for various kcy conditions, and be available to serve as a backup to on-line MAAP runs."

The neuronic hybrids referred to by Klopp would be AI systems containing ANNs as pattern recognizing components. The ANN components typically requirc lengthy training, but, once trained, respond very rapidly to any given input. As with natural neural networks (i.e., nervous systems), they sometime make mistakes but perform very well with noisy or degraded input data, conditions not unlikely during a scvere accident.

\subsection{Plant-Specific Implementation}

Westinghousc plants bave ex-vessel flux deteclors and movable incore fission chamber fiux detectors. The movable deteciors could apparently be "parked" below the vessel to detect relocation. There are also core exit thcrmocouples.

Babcock \& Wilcox plants bave ex-vessel flux detectors, fixed incore SPNDs, and core exit thermocouples. Many of the diagnostic criteria in the B\&W Abnormal Transient Operating Guidelines (ATOG) emergency response guidelines (B\&W 1982; B\&W 1985) are based on corc exil thermocouple reatings.

Combustion Engineering plants have ex-vessel flux deteclors, fixed in-core SPNDs, and core exit thermocouples. 


\subsection{Evaluation of the Strategy}

The creation of calculational tools to belp operators and technical support staff understand the cvolution of a scvere accident is widely recommended, but, to date, not implemented. The proposed system described in Section 10.1 is more extensive than previous recommendations, but uses components which are well-understood, or on the way to being well-understood. The calculation modules or subroutines are identical to, or simplificd versions of, modules used in today's accident analysis codes. The uses and limitations of expert systems are becoming reasonably well-understood and the knowledge necded to build reliable and logically valid expert systems is becoming more widc-spread throughout industry, academia, and the regulatory community. Artificial ncural networks build on a body of research dating back 50 years and have been the subject of intensive and widespread research for the last ten years.
A substantial effort would be required to knit the tools described together with data derived from experiments and code analyses to form an integrated tool that could help operators and technical support personnel understand, in real lime, an evolving accident. The challenge is to create a tool that can do for the opcrators in real time what the TMI-2 forensic analysis did in months and years of experimentation, reflection, code development, and analysis. The potential benefits of transfcrring the developing understanding of scvere accident phenomena from the research community to opcrating plants are also substantial. 


\section{Human Factors Considerations in Severe Accident Management}

\subsection{Introduction}

While considerable effort has been expended to study the bchavior of nuclear power plants under scvere accident conditions and to develop strategies to deal with this class of accidents, less attention has been paid to the human's rolc in carrying out the severe accident strategies being developed. In fact, many of the human factors considerations discussed below are significant enough to jeopardize the success of any severe accident strategy. Among the most significant problems are:

- The information available to plant personncl in the control room and Emergency Response Center during a severe accident about conditions within the core and in containment is often very limited and may be unreliable.

- The implementation of severe accident strategies may require the auxiliary opcrators, maintenance personnel, instrumentation technicians, and others to perform tasks, such as diagnosing faults and locally operating equipment under extreme conditions, without adequate technical data, prior training, or experience.

- Managers at all levels in the organization will be faced with decision-making situations unique to severe accidents.

- Firm critcria will be needed for when (or if) decision-making authority passes from the operating crew on duty at the time of the accident to the management and technical personnel assembling in the Technical Support Center Juring the accident.

- The lack of procedures and reliablc technical information about plant behavior nnder severc accident conditions fundamentally changes the roles of plant personnel and the decision-making process.

- Personnel may be required to work under conditions of high physiological stress including heat, noisc, high radiation levels, high humidity, toxic fumes, smoke, and /or communications overload.

\subsection{Approaches to Mitigate Human Factors Problems}

The following approaches can make a major contribution to an cffective severe accident management program:

1. Development of decision aids for determining when to invoke severe accident strategies.

2. Development, testing, validation, and verification of Job Performancc Ajds (JPAs) for severe accident mitigation.

3. Development of a training program for choosing and implementing severc accident strategies.

4. The design, development, and testing of special equipment and tools to be used by personnel working under hazardous conditions associated with scverc accidents.

\subsection{Implementation of These Mitigating Approaches}

Since severe accidents by definition go beyond the design-basis accidents and off-normal events covered by technical guidelines and procednres, the mechanisms that have been developed for utilities to respond 10 emcrgencies may require extensive adaptation to thc unique circumstances of severe accidents. These adaptations will include the development of job performance aids that differ in their basic orientation from conventional EOPs. Existing Jecision aids such as the Safety Parameter Display System (SPDS) may require modification of the organizational structure dcveloped on the basis of NUREG-0654 for responding to emergency events. 


\section{Approach \#1: Decision Aids for Declaring Severe Accident Status}

One of the most important factors in implencnting any strategy for severe accident management is deciding when and who makes the decision that it is time to deal with the situation at hand as a severe accident. This key decision will determine when the focus of activities will shift from "normal" procedures for dcaling with emergencies and off-normal events to implementing strategics to deal with core mclt, core displacement, and severe challenges to containment integrity. The lack of reliable information on the status of the core can make this a very difficult decision. Thus, problem rceognition becomes a matter of making a judgment based on multiple data sources, most of which are indirect and of unknown validity.

Since humans are rclatively poor at máking complex decisions under conditions of stress and limited information (although humans are arguably better at it than anything else but post facto investigating commissions), a useful approach would be to develop decision aids. Any dependence of these decision aids on particular computational resources or plant instrumentation needs careful consideration, since both may be unavailable in some severe accidents such station blackouts. Therc are several possible approaches to this dependence. A series of graphs or nomographs could be devcloped that represent various severe accident scenarios. These would be hased on plant data that would be available at some point in the event sequence, such as data trends over time (c.g., temperature, pressurc, status of injection systems, elc.). Calculations can be implemented in programs than run on programmable calculators or batterypowered portable computers.

In order to develop a problem rccognition decision aid, a process of knowledge engincering must take place. This incjudes identifying the relevant physical parameters in the plant, time constants for consideration, alternate sources of data should the plant information systems fail, and development of decision rules. This latter step would be based both on analyses of past severe accidents, on-going rescarch, and modeling exercises. As with all decision aids, the feasibility of a severe accident problem recognition aid depends on the thoroughness of analysis. Since all possible contingencics cannot be anticipated, the development of decision aids should concentrate on heuristics, i.e, general rules for assessing the plant state. The effectiveness of such decision aids can be evaluated in exercises in which personnel attempt to diagnose plant status and take actions using the decision aids.

'The goal in the development of this decision aid would be to design, develop, and test relatively simple decisions aids in the form of graphs, nomographs, Jecision matrices, decision trees, simple thermal hydraulic calculations, or similar devices that would be independent of the availability of plant computers or plant power.

Approach \#2: Job Performance Aids for Accident Mitigation

Once it is recognized that a severe accident is in progress, steps must be taken to minimize the probability of major releases that endanger public safety. It is unlikely that elaborate step-by-step written procedures would be useful in severe accident scenarios, even if they could be developed. Rather, the strategy should be to develop JPAs to facilitate accident management by aiding both the inductive and deductive reasoning processes of the decision-makers. The step-by-step sequences of actions used in conventional operating procedures should be minimized. The tendency to skip or alter steps will be entanced by the stressful circumstances of the accident; the in-plant environment may not be conducive to prolonged occupation by opcrators or provide the conditions for detailed actions.

The most appropriate JPA would resemble the expert systems that have proved so effective for medical diagnostics. These JPAs guide the person's thinking by a series of questions and instructions. These system also include the capability to supply to the user the logic behind each sequence should the user ask for it. If implemented on computers, they can provide multiple possjble diagnoses and an estimate of the likelihond of each being true. These JPAs should be located with the systems and equipment in the locations where they are most likely to be used.

More conventional JPAs would be used for more conventional tasks. For example, in using alternative means for pumping water, instructions may be required for making unconventional cross-over connections and starting the punp. These instructions should be located 
with or on the pump and should make heavy use of graphics to illustrate the process. Any special toots must also be prepositioned. Detailed task analysis of personnel actions for each accident mitigation strategy will help to identify the most appropriate form of JPA to facilitate personnel response. Within this context, the severity of the environment will need to be considered, since multiple human resources may be required to provide breaks for others who have worked up to their threshold level of exposure to heat, smoke, radiation, or noise. In this context, one of the plants considered in this report has a procedure for connecting a portable pump to one of the plant systems. The necessary flexible hoses for making the connections are on location and color coded, red for the supply flow path and grcen for the drain flow. This color-coding might still be difficult to use in conditions of poor visibility.

\section{Approach \# 3: Develop Training Programs for Severe Accident Managentent}

Power plant personncl receive a diversity of training. For purposes of this discussion, it will be assumed that the training received by the operators and other technical personnel is sufficient for normal conditions and emergencies that do not meet the definition of a severe accident. Included in this training are information and exercises designed to facilitate emergency response.

A training strategy for severe accident mitigation would encompass operating personnel and their supervisors, inanagement, and support personnel; cach of these stalf categorics will have functions in a severe accident that may differ from their responsibilities during non-severe accident conditions.

Training for personnel directly involved with severe accident management would emphasize an understanding of the physical and chemical processes associated with severe accident scenarios. It would fortn the basis for understanding the mitigation strategies and for the decisions on which strategies to implement. This type of traisting would differ fundamentally from conventional training by emphasizing the ability to conceptualize what is going on in the vesscl and in containment, based on a limited number of clues, some of which are of dubious reliability. An important feature of the training would be iniparting knowledge of which data sources are most likely to be reliable under a given set of conditions and which are most likely to be unreliable. The training would also develop skills in pattern recognition using limited data and help create a "cognitive mapping" of the most likely status of the core and the RCS.

A training program that is somewhat analogous to the type needed for severe accident management is the "confidence course" type training developed by the military. The basic idea is that a group of people are presented with a very difficult task and are given very limited, seemingly inadequate resources. Their task is to devise innovative strategics to achieve their goals. This typc of training could be dcveloped for severe accident scenarios.

Training of management personnel--those not directly responsible for operating the plant--represents a different set of problems. People who have studied the rcsponse of management under severe accident conditions agrce that many managers who function well under normal conditions are ill-equipped to handle scvere accident situations. Medvedev (1991) argues that the plant manager and the operating crew chief at Chernobyl continued to order inappropriate responses to the accident for approximately 24 hours, because they were unwilling to belicve accurate reports of conditions in the plant. Most experts agree that the most important functions of managers are to act as filters, buffers, and facilitators for the operational personnel who are dealing with the accident directly. The problent is that there has been little or no research on the type of training needed to develop effeclive strategies for these managers.

Approach \#4: The design, development, and testing of special tools and equipment to be used by personnel working under hazardous conditions associated with severs accidents

Experiences at TMI-2 and during the firc at Browns Ferry give us some insight into the type of conditions that could be expected during scvere accidents.

During the fire at Browns Ferry, personncl were dispatched to the equipment room in the reactor building to lift leads and install jumpers. They cnconntered dense smoke and toxic fumes that reduced visibility to inches. The requirement to wear breathing apparatus made movement within confined areas difficult. It was difficult to find the right cabinct and even more difficult 
to identify the correct lead to lift or jumper. Communications with the control room were almost impossible, so it was hard to determine that the correct actions had been taken.

During the TMI-2 accident, personnel were dispatched to the auxiliary building and into the reactor building a number of times to operate controls, read thermocouple voltages and take readings of radiation levels. Radiation levels reached high levels $(>1,000 \mathrm{mR} / \mathrm{hr})$ and icmperatures in the auxiliary building reached $170^{\circ} \mathrm{F}$. The investigators noted that radiation protection procedures wcre extremely lax and that actions of the people while in high radjation areas violated technical specifications. Had the radiation protection rules been foltowed, entry into the auxiliary building would have bcen prevented or severely restricted.

As the specific approaches and JPAs to be used by personnel in performing the tasks are developed, information on the environment in which personnel may have to work will also be described. As these environments are identified their impact on human performance can be assessed. The nced for special tools and equipment to protect personnel and make it possible for them to perform the required tasks will also be identified. An example of this type of personal protective equipment is the "cool suit" developed for use in the post-TMI recovery effort. PNL recently submitted a draft report to the NRC entitled "Review of the Impact of Environ. mental Factors on Human Performance." This report supports the preparation of performance specifications for both special tools and personal equipment that may bc required for severe accident management.

Prior to the decision to actually begin the development of special tools and equipment, a detailed and exhaustive search should be made of items already developed for other industries and the military.

In any case, it is vital that good task and human performance information be obtained so that the performance specifications reftect the real requirements of the human element of strategy implementation. 


\section{Conclusions}

The objectives of this report were twofold: first, to determine the current understanding and practice in the Pressurized Water Reactor (PWR) Emergency Procedurc Guidelines (EPGs), as it may relate to severe accident management; and second, to identify and evaluate strategies for mitigating the effects of severe accidents during the in-vessel phase of the accident, which is defined as being after the initiation of core degradation and prior to the failure of the reactor vessel. It is well-known that the EPGs arc success-oriented, and they indeed provide success paths to deal with many of the critical accident sequences discussed in the report. In addition, many of the preventive (i.c., tending to prevent the initiation of core melt) strategies identified in NUREG/CR-5474 have been impiemented, either entirely or partially, in the EPGs. However, the EPGs are not designed to provide guidance to the operators in response to the severe core damage accidents in which nothing works (or not enough things work) and core damage initiates. The functional operating guidelines dealing with inadequate core cooling and containment integrity do offer some guidance that would be useful during the in-vessel phase of a severe accident.

The vendor EPGs provide minimal guidance for the cvaluation of human factors issues that will impact the ability of control room operators and in-plant operations and maintenance personncl to carry out the actions required under accident conditions; e.g., high temperatures, moisture, and radiation levels, with possibly impaircd visibility. The Westinghouse ERGs do note some of the points at which utilities may have difficult decisions as to the capability of non-control-room staff to implement in-plant actions.

The fact that an accident has progressed to initiation of core damage implies some or all of the following plant conditions:

1. Several major plant front-line or support systems are unavailable or degraded.

2. Environmental conditions in containment are degraded, implying difficulty in carrying out some desired plant system manipulations.
3. Quality of the operator's knowlcdge of plant status, and particularly core status, is deteriorating.

4. The core may still be critical.

5. AC power may be unavailable, with $D C$ power degrading.

6. The situation in the control room may be chaotic, with personnel present who are not normally in the control room and plant conditions that have been experienced only during training sessions, if at alt.

7. Decision making responsibility and authority may not be clcarly defined.

Even with these deteriorating conditions, there are elcar actions that operators can take to prevent or mitigate further plant degradation. First and foremost, get the rcactor subcritical, if it isn't already. Second, get water into the vessel by any means possible (although there is a hicrarchy of preferred means). Third, if possible, maintain the secondary system as a heat sink for the primary system, Fourth, if electrical power is degraded or unavailable, do everything possible to restore it. Fifth, a number of relatively modest preventive and mitigative efforts may have a significant impact on plant risk. These include the flexibility to use portable $\mathrm{AC}$ power generators and portablc self-powered pumps to supply water or power critical equipment. Also included is the use of feed and blecd flow in the service water system to maintain cooling of the centrifugal charging pumps, bence maintaining $\mathrm{RCP}$ seal injection and/or RCP seal cooling. Sixth, if the core is truiy endangered, the operators should be prepared to sacrifice any other plant systems to the goal of minimizing the damage to the core and the threat to containment.

The arguments supporting RCS depressurization prior to vessel breach are persuasivc. Early dcpressurization gets the plant closer to the accident conditions it was designed for, but may accelerate core degradation by comparison with remaining at high pressure. The analysis of Hanson et ai. (1990) strongly suggests that late depressutization is prefcrable to carly depressurization, 
preferable in the sense of leading to delayed initiation of core degradation and lower hydrogen generation. Early or late depressurization should significantly reduce the risk associated with high pressure melt ejection and direct containment heating.

Improved knowledge of the status of a degrading core might improve the quality of accident management. This improved knowlcdge will require calculational tools that can integrate plant data with knowledge of the plant design to choose those descriptions of plant status that are consistent with the data and the time history of the accident-and do it all in real timc.

Flooding the rcactor cavity to the top of the RVP lower head may improve heat removal from the outer surface of the lower head enough to prevent creep-rupture failure of the lower head after relocation of part of the molten corium to the lower plenum.
Continuing to operate RCPs and maintain forced flow through the vessel (under conditions that put the RCPs at risk) may prevent or mitigate core damage or may buy time for actions to recover or protect containment or protect the public. For some LOCAs, this choice may increase the ratc of inventory loss from the break, thus requiring increased makeup flow.

Thus, this work has identified several strategies, which extend beyond the EPGs into the severe accident regime, that will mitigate the seriousness of events and their consequences during the in-vessel phase of severc accidents. Further work in this area can be expected to better define the feasibility, effectiveness, and potential disadvantages of these strategies in the context of application to specific plants. 


\section{References}

Abolfadl, M. A. and T. G. Theofanous, (1987), "An Assessment of Steam-Explosion-Induced Containment Faiiurc. Part II: Premixing Limits", Nuclear Science and Engineering, Vol. 97, 282-295, Deccmber 1987.

Adams, J. P., and V. T. Berta, (1980), "Response of LOFT SPNDs to Reactor Coolant Density Variations During a LOCA Simulation", Transactions of the Amer. ican Nuclear Society, TANSAO, Vol. 35, pp. 334-336, November 1980.

Adams, J. P. and G. E. McCrcery, (1984), "Limitations of Detecting Inadequate Core Cooling with Corc Exit Thermocouples". Transactions of the American Nuclear Socicty, Vol. 46., pp. 474-476, American Nuclear Socicty, La Grange Park, IL, June 1984.

Amarasooriya, W. H. and T. G. Theofanous, (1987), "An Assessment of Steam-Explosion-Induced Containment Failure. Part III: Expansion and Energy Partition ${ }^{*}, \mathrm{Nu}$ clear Science and Engineering, Vol. 97, 296-315, December 1987.

Anderson, J. L., (1989), "Technical Notc: Instrumentation Systems for Detecting Inadequate Core Cooling", Nuclear Safety, Vol. 30, No. 4, October-December 1989.

Babcock \& Wikcox, Abnormal Transient Operating Guidelines, B\&W Technical Documents \#74-1123297-00 and \#74-1123298-00, March 1982.

B\&W Owners Group Operator Support Committee, (1985), Emergency Operating Procedures Technical Bases Document, B\&W Technical Document \#74-1152414-00, July 1985 .

Bayless, P. D., (1988), Analyses of Natural Circulation During a Sury Station Blackout Using SCDAP/RELAPS, NUREG/CR-5214, EG\&G Idaho, Idaho Falls; Idaho, October 1988.

Bchr, V. L., ct al., (1987), Containntent Event Analysis for Postulated Severe Accidents: Sequoyah Power Station Unit 1, NUREG/CR-4700, Vol. 2, Sandia National Laboratory, February 1987.
Bcnjamin, A. S, et al., (1987), Evaluation of Severe Accident Risks and the Potential for Risk Reduction: Sequoyah Power Station, Unit 1 (DRAFT), NUREG/ CR-4551, Vol. 2, Sandia National Laboratory, February 1987.

Berman, Marshall, "Comments on 'An Assessment of Steam-Explosion-Induced Containment Failure. Parts I-IV", Nuclear Science and Engineering, Vol. 100, 149-162, October 1988.

Bertucio, R. C., et al., (1987), Analysis of Core Damage Frequency from Intemal Events: Sequoyah Unit I, NUREG/CR-4550, Vol. 5, Sandia National Laboratory, February 1987.

Broughton, J. A., et al., (1989), "A Scenario of the Three Milc Island Unit 2 Acciden1", Nuclear Technology, Vol. 87, pp. 34-53, August 1989.

Cha, Y. S., ct al., (1989), Numerical Simulation of Natural Circulation Phenomena in a PWR During TMLB' Transients Prior to Core Damage, NUREG/CR-5247, Argonne National Laboratory, May 1989.

Chambers, Rosanna, D. J. Hanson, R. J. Dallman, and Fuat Odar, "Depressurization to Mitigate Direct Containment Heating", Nuclear Technology, Vol. 88, 239 250, December 1989.

Cheng, Shih-Kuei, (1989), "Seal Loss-of-Coolant Accident and Recovery Actions Following Loss of Component Cooling Water", Nuclear Technology, Vol. 84, pp. 305-314, March 1989.

Cokinos, D. and D. J. Diamond, (1979), "Recriticality duc to Clad-Free Pehtet Rearrangements in a PWR", Transactions of the Anierican Nuclear Society, Vol. 33, pp. 844-845, American Nuclear Society, La Grange Park, IL, November, 1979.

CEN-152 Rev. 1, Combustion Engineering Emergency Procedure Guidelines, developed by the Combustion Engincering Owners Group, 1982. 
CEN-152, Combustion Engineering Emergency Procedure Guidelines, Rev, 3, SVB I, developed by Combustion Engineering Owners Group, 1985.

Corradini, M. L., "Comments on 'An Assessment of Stcam-Explosion-Induced Containment Failure. Parts I-IV", Nucleur Science and Engineering, Vol. 100, 171-174, October 1988.

Corradini, M. L., "Response to 'Comments on FuelCoolant Premixing Modcling', Nuclear Science and En. gineering, Vol. 103, 103-104, September 1989.

di Marzo, M., et al., (1988), "The Phenomenology of a Small Break LOCA in a Complex Therma! Hydraulic Loop", Nuclear Engineering and Design, Vol. 110, pp. 107-116, 1988.

Emergency Operating Procedures Technical Bases Document, B\&W Owners Group Operator Support Committee, 1985.

El-Wakil, M. M., Nuclear Heat Transport, International Textbook Co., Scranton, Pennsylvania, $197 \mathrm{~L}$.

Espefalt, Ralf, (1989), "Severe Accident Mitigation Program for the Forsmark and Ringhals Plants", Nuclear Engineering and Design, Vol. 117, pp. 19-24, 1989.

Fletcher, D. F and A. Thyagaraja, "Comments on Fue:Coolant Premixing Modeling", Nuclear Science and Engineering, Vol. 103, 101-102, September 1989.

Golden, D. W., ct al., (1989), Depressurization as an Accident Managentent Strategy to Minintize the Consequences of Direct Containment Heating (DRAFT), NUREG/CR-5447, EGG-2574, Idaho National Engineering Laboratory, September 1989.

Hanson, D. J., et al., (1990), A Systematic Process for Developing and Assessing Accident Management Plants, NUREG/CR-5543, Idaho National Enginecring Laboratory, March 1990.

Henry, R. E., et al., (1991a), "Cooling of Corc Debris Within the Reactor Vessel Lower Head", preprint, Fauske \& Associates, Inc., Burr Ridge, lllinois.
Henry, R. E., et al., (1991b). "Cooling of Core Debris Within the Reactor Vessel Lower Head", "Transactions of the ANS, Vol. 63, pp. 260-261, American Nucicar Socicty, La Grange Park, IL, June 1991.

Hopenfeld, J., "Comments on 'An Assessment of SteamExplosion-Induced Containment Failurc. Parts I-IV', Nuclear Science and Engineering, Vol. 103, p. 100, September 1989.

Karassik, Igor J., et al., editors, (1976), Pump Handbook, P. 2-170, McGraw-Hill, New York, 1976.

Karassik, Igor J., (1989), "Resist seizure of flashed pump with new operating procedure", Power, pp. 55-57, August 1989.

Kastenberg, W. E., et al., (1990), Proceedings of a Workshop on Severe Accident Management for PWRs (DRAFT), prepared by the UCLA Dept. of Nuclear Engineering for the U. S. Nuclear Regulatory Commission.

Kersting, E., "Investigation of Accident Management Measures for PWR, Presentation made to UCLA Workshop on PWR Severe Accident Management, Westwood, California, May 13-15, 1990.

Klopp, George T., (1990), "Accidenı Management Program Evolution at Commonwealth Edison", Nuclenr Plant Journal, Vol. 8, No. 5, pp. 46-54, Septenber. October 1990.

Kuan, P. et al., (1989), "Thermal Interactions During the Threc Mile island Unit 22-B Coolant Pump Transient", Nuclear Technology, Vol. 87, pp. 977-989, Decembcr, 1989.

Kuan, P. and D. J. Hanson, (1991), "Managing Watter Addition to a Degrad Core", preprint of a paper to be published in the Proceedings of the 19th Water Reactor Safety Information Mecting, held at Bethesda, Maryiand, October 28-30, I991.

Lehner, J. R., ct al., (1988), Severe Accident Insights Repon, NUREG/CR-5132, Brookhaven National Laboratory, Aprit 1988. 
Lucas, G. E., W. H. Amarasooriya, and T. G. Theofanous, (1987), "An Assessment of SteamExplosion-Induced Containment Failure. Part IV: Impact Mechanics, Dissipation, and Vessel Head Failure", Nuclear Science and Engineering, Vol. 97, 316-326, 1987.

Luckas, W. J., J. J. Vandenkicboom, and J. R. Lehner, (1990), Assessment of Candidate Accident Manogement Srrategies, NUREG/CR-5474, Brookhaven National Laboratory, March 1990.

Marshall, Billy W, Jr., "Comments on 'An Assessment of Steam-Explosion-Induced Containment Failure. Parts I-lV', Nuclear Science and Engineering, Voi. 100, 165-170, October 1988.

Medvedev, Grigoriy, Chernobyl Notebook, Basic Books, New York, 1991.

Nuclear Safety Analysis Center, (1984), Oconee PRA: $A$ Probabilistic Risk Assessment of Oconee Unit 3, NSAC- 60 , Cosponsored by NSAC, EPRI, and Duke Power Co., June 1984.

Park, H. and V. Dhir, (1991), "Effect of Outside Cooling of the Thermal Behavior of a Pressurized Water Reactor Vessel Lower Head", preprint, UCLA Mechanical, Acorspacc, and Nuclear Engineering Department, Los Angeles, California, 1991.

Payne, Arthur C., Jr., et al., (1984), Interim Reliability Evaluation Program: Analysis of the Calver Cliffs Unit 1 Nuclear Power Plant, NUREG/CR-3511, Sandia National Laboratory, March 1984.

Pickard, Lowe \& Garrick, (1982), Zion Probabilistic Safety Srudy, Rev. l, for Commonwealth Edison Company, Septcmber 1982.

Saito, M., et al., (1990), "Melting Aitack of Solid Plates by a High Temperature Liquid Jet - Effect of Crust Formation", Nuclear Engineering and Design, Vol. 121, pp. 11-23.
Theofanous, T. G., B. Najafi, and E. Rumble, (1987), "An Assessment of Steam-Explosion-Induced Containment Failure. Part I: Probabilistic Aspects", Nuclear Science and Engineering, Vol. 97, 259-281, 1987.

Theofanous, T. G. (1988a), "Response to 'Conments on "An Assessment of Steam-Explosion-Induced Containment Failure. Parts I-IV"' by Marshall Berman", Nuclear Science and Engineening, Vol. 100, 162-165, October 1988;

Theofanous, T. G. (1988b), "Response to 'Comments on "An Assessment of Steam- Explosion-Induced Containment Failure. Parts I-IV" by B. W. Marshall, Jr. ${ }^{n}, \mathrm{Nu}$ clear Science and Engineering, Vol. 100, p. 171, October 1988.

Theofanous, 'T. G. (1988c), "Response to 'Comments on "An Assessment of Steam-Explosion-Induced Containment Fajlure. Parts I-IV"' by M. L. Corradini", Nuclear Science and Engineering, Vol. 100, 174-175, October 1988.

Theofanous, T. G.(1989a), "Response to 'Comments on "An Assessment of Steam-Explosion-Induced Containment Failure. Parts I-IV"n, Nuclear Science and En. gineering, Vol. 103, 100-101, September 1989.

Theofanous and Amarasooriya, "Response to 'Comments on Fuel-Coolant Premixing Modeling'", Nuclear Science and Engineering, Vol. 103, 102-103, Septembcr 1989.

Theofanous, T. G. (1989b), "Response to 'Comments on Fuel-Coolant Premixing Modeling", Nuclear Science and Engineening, Vol. 103, p. 105, Scptember 1989.

Theofanous, T. G. (1989c), "Response to 'Comments on the Fuel-Coolant Premixing Debate', Nuclear Science and Engineening, Vol. 103, 107-108, September 1989. 
U.S. Nuclear Rcgulatory Commission, (1980a), Criteria for Preparation and Evaluation of Radiological Emergency Response Plans and Preparedness in Suppor of Nuclear Power Plants, NUREG-0654, November 1980.

U.S. Nuclear Regulatory Commission, (1980b), Instrumentation for Light-Water-Cooled Nuclear Power Plants to Assess Plant and Environs Conditions During and Following an Accident, Regulatory Guide 1.97, December 1980.

U.S. Nuclear Regulatory Commission, 1987, Uncentainty Papers on Severe Accident Source Terms, NUREG-1265, May 1987.

U.S. Nuclear Regulatory Commission, 1989, Staff Plans for Accident Management Regulatory and Research Programs, SECY-89-012, Jaлuary 18, 1989.
Westinghouse Owners Group, Emergency Response Guidelines, September 1, 1983.

Wheeler, T. A, (1986), Analysis of Core Damage Frequency from Internal Events: Zion Unit 1, NUREG/CR-4550, Vol. 7, Sandia National Laboratory, October 1986.

Wu, Horng-yu, (1989), "Analysis of the Source Range Monitor During the First Four Hours of the Three Milc Island Unit 2 Accident", Nuclear Technolog, Vol. 84 , pp. 169-181, February 1989.

Young, M. F., "Comments on the Fuel-Coolant Premixing Debatc", Nuclear Science and Engineering, Vol. 103, 1063-107, Septenber 1989. 


\section{Appendix A}

Westinghouse Large, Dry Containment Plant - Zion 
Appendix A

\section{Appendix A}

\section{Westinghouse Large, Dry Containment Plant - Zion}

\section{A.1 Critical Accident Sequences}

Critical accident sequences for a large, dry containment plant were determined using information from NUREG/CR4550, Vol. 7, Core Damage Frequency from Internal Events. This NUREG report documents the probabilistic risk assessment (PRA) performed on Zion Unit 1 in support of NUREG-1150. Additional information was inferred from the Westinghouse Owner's Group Emergency Response Guidelines (ERGs), High-Pressure Version, Revision 1, September 1, 1983. Zion is one of the Westinghouse "high-pressure" plants; that is, it has a safety related, fully qualified, charging system available to inject water in accidents where the reactor coolant system (RCS) pressure stays near the relief valve setpoints.

\section{A.1.1 Core Melt Risk}

The following 17 sequences were identified in the Zion PRA as dominating the risk of core melt:

Z-1 Loss of component cooling water (CCW), causing loss of cooling to the RCP seal thermal barriers and eventually inducing an RCP seal LOCA. In addition, loss of CCW flow to the charging and safety injection (SI) pumps will cause their failure. Containment cooling remains available, but core damagc results from an inability to replace primary coolant. This sequence accounts for $79.4 \%$ (!!) of the total core damage frequency $(\mathrm{CDF})$ calculated in the PRA. The sequence leads to early core damage and vessel failure with the RCS at high pressure, with containment systems functioning.

Z-2 Small-break LOCA ( $<2$ in.) followed by failure of the recirculation system to provide high-pressure SI into the primary system. The dominant contributor to this sequence is human error in switching the low-pressure suction lines from injection to recirculation. This sequence accounts for $10.6 \%$ of the CDF and leads to late core damage and high pressure RPV failure with containment systems functioning.

Z-3 Large-break LOCA followed by an independent failure of low-pressure SI into the primary system during the recirculation phase. The dominant contributor is human error in realigning the low-pressure injection (LPI) system suetion valves from injection to recirculation. This sequence accounts for $3.2 \%$ of the CDF and leads to a late, low pressure RPV failure with containment systems functioning.

$\mathrm{Z} 4 \mathrm{~T}$ This scquence is identical to sequence $\mathrm{Z}-3 \mathrm{except}$ the initiating event is a medium-break LOCA. It accounts for $3.2 \%$ of the CDF.

Z.5 Loss of $A C$ power; independent failure of auxiliary feedwater (AFW) system; failure of feed and bleed; failure to restore offsite power in $1 \mathrm{~h}$ but recovery before $4 \mathrm{~h}$. The dominant contributors to this sequence are human error in implementing feed and bleed and random failures of the AFW system. This sequence accounts for $1.4 \%$ of the CDF and leads to early, high pressure RPV failure with containment systems functioning because of the restoration of $A C$ power. 
Appendix A

Z-6 Large-break LOCA and failure of LPI. The primary contributor is human crror in leaving certain motoroperated valves (MOVs) closed after testing the LPI system. This sequence accounts for $0.9 \%$ of the CDF and leads to early, low pressure failure of the RPV with containment systems functioning.

Z.7 This scquence is the same as sequence Z-5 except AC power is restored between 4 and $8 \mathrm{~h}$. This sequence accounts for $0.3 \%$ of the CDF and leads to carly, high pressure failure of the RPV. AC powcr is restored carly enough to allow successful functioning of containment systems.

Z-8 Loss of $A C$ power, causing loss of CCW and service water system (SWS); power restored in morc than ith and less than $4 \mathrm{~h}$. An RCP seal LOCA is induced. CCW/SWS are recovered after restoration of AC power; however, core melt has already occursed. The dominant contributors are hardware and maintenance failures in CCW, SWS, and diesel generators (DGs). This sequence accounts for $0.2 \%$ of the CDF and leads to carly, high pressure RPV failure with successful functioning of containment systems.

Z-9 Same as sequence Z-8 except for the unrecoverable failure of the SWS. An RCP seal LOCA is caused by loss of $\mathrm{CCW}$, which is caused by the unrecoverable loss of the SWS. The permanent loss of the SWS atso results in failure of containment systems. Dominant contributors to this sequence are common-cause failures of the SWS. This sequence accounts for $0.2 \%$ of the CDF and icads to early, high pressure failure of the RPV and carly containment failure.

Z-10 Loss of AC power, causing loss of CCW and SWS followed by induced RCP Scal LOCA; failure to restore power in $8 \mathrm{~h}$, causing failure of containment sprays and fan coolers. This sequence accounts for $0.1 \%$ of the CDF and leads to early, high pressure RPV failurc and early containment failure.

Z-11 Loss of AC power, causing loss of CCW and SWS; AC power restored after $4 \mathrm{~h}$ and before $8 \mathrm{~h}$. This sequence is similar to sequence Z-8. An RCP seal LOCA does occur and restoration of AC power does not occur soon enough to prevent core melt. AC power is restored in time to prevent failure of containment. This sequence accounts for $0.1 \%$ of the CDF and leads to early, high pressurc RPV failure with succcssful functioning of containment systems.

Z-12 Loss of offsite AC power and partial failure of emergency AC power with no recovery within $8 \mathrm{~h}$, causing failure of SWS. This sequence is similar to sequence Z-10 except that RCP seal LOCA and the loss of CCW are caused by loss of SWS. The failure to restore AC power within $8 \mathrm{~h}$ results in complete loss of containment systerns. This sequence accounts for $0.1 \%$ of the CDF and results in early, high pressure failure of the RPV and carly faiture of containment.

Z-13 Same as sequence Z-12 except containment fans fail directly as a result of the loss of AC power rather than as a result of a loss of cooling to the chillers. Since AC power is not restored in $4 \mathrm{~h}$, an RCP seal LOCA wil! occur. This sequence accounts for $0.07 \%$ of the CDF and leads to early, high pressure failute of the RPV with partial success of containment systems.

Z-14 Interfacing systems LOCA. In this sequence two MOVs in the residual heat removal (RHR) system fail to isolate low-pressure piping from the high-pressure RCS. Although the simultancous failure of two MOVs is a low probability cvent, it was inciuded becausc this failure dircctly bypasses containnent. This sequence accounts for $0.07 \%$ of the CDF and can lead to either early or late failure of the RPV. Containment is already bypassed at the time of core damage initiation.

Z-15 Fajlure of DC bus 112 causing loss of one power-operated relief valve (PORV) and loss of AC bus 148 and failure of $\mathrm{AFW}$. Failure of $\mathrm{DC}$ bus 112 causes loss of main fecdwater (MFW) and a reactor trip. Containment 
systems succeed. Although feed and bleed might be feasible without any functioning PORVs, this sequencc includes loss of feed and bleed because of the loss of one PORV and the relatively high probability of operator error in operating PORVs. This sequence accounts for $0.03 \%$ of the CDF and leads to early, high pressure failure of the RPV with containment systems functioning.

Z-16 Same as sequence Z-11 with the SWS common-mode portion of sequence Z-12. SWS failure causes failure of CCW. Since SWS cannot be restored, the CCW and injection pumps will not operate and an RCP scal LOCA occurs. This sequence accounts for $0.03 \%$ of the CDF and leads to early, high pressure failure of the RPV and early failure of containment due to loss of SWS and CCW.

Z-17 Loss of offsite power and degraded emergency $\mathrm{AC}$ power, causing $\mathrm{CCW}$ failure; failure to recover full $\mathrm{AC}$ power or start faulted DGs in $8 \mathrm{~h}$. In this sequence, an RCP seal LOCA occurs in a manner similar to sequence Z-8. This sequence is comprised of degraded $A C$ power scenarios which allow the SWS and containment fans and cooling systems to succeed. This sequence accounts for $0.03 \%$ of the CDF and leads to early, high pressure failure of the RPV with sucessful functioning of containment systems

\section{A.1.2 Public Risk}

Accident sequences that resulted in the failure of containment systems are considered to present a risk to the public. These scquences arc Z-9, Z- 10, Z-12, Z-13, and Z-14.

\section{A.1.3 Challenges to Safety Functions}

There are six critical safety functions identified in the Westinghouse ERGs:

(1) Reactor subcriticality.

(2) Core cooling.

(3) Reactor pressure vessel (RPV) integrity.

(4) Primary system heat sink (i.e., the sccondary system).

(5) Containmenl integrity.

(6) Primary system inventory.

All 17 sequences in the Zion PRA represent a threat to some of the critical safety functions. Other events that would also pose a threat to the safety functions are pressurized thermal shock (PTS), anticipated transient without scram (ATWS), and steam gencrator tube rupture (SGTR).

\section{A.1.4 Threats to Safety Systems}

Each of the 17 sequences in the Zion PRA poses a threat to safety systems. The PRA sequences represent the combination of failures of a number of safety systems. Some events involving the failures of support systems also represent a threat to safety systems, i.e., failure of CCW or SWS, station blackout, and SGTR. In addition, seismic events, fires, and internal hooding threälen safety systems. 
Appendix A

\section{A.2 ERG Coverage of the Critical Accident Sequences}

\section{A.2.1 Methodology}

Critical accident sequences were identified in NUREG/CR-4550, Vol. 7, Analysis of Core Damage Frequency from Interna! Events: Zion Unit 1. Each sequence was analyzed to determine what components and systems were affected (in many cases this was included in the PRA). The Westinghouse Owner's Group ERGs were analyzcd to determine if they provided information and direction to adequately handie or at least provide some help in responding to the critical accident sequences. The Westinghouse ERGs contain both event- and safety function-based guidelines, and both types werc included in the analysis. The event-based guidelines have EXX-y.z numbering; the safety functionbased guidclines have FX-y.z numbering (where X represents various letters and $y$ and $z$ represent various numbers).

The analysis showed that the ERGs provide significant guidance, particularly for those sequences that have a large human error component (such as sequences $Z-2$ and $Z-3$ ). This is not surprising since the ERGs provide guidance for the development of Emergency Operating Procedures (EOPs), which, by definition, specily appropriate operator actions in various situations and scenarios. In addition to the PRA sequences summarized below, there are other cvents (e.g., SGTR. ATWS, and PTS) that also represent threats to public safely, safety functions and safety systems. These threats are identified in Sections A.1.2 through A.1.4. For these threats, the ERGs contain specilic guidance.

\section{A.2.2 Summary of ERG Guidance for Each of the Sequences in the Zion PRA}

\section{Sequence Z-1 (Loss of CCW)}

The Function Restoration (FR) Procedures FR-C.1 and FR-C.2 deal with inadcquate core cooling and degraded corc cooling. The guidance in these procedures is limited to atiempts to restore systems that will provide coolant to the corc. The only steps that would temporarily provide a limited amount of coolant are those for depressurizing and injecting the coolant into the vessel from the SI accumulators. At this point the FR Procedures exit to the event-based procedure, E-1, LOSS OF REACTOR OR SECONDARY COOLING. No additional help was found in this procedurc.

\section{Sequence Z-2 (Small-break LOCA and high-pressure recirculation failure)}

Bolh FR Procedures and Optimal Recovery Guidelines (ORGs), which are the crent-bascd guidelines, provide steps to recstablish high-pressure safety injection (HPSI).

\section{Scquence Z-3 (Large-break LOCA and low-pressure recirculation failure)}

The ERGs contain steps to establish and verify low-pressure injection. Although these steps do not explicily state that the operators should ensure that the suction valves are in the proper position, steps can be taken to initiate injection by the LPI system.

\section{Sequence Z-4 (Medium-break LOCA and low-pressure recirculation failure)}

Same as sequence Z-3.

Sequence Z-5 (Loss of AC power, failure of AFW, failure of fecd and bleed, and power not recovered in $1 \mathrm{~h}$ ) 
Guidelines for loss of all AC power are contained in Section ECA-0.0 of the ERGs. The guidelines rely on the ability to reestablish AFW or, failing that, to depressurize and use fecd and bleed. No guidance is given for the conditions in this accident scquence.

\section{Sequencc Z-6 (Large-break LOCA and LPl failure)}

As is the case with other sequences in which the primary factor contributing to the probability of the sequence is human error, the ERGs provide steps to initiate the system required (i.e., the LPI system). The ERGs contain steps for dealing with a large-break LOCA (ERG E-1), and these would be effective once LPI were restored. The actual testing of MOVs and the proper lineup for the MOVs after testing should be contained in a normal operating procedure or a surveillance procedure.

Scquence Z-7 (Loss of AC power, failure of AFW, failure of feed and bleed, and power not recovered in $8 \mathrm{~h}$ )

Sequence Z-8 (Loss of AC power, temporary loss of CCW and SWS, power and systems restored between 1 and $4 \mathrm{~h}$, but not before core damage occurs)

Sequence Z-9 (Loss of AC powcr, permanent loss of SWS and CCW)

Guidclines for loss of power are contained in Section ECA-0.0 of the ERGs. However, the ERGs do not provide guidance for the combination of conditions described in these three sequences.

Sequence Z-10 (Loss of power, loss of CCW and SWS, power not restored in $8 \mathrm{~h}$ )

This sequence results in both core damage and a severe challenge to containment. The ERGs do not provide any help in dealing with the loss of all component cooling and service water systems. Likewise, the ERGs provide no guidance for dealing with maintaining containment integrity without sprays and cooling fans. Presumably plant AOPs provide guidance for response to loss of $\mathrm{AC}$ power, CCW, and SWS.

Sequence Z-11 (Loss of AC power, temporary loss of CCW and SWS, power and systems restored between 4 and $8 \mathrm{~h}$, but not before core damage occurs)

Sequence Z-12 (Loss of offsite power and partial failure of emergency AC power, permancnt loss of SWS, and power not recovered in $8 \mathrm{~h}$ )

Sequence Z-13 (Loss of offsite power and partial failure of emergency AC power, loss of SWS, containment fans failed, and power not restored in $8 \mathrm{~h}$ )

Guidelines for loss of power are contained in Section ECA-0.0 of the ERGs. However, the ERGs do not provide guidance for the combination of conditions described in these three sequences.

Sequence Z-14 (Interfacing systems LOCA)

ERG ECA-1.2, LOCA OUTSIDE CONTAINMENT, provides procedural guidance for actions to identify and isolatc a LOCA outside containment. The major action categories in ECA-1.2 are: 
(1) Verify proper valve alignment.

(2) Identify and isolate break.

(3) Verify that the break is isolated.

If the operator succeeds in isolating the LOCA, control transfers to ERG E-I, LOSS OF REACTOR OR SECONDARY COOLANT; if the LOCA cannot be isolated, then control transfers to ECA-1.1, LOSS OF EMERGENCY COOLANT RECIRCULATION, since there will not be any inventory in the containment sump to provide recirculation capability. Diagnosing the interfacing LOCA, identifying the location, and isolating the break are difficult tasks, and the ERGs providc only minimal guidance.

Sequence Z-15 (Loss of DC bus 112, failure of AC bus 148, and failure of AFW)

ERG E-0, REACTOR TRIP OR SAFETY INJECTION, and ECA-0.0, LOSS OF ALL AC POWER, provide guidance on switching from normal to both emergency $A C$ and $D C$ buses given loss of main and auxiliary feedwatcr. The ERGs contain guidance in a number of places on the opcration of PORVs.

Sequence Z-16 (Loss of AC power and permanent loss of SWS)

No ERG guidance is availablc beyond handling the initial power failure and subsequent loss of $S W$ and $C C W$. As AC power is not restored before $4 \mathrm{~h}$, an RCP seal LOCA occurs and coolant continues to be Iost with no guidance that will prevent core damage. Recovery of $\mathrm{AC}$ power within $8 \mathrm{~h}$ results in containment success.

Scquence Z-17 (Loss of AC power, CCW failure, and power not restored in $8 \mathrm{~h}$ )

Guidelines for loss of power are contained in Section ECA-0.0 of the ERGs. However, the ERGs do not providc: guidance for the combination of conditions described in this sequence.

\section{A.3 ERG Coverage of "A" Strategies}

The "A" strategies were studied extensively by Brookhaven National Laboratory and Pacific Northwest Laboratory during FY 1989. The results of this study are documented in NUREG/CR-5474, Assessment of Candidate Accident Management Strategies. This section uses the stratcgy numbering system of NUREG/CR-5474 and evaluates the extent to which the Westinghouse ERGs cover the proposed strategies.

Strategy 2.1 (Reduce Containmeni Spray Flow Rate to Conscrve Water for Core Injection)

FRG ECA-1.1, LOSS OF EMERGENCY COOLANT RECIRCULATION, provides for terminating flow to containment sprays and throtting corc injection how to conserve refucling water storage tank (RWST) inventory, in situations in which the operators cannot estabiish recirculation flow. The same ERG also provides for the use of all available fan coolers to reduce the need for containnent spray.

Strategy 2.2 (Enable Early Delection, Isolation, or Otherwise Mitigatc the Effects of an Interfacing Systems LOCA)

The Section A.2 evaluation of Sequence Z-14 describes the ERG coverage of the interfacing systems LOCA.

Strategy 2.3.2 (Refill Refueling Water Storage Tank with Borated Watcr) 
Guidelines for loss of all AC power are contained in Section ECA-0.0 of the ERGs. The guidelines rely on the ability to reestablish AFW or, failing that, to depressurize and use feed and blecd. No guidance is given for the conditions in this accident sequence.

\section{Sequence Z-6 (Large-break LOCA and LPI fajlure)}

As is the case with other sequences in which the primary factor contributing to the probability of the sequence is human error, the ERGs provide steps to initiate the system required (i.e., the LPI system). The ERGs contain steps for dealing with a large-break LOCA (ERG E-1), and these would be effective once LPI were restored. The actual testing of MOVs and the proper lineup for the MOVs after testing should be contained in a normal operating procedure or a surveillance procedure.

Sequence Z-7 (Loss of AC power, failure of AFW, failure of feed and bleed, and power not recovered in $8 \mathrm{~h}$ )

Sequence Z-8 (Loss of AC power, temporary loss of CCW and SWS, power and systems restored between 1 and $4 \mathrm{~h}$, but not before core damage occurs)

Sequence Z-9 (Loss of AC power, permanent loss of SWS and CCW)

Guidelines for loss of power are contained in Section ECA-0.0 of the ERGs. However, the ERGs do not provide guidance for the combination of conditions described in these three sequences.

Sequence Z-10 (Loss of power, loss of CCW and SWS, power not restored in $8 \mathrm{~h}$ )

This sequence results in both core damage and a severe challenge to containment. The ERGs do not provide any help in dealing with the loss of all component cooling and service water systems. Likewise, the ERGs provide no guidance for dealing with maintaining containment integrity without sprays and cooling fans. Presumably plant AOPs provide guidance for response to loss of $\mathrm{AC}$ power, $\mathrm{CCW}$, and SWS.

Sequence Z-11 (Loss of AC power, temporary loss of CCW and SWS, power and systems restored between 4 and $8 \mathrm{~h}$, but not before core damage occnrs)

Sequence Z-12 (Loss of offsite power and partial failure of emergency AC power, permanent loss of SWS, and power not recovered in $8 \mathrm{~h}$ )

Sequence Z-13 (Loss of offsite power and partial failure of emergency $\mathrm{AC}$ power, loss of SWS, containment fans failed, and power not restorcd in $8 \mathrm{~h}$ )

Gujdelines for loss of power are contained in Section ECA-0.0 of the ERGs. However, the ERGs do not provide guidance for the combination of conditions described in these three sequences.

Sequence Z-14 (Interfacing systems LOCA)

ERG ECA-1.2, LOCA OUTSIDE CONTAINMENT, provides procedural guidance for actions to identify and isolate a LOCA outside containment. The major action categories in ECA-1.2 are: 
(1) Verify proper valve alignment.

(2) Identify and isolate break.

(3) Verify that the break is isolatcd.

If the operator succeeds in isolating the LOCA, control transfers to ERG E-1, LOSS OF REACTOR OR SECONDARY COOLANT; if the LOCA cannot bc isolated, then control transfers to ECA-1.1, LOSS OF EMERGENCY COOLANT RECIRCULATION, since there will not be any inventory in the containment sump to provide recirculation capability. Diagnosing the interfacing LOCA, identifying the location, and isolating the break are difficult tasks, and the ERGs provide only minimal guidance.

Sequence Z-15 (Loss of DC bus 112, failure of AC bus 148, and failure of AFW)

ERG E-0, REACTOR TRIP OR SAFETY INJECTION, and ECA-0.0, LOSS OF ALL AC POWER, provide guidance on switching from normal to both emergency $A C$ and DC buses given loss of main and auxiliary feedwatcr. The ERGs contain guidance in a number of places on the operation of PORVs.

Sequence Z-16 (Loss of AC power and permancnt loss of SWS)

No ERG guidance is available beyond handling the initjal power failure and subsequent loss of SW and CCW. As AC power is not restored before $4 \mathrm{~h}$, an RCP seal LOCA occurs and coolant continues to be lost with no guidance that will prcvent core damage. Recovery of $\mathrm{AC}$ power within $8 \mathrm{~h}$ results in containment success.

Sequence Z-17 (Loss of AC power, CCW failure, and power not restored in $8 \mathrm{~h}$ )

Guidelines for loss of power are contained in Section ECA-0.0 of the ERGs. However, the ERGs do not provide guidance for the combination of conditions describcd in this scquence.

\section{A.3 ERG Coverage of "A" Strategies}

The "A" strategies were studied extensively by Brookhaven National Laboratory and Pacific Northwest Laboratory during FY 1989. The results of this study are documented in NUREG/CR-5474, Assessment of Candidate Accident Management Strategies. This section uses the strategy numbering system of NUREG/CR-5474 and evaluates the extent to which the Westingbouse ERGs cover the proposed strategies.

Strategy 2.1 (Reduce Containment Spray Flow Rate to Conserve Water for Core Injection)

ERG ECA-1.1, LOSS OF EMERGENCY COOLANT RECIRCULATION, provides for terminating tlow to containment sprays and throttling core injection flow to conserve refucling water storage tank (RWST) inventory, in situations in which the operators cannot establish recirculation flow. The same ERG also provides for the use of all available fan coolers to reduce the need for containment spray.

Strategy 2.2 (Enable Early Detccion, Isolation, or Otherwise Mitigatc the Effects of an Interfacing Systems LOCA)

The Section A.2 evaluation of Sequence Z-14 describes the ERG coverage of the interfacing systems LOCA.

Strategy 2.3.2 (Refill Refueling Watcr Storage Tank with Boratcd Water) 
Step 2 of ERG ECA-1.1, LOSS OF EMERGENCY COOLANT RECIRCULATION, requires the operator to add makeup to the RWST to extend the time it can be used as a suction source. The ERG notes that details of makcup watcr sources will be plant-specific, but the reactor makeup water control system and the spent fuel pit cooling system would be rypical sources.

Strategy 2.4 (Ensure Appropriate Recirculation Switchover and Manual Intervention Upon Failure of Automatic Switchover)

ERG E-1, LOSS OF REACTOR OR SECONDARY COOLANT, and ES-1, TRANSFER TO HOT LEG RECIRCULATION, contain steps to establish and verify recirculation. ECA- 1.1, LOSS OF EMERGENCY COOLANT RECIRCULATION, contains steps for manual establishment of recirculation.

The ERG ECA-1.1 gives detailed guidance on response to a failure to establish recirculation flow. lt is cntered from:

1. ERG E-1, LOSS OF REACTOR OR SECONDARY COOLANT, Step 12, which requires verification of the capability to use cold leg recireulation flow. However, a note in Step 12 specifies that verification implies verifying the availability of the required equipment and not its proper alignment.

2. ES-1.3, TRANSFER TO COLD LEG RECIRCULATION, Step 3, which requires alignment of the safety injection system for recirculation.

3. ES-1.2, LOCA OUTSIDE CONTAINMENT, Step 3, requires transfer to EDA-1.1 if the LOCA outside containment cannot be isolated (in this case, "appropriate" recirculation switchover is not to switch over, since there is no inventory in the containment sump).

Stratcgy 2.5 (Ensure Adequate Plant Heat Removal Capability by Emergency Connection(s) of Existing or Alternate Water Sources)

ECA-1.1, Step 16, instructs the operator to try to add water to the RCS from an alternate source. The ERG notes that the possible alternate sources will be plant-specific and offers the reactor makeup water control system, delivered using the normal charging pumps and the centrifugal charging pumps (i.c., the safety-rclated charging pumps), as a typical alternate source.

There are steps in E-1 that have non-specific guidance to use non-safety related pumps and coolant sources. No specific guidance on the use of sources such as rivers, lakes, or reservoirs was found in the ERGs.

Stralegy 3.2.1 (Enable Emergency Bypass or Change of Protective Trips for Injection Pumps)

No ERG steps specilically implementing this strategy were found, but it is consistent wilh guidance to operate the RCPs in situations requiring them to protect the core, even though the normal support conditions for RCP operation are not met.

Strategy 3.3.2 (Use Non-Safety Related Charging Pumps for Core Injection)

ECA-1.1, Step 16, instructs the operator to try to add water to RCS from an alternate source. The ERG notes that the possible alternate sources will be plant-specific and offers the reactor makeup water control system, delivered using the 
normal charging pumps (which are non-safety-related) and the centrifugal charging pumps (i.e., the safery-retated charging pumps), as a typical alternate source. ERG E-? makes reference to switching to alicrnative means if charging pumps are not running. The operator is then directed 10 "plant specific information" for means of reestabtishing necessary charging low.

Strategy 3.4 (Use Alternate Seal Injection (e.g., Hydrotest Pump) When Reactor Coolanı Pump Seal Cooling is Lost)

No ERG guidance implementing this proposed strategy was found. The general approach laken in the ERGs to loss of RCP seal cooling is to trip the RCPs, secure the seal cooling system btock valves, attempt to cool dow' the RCS, and exercise extreme care when reestablishing seal cooling flow in order to prevent damage to the RCP by thermal stresses. Most causes of seal cooling failure (i.e., loss of $\mathrm{AC}$ power, loss of $\mathrm{CCW}$, and loss of $\mathrm{SW}$ ) would affect alternate sources of seal cooling also.

Suategy 3.5 (Use Condensate Pumps or Startup Feedwater Punpss for Stcam Generator Injection)

ERG FR-H.1, RESPONSE TO LOSS OF SECONDARY HEAT SINK, Step 2, instructs the operator to attempt 10 establish AFW flow to one sicam generator (SG). If that is unsuccessful, Steps 5 and 7 direct the operator to iry to establish SG feed llow using the MFW pumps (Step 5) or the condensate pumps (Step 7).

Strategy 4.1 (Conserve Battery Capability by Shedding Non-Essential Loads)

ERG ECA-0.0, LOSS OF ALL AC POWER. Step 14, directs the operator to conserve DC power by shedding nonessential DC loads as soon as practical.

Strttegy 4.2 (Use lortable Battery Chargers or Other Power Sources to Recharge Station Batterics) ECA-0.0, Step 14, also states "consideration should also be given to securing a portable diescl powered battery' charger to ensure DC power availability."

Strategy 4.3 (Enable Emergency Replenishment of the Pncumatic Supply for Safely Related Air Operated Components)

ERG ECA-0.1, LOSS OF ALL AC POWER RECOVERY WITHOUT SI REQUIRED, makes reference 10 determining the avalability of instrument air and loading an air compressor if necessary.

Sirategy 4.4 (Enable Emergency Bypass or Change of Protective Trips for Emergency Diesel Generators)

ECA-0.0, Step 7, directs the operator to dispatch personnel to locally restore AC power using plant-specific procedures. The ERG has no explicit recommendation to bypass or change DG protective trips.

Strategy 4.5 (Enable Emergency Crosstie of AC Power Between Two Units or to an Onsite Gas Turbine Generator)

No reference was found for this strategy in the ERGs.

Strategy 4.7 (Use Diesel-Driven Firewater Pump for ... Steam Generator Injection or Containment Sprays) 
Appendix A

ERG FR-H.1, RESPONSE TO LOSS OF SECONDARY HEAT SINK, directs the operator to try to re-establish feed flow to one SG using the AFW system, the MFW system, or the condensate system (in that order). No mention was found of the possibility of using the diesel-driven firewater pump for SG feed flow.

Strategy 5.1 (Reopen Main Steam Isolation Valves and Turbine Bypass Valves to Regain the Main Condenser as a Heat Sink)

ERG FR-H.1, RESPONSE TO LOSS OF SECONDARY HEAT SINK, Steps 5 and 7, and E-1, LOSS OF REACTOR OR SECONDARY COOLANT, mention attempts to establish SG coolant flow, using first the MFW system and then the Condensate system, but no specific reference is made to attempting to establish a flow loop by manually opening the main steam isolation valve(s) (MSIV) or turbine bypass valves (TBVs).

Strategy 6.1 (Provide Additional Supply of Borated Makeup Water for Long-Term Accident Control)

ERG FR-S.1, RESPONSE TO NUCLEAR POWER GENERATION/ATWS, Note on Step 13, direets the operator to continue boration to obtain adequate shutdown margin during subsequent actions. Furthermore, "boration should continue by other means, if possible." Other than this step, there is no apparent guidancc for securing additional or altcrnate sources of borated watcr. 

Appendix B

Westinghouse Ice Condenser Containment - Sequoyah 
Appendix B

\section{Appendix B}

\section{Westinghouse Ice Condenser Containment - Sequoyah}

Critical accident sequences for an ice condenser plant were determined using the information contained in a number of NUREG/CR reporis supporting the development of NUREG-1150. These reports document the probabilistic risk assessment performed on Sequoyah Unit 1. They include (with abbreviated titles):

NUREG/CR-4550, Vol. 5 - Core Damage Frequency from Internal Events.

NUREG/CR-4551, Vol. 2 - Severe Accident Risks and the Potential for Risk Reduction.

NUREG/CR-4700, Vol. 2 - Containment Event Analysis for Postulated Severc Accidents.

Additional information was inferred from the emergency procedures guidelines in the Westinghouse Owners Group Emergency Response Guidelines (High-Pressure Version), Revision 1, September 1, 1983. Sequoyah is one of the Westinghouse "high-pressure" plants; that is, it has a safety-related, fully qualified, charging system available to inject water in accidents where the RCS pressure stays near the relief valve setpoints.

\section{B.1 Critical Accident Sequences}

\section{B.1.1 Core Melt Risk}

Eight accident sequences account for approximately 93\% of the core melt risk calculated in the NUREG-1150 PRA for the Sequoyah plant, as reported in NUREG/CR-4550, Vol. 5:

S-1 $\quad \mathrm{S} 2 \mathrm{H}_{2}$ - A small-break LOCA, followed by failure of core injection in the recirculation phase. Electrical power and containment heat removal and spray are available. The major contributing cause of this accident is operator failure to switch over to recirculation flow. This sequence accounts for $34 \%$ of the core melt risk and leads to high pressure failure of the RPV.

S-2 $\mathrm{T}_{\mathrm{CCW}}$ - Failure of the CCW system, which leads eventually to a reactor coolant pump seal LOCA and failure of emergency injection and containment spray. Electrical power is available, but neither containment heat removal nor containment spray function are. The major contributing cause of this accident is common cause failure of the CCW pumps. This sequence accounts for $31 \%$ of the core mclt risk and leads to late, high pressure failure of the RPV and tate containment failure.

S-3 $\quad \mathrm{S}_{2} \mathrm{H}_{3}$ - A small-break LOCA, followed by failure of the low-pressure rccirculation system (i.c., failure of the lowhead pumps, which take water from the containment sump and deliver it to the suction header of the high-head recirculation pump, or failure of the associated valves). Electrical power and containment heat removal and spray are availablc. This sequence accounts for $11 \%$ of the core melt risk and lcads to high pressure failure of the RPV with successful functioning of containment systems. 
Appendix B

S-4 $\quad \mathrm{S}_{2} \mathrm{H}_{3} \mathrm{~F}$ - This is sequence S-3 followed by failure of containment spray. Electrical power is available, but neither containment heat removal nor containment spray are. The major cause of this sequence is common cause failure of low-pressure recirculation and containment spray (in recirculation mode). This sequence accounts for $9 \%$ of the core melt risk and leads to high pressure failure of the RPV and late failure of containment.

S-5 $\quad \mathrm{T}_{1} \mathrm{D}_{3} \mathrm{WD}_{1} \mathrm{~F}$ - This is a station blackout, causing an RCP seal LOCA (due to loss of seal couling and seal injection flow). Because of the loss of all AC power, core injection, containment heat removal, and containment spray are no1 availablc. The cause of this sequence is the initial loss of offsitc power transient, followed by inclependent or common cause failure of the emergency AC power system. This sequence accounts for $3.3 \%$ of the core melt risk and leads to a late, high pressure failure of the RPV and late containment failure.

S-6 $\quad \mathrm{S}_{1} \mathrm{H}_{2}$ - An intermediate-break LOCA, followed by loss of high-pressure recirculation flow. This lcads to an inability to inject water into the core during the recirculation phase, causing a corc melt. Unlike the previous five sequences, however, the RPV is expected to be at low pressure by the time core melt has progressed to the point of RPV breach for this sequenec. Electrical power, containment heat removal, and containment spray are dvailable. The major contributing cause is operator failure to switch over to recirculation fow. Thís sequence accounts for $1.9 \%$ of the core melt risk and leads to a low pressure failure of the RPV with successful functioning of containment systems.

S-7 T $\mathrm{T}_{\mathrm{DCI}} \mathrm{L}_{1} \mathrm{P}_{1}$ - Loss of DC bus $\mathrm{l}$, followed by independent failures in the AFW systcm (the loss of the DC bus causes failure of one of the PORVs). Loss of AFW requircs fecd \& hlecd cooling, which fails because only one PORV is available. Electrical power is available, except for the failed DC bus, as arc containment heat removal and containment spray. The major contributor to this sequence is the initiating loss of DC bus. This sequence accounts for $1.3 \%$ of the core melt risk and leads to an carty, high pressure failure of the RPV with successfuI functioning of the containment systems.

S-8 $T_{D C J S} L_{1} P_{1}$ - Loss of DC bus II. The rest of the description of this sequence is identical to that for seguenee $S-7$.

\section{B.1.2 Public Risk}

Sequences important from the public risk standpoint for Sequoyah include S-2, S-4, S-5, and the foilowing sequences:

S-9 Intermediatc- or large-break LOCA followed by failure of the ice condenser system. Containment will fail because of the failure of the ice condenser. Because of flashing in the sump, core injection may fail in the recirculation phase of the aceident. NUREG/CR-4550, Vol. 5 assigns a conditional probability $=0.13$ that corc recirculation fails given containment failure. NUREG/CR-455L, Vol. 2, reviewers assigned probahilities in the range from 0.03 to 0.4 to failure of core heat removal due to containment failure.

S-10 Event $V$ (interfacing system LOCA) followed by additional failures resulting in core damage. Bccause of the LOCA outside containment, containment is alseady breached at the timc of initiation of corc dantage.

S.11 SGTR followed by additional failures resulting in core damage. As with sequence S-10, conlainment is already breached at initiation of core damage. 


\section{B.1.3 Challenges to Safety Functions}

The safety functions denined in the Westinghouse ERGs (High-Pressure Version) are:

(1) Reactor subcriticality.

(2) Core cooling.

(3) RPV integrity.

(4) Primary system heat sink (i.e., the secondary system).

(5) Containment integrity.

(6) Primary system inventory.

All of the enumerated scquences, resulting in core damage and perhaps containment failure, involve challenges to one or more safety functions. Other sequences that challenge safety functions are:

\section{S-12 PTS cha!lenges RPV integrity.}

S-13 Excessive heat transfer from primary system to the secondary system due to shell-side depressurization challenges reactor subcriticality, RPV integrity, and eventually other safety funetions S-14 Loss of SG heat sink chalicnges the primary system inventory and core cooling safety functions.

S-15 Pressurizer flooding (i.e., solid primary coolant system) challenges primary system and RPV integrity.

S-16 ATWS challenges the reactor subcriticality, RPV integrity, and core cooling safety functions.

\section{B.1.4 Threats to Safety Systems}

Each of the 16 sequences dcveloped above poses a threat to one or more safety systems. The PRA sequences all involve the failure of one or more safety systems. In addition to the developed sequences, seismic events, fires, and internal nooding all threaten safety systems.

The most significant threat to safety systems is the station blackout, sequence $\mathrm{S}-5$, since it climinates all safety injection (except for the accumulators), the charging pumps, containment spray and heat removal, RCP seal injection and seal cooling, two trains of AFW, all pumps, and all MOVs.

Another significant accident sequence for Sequoyah is the loss of CCW sequence S-2, which causes the eventual loss of all safely injection, the charging pumps, the RCP seals, containment spray, and containment heat removal.

A final sequence posing a threat to safety systems is:

S-17 loss of the service water system, causing the loss of room cooling, loss of cooling for the AFW pump motors, and loss of sheli-side flow in the heat exchangers for the CCW and containment spray (in the rccirculation mode). 


\section{B.2 ERG Coverage of the Critical Accident Sequences}

Sequence S-1 (Small-break LOCA with loss of recirculation phase injection)

Emergency Response Guideline E-1 describes how to respond to a small- break LOCA, including possible repressurization of the RCS because the safety injection flow is excessive or the SG heat sink is lost. ERG ES-1.3 governs the Iransfer to recirculation core injection when the RWST tank has reached the switchover setpoint. ES-1.3 has six steps; Caution 1 for Step 1 notes that Steps 1 through 3 must be done as quickly as possible, because of the limited amount of walcr in the RWST below the switchover setpoint. ERG ECA- 1.1, LOSS OF EMERGENCY COOLANT RECIRCULATION, provides guidance in the event of loss of recirculation phase safety injection. It gives threc possible symptoms of loss of recirculation flow:

(i) Loss (failure to open) of both sump recirculation isolation valves.

$+$

(2) Loss (failure to start) of both fow-head SI pumps.

i

(3) Inadequate sump inventory due so LOCA outside containment or depletion of RWST without a corrcsponding increase in sump level.

There is no clear indication how the operator will find his/her way to ECA-1.1 if the loss of emergency recirculation is due to operator failure to swich over when required. ECA-1.1 has five major action caicgorics:

(1) Continue attempts to restore emergency coolant recirculation.

?

(2) Increasc/conserve RWST level.

(3) Try to add makeup to RCS from an alternate source.

(4) Depressurize SGs to cool down and depressurize RCS,

(5) Maintain RCS heat removal.

Recommendations supporting Action 2 include eliminating unnecessary containment spray and throttling safety injection flow. The only atternate source suggested is the normal plant water control system with injection via the charging pumps. The 24 steps of ECA-1.1 provide relatively detailed guidance for the operator facing loss of recirculation injec1іол flow.

Sequence S-2 (Loss of component cooling water)

Although the Reference Plant Description recognizes the importance of the $\mathrm{CCW}$ system, there is no dircct guidance in the ERGs for response to Loss of CCW. Presumably, each plant has Abnormal Operating Procedures (AOPs) instructing the operator on response to a loss of CCW. The functional ERGs FR-C. 1, RESPONSE TO INADEQUATE CORE COOLING, and FR-C.2, RESPONSE TO DEGRADED CORE COOLING, provide three major actions:

(1) Reiniliation of high-pressure safcty injection (which will not work in this case).

(2) Rapid secondary depressurization (which might help temporarily).

i 
(3) RCP restart and/or opening pressurizer PORVs (which also might help temporarily).

Sequence S-3 (Small-break LOCA with loss of low-head recirculation trains)

The evaluation given for ERG coverage of sequence S-1 applies here also.

Sequence S-4 (Sequence S-3 with loss of containment spray)

The evaluation given for ERG coverage of sequence S-1 applies here with the added note that Step 4 of ECA-1.1 requires the operator to start both the normal and emergency fan coolers, which will provide some containment heat removal and steam condensation.

Sequence S-5 (Station blackout)

The ERGs ECA-0.0, ECA-0.1, and ECA-0.2 address loss of all AC power, both when safety injection is required and when it is not. Westinghouse states that these guidelines specifically address the generic aspects of Items a, e, $\mathrm{f}$, and $\mathrm{g}$ of NRC Generic Letter 81-04, "Emergency Procedures and Training for Station Blackout". The three guidelines run to about 250 pages.

ECA-0.0 has five major action categories:

(1) Perform immediate actions; i.e., checking RCS isolation, verifying secondary heat sink.

(2) Restore AC power.

(

(3) Maintain plant conditions for optimal secovery.

(4) Evaluate the encrgized AC emergency bus (after recovery of emergency $A C$ ).

(

(5) Select appropriate recovery guideline after restoration of $\mathrm{AC}$ power.

The guidelines note 10 to 15 key operations involving proposed local (i.e., outside the control room) operator actions that utilities must evaluate based on plant-specific constraints such as availability and accessibility of equipment, personnel available for in-plant operations, communications capabilities, and personnel safety.

Siep 5 of ECA- 0.0 instructs the operators to take actions to restore emergency AC power from the control room. Step 7 requires tocal operator actions to restore emergency AC power. The ERGs provide no guidance when evaluation of the loss of offsite power and the loss of emergency AC suggests that none of these actions are likely to be successful in a timely manner. If the station blackout proceeds to core damage, it continues to be imperative to restore $\mathrm{AC}$ power. Most plausible mitigative actions during the in-vessel phase of a core melt require AC power.

Sequence S-6 (Intermediate-break LOCA with failure of high-head recirculation)

The evaluation of ERG coverage given for sequence $S-1$ applies here.

Sequences S-7 and S.8 (Loss of vital DC bus) 
Appendix B

The ERGs provide no direct guidance for this sequence. Presumably, the plant AOPs provide guidance for the loss of vital support systems.

Sequence S-9 (Intermediatc-break, or larger, LOCA with failure of the ice condenser)

This sequence chaltenges containment integrity because the (clean) steam and water (and no hydrogen) from the break may overpressurize the containment. The functional ERG FR-Z.1, RESPONSE TO HIGH CONTAINMENT

PRESSURE, specifies the following major action categories:

(1) Verify containment isolation and heat removal.

(2) Check for and isolate faulted steam generator.

(3) Check for excessive containment hydrogen and detcrmine appropriatc action.

Action 3 is not relcvant to this sequence (at least, not until cladding damage occurs). Actions 1 and 2 may mitigate this sequence, depending on the size and location of the break and the extent of the icc condenser failure.

Sequence S-10 (Event $V$ with additional failures leading to core damagc)

ERG ECA-1.2, IOOCA OUTSIDE CONTAINMENT, provides procedural guidance for actions to identify and isolate a LOCA outside containment. The major action categories in ECA-1.2 are:

(1) Verify proper valve alignment.

(2) Identify and isolate break.

(3) Vcrify that the break is isolated.

If the operator succeeds in isolating the LOCA, control transfers to ERG E-1, LOSS OF REACTOR OR SECONDARY COOLANT; if the LOCA cannot be isolated, then control transfers to ECA-1.1, LOSS OF EMERGENCY COOLANT RECIRCULATION, since there will not be any inventory in the containment sump to provide recirculation capability. Diagnosing the interfacing LOCA, identifying the location, and isolating the break are difficult tasks, and the ERGs provide only minimal guidance.

Sequence S-11 (SGTR with additional failures leading to core damage)

Guidance for responding to an SGTR is provided by ERGs E-3, STEAM GENERATOR TUBE RUPTURE; ES-3.1, POST-SGTR COOLDOWN USING BACKFILL; ES-3.2, POST-SGTR COOLDOWN USING BLOWDOWN, ES-3.3, POST-SGTR COOLDOWN USING STEAM DUMP; ECA-3.1, SGTR WITH LOSS OF REACTOR COOLANT - SUBCOOLED RECOVERY DESIRED; ECA-3.2, SGTR WITH LOSS OF REACTOR COOLANT SATURATED RECOVERY DESIRED; and ECA-3.3, SGTR WITHOUT PRESSURIZER PRESSURE CONTROL. The guidance is extensive; the seven ERGs run to approximately 750 pages.

The major action categories in ERG E-3 are:

(1) Identify and isolate ruplured $S G(5)$.

(2) Cool down to cstablish RCS subcooling margin.

(3) Depressurize RCS to restore inventory.

(4) Terminate safety injection to stop primary-to-secondary leakage. 
(5) Prepare for cooldown to a cold shutdown condition.

Although they provide adequate guidance for terminating the SGTR with the plant in a safe condition, these ERGs, as all the others, are success- oriented and do not say much about mitigation of accident sequences in which additional failures have led to the initiation of core damage.

Sequence S-12 (PTS challenging RPV integrity)

The functional ERGs FR-P.1, RESPONSE TO IMMINENT PRESSURIZED THERMAL SHOCK CONDITION, and FR-P.2, RESPONSE TO ANTICIPATED PRESSURIZED THERMAL SHOCK CONDITION, provide guidance for the management of overcooling conditions and over-pressurization at low temperatures.

Sequence S-13 (Excessive heat removal from the primary system)

The functional ERGs FR-P.1, RESPONSE TO IMMINENT PRESSURIZED THERMAL SHOCK CONDITION, and FR-P.2, RESPONSE TO ANTICIPATED PRESSURIZED THERMAL SHOCK CONDITION, provide gujdance for the management of overcooling conditions and over-pressurization at low temperatures.

Sequence S-14 (Loss of secondary heat sink)

The functional ERGs, FR-H.1, RESPONSE TO LOSS OF SECONDARY HEAT SINK; FR-H.2, RESPONSE TO STEAM GENERATOR OVERPRESSURE; FR-H.3, RESPONSE TO STEAM GENERATOR HIGH LEVEL; FR-H.4, RESPONSE TO LOSS OF NORMAL STEAM RELEASE CAPABILITIES; FR-H.5, RESPONSE TO STEAM GENERATOR LOW LEVEL, provide responses to a variety of events threatening immediate or incipient loss of secondary heat sink.

Sequence S-15 (Pressurizer flooding)

The functional ERG FR-I.1, RESPONSE TO HIGH PRESSURIZER LEVEL, provides guidance for the event of pressurizer level increasing and incipient solid primary systen.

Sequence S-16 (ATWS)

The functional ERGs FR-S.1, RESPONSE TO NUCLEAR POWER GENERATION/ATWS, and FR-S.2, RESPONSE TO LOSS OF CORE SHUTDOWN, guide the operator in responding to ATWS conditions.

Sequence S-17 (Loss of service water)

The ERGs provide no guidance on operator response to loss of service water.

\section{B.3 ERG Coverage of the "A" Strategies}

Since the same Westinghousc Emergency Response Guides (High Pressure vcrsion) apply to Sequoyah as Zion, information about ERG coverage of the "A" Strategies can be found in Section A.3. 

Appendix C

Combustion Engineering Large, Dry Containment - Calvert Cliffs 1 


\section{Appendix C}

\section{Combustion Engineering Large, Dry Containment - Calvert Cliffs 1}

Critical accident scquences for a Combustion Engineering (CE) large, dry containment plant, were determined mainly from the information contained in NUREG/CR-3511, Interim Reliability Evaluation Program: Analysis of the Calvert Cliffs Unit 1 Nuclear Power Plant, Volume 1. Main Report. The degree of coverage of these eritical sequences and of the "A" strategies by the CE EPGs was determined by reviewing CEN-152, Combustion Engineering Emergency Procedures Guidelines, Rcv. 3.

\section{C.1 Critical Accident Sequences}

\section{C.1.1 Core Melt Risk}

NUREG/CR-3511 cites the following accident sequences as dominating the Calvert Cliffs-1 (CC-1) core melt frequency. Many of these sequences are impacted by the low shutoff head of the CC-1 HPI pumps (1275 psia), which causes feed and bleed cooling to fail in many high-pressure accident situations.

C-1 ATWS(PSF) - An ATWS occurs that leads to primary system failure. This sequence is considered likely to lead to containment failure from overpressure and/or hydrogen burn. This sequence contributes $20 \%$ of the core melt frequency and leads to early RPV failure and early containment failure.

C-2 $\mathrm{T}_{\mathrm{DC}}$ - Failure of DC bus 11 causes a trip of the plant, failure of the power conversion system, failure of AFW pump 13, and degradation of the safety systems. The plant scrams successfully, but AFW fails subsequently Jue to additional independent failures. With no secondary heat sink, core inventory boits off through the PORVs. Containment fails due to overpressure or a hydrogen burn. This sequence contributes $16 \%$ of the core melt frequency and leads to carly, high pressure failure of the RPV and early containment failure.

C-3 $\quad \mathrm{S}_{2} \mathrm{H}$ - Small-small-break LOCA followcd by successful scram, AFW operation, and HPSI operation. When the refueling water tank depletes and switchover occurs, high-pressure safety recirculation fails leading to core uncovery and core mek. Containment systems succeed and cool containment early on, but containment fails due to overpressure or hydrogen burn. This sequence contributes $11 \%$ of the total CMF and leads to early, high pressure RPV failure and early containment failure.

C-4 $\quad \mathrm{S}_{2} \mathrm{FH}$ - Same as sequence $\mathrm{C}-3$ with the additional failure of the containment sprays in the recirculation mode. The core melts duc to lack of recirculation phase makeup; the containment fan coolers provide some containment cooling, but containment fails due to hydrogen burn and/or overpressure. This sequence contributes $9 \%$ of totat core melt risk and leads to early, high pressure RPV failure and early containment failure.

C-5 $\mathrm{T}_{2} \mathrm{~L}$ - Loss of the power conversion system (PCS) causes a plant trip, which is followed by an independent loss of $\mathrm{AFW}$. The reactor scrams successfully and containment systcms work, but feed \& bleed cooling fails due to 
Appendix C

the low head of the HPI pumps. RCS inventory boils off through the PORVs and the core melts. Containment fails due to hydrogen burn and/or overpressure. This sequence contributes $6 \%$ of the CMF and leads to an early, high pressure failure of the RPV and early failure of containment.

C-6 $\mathrm{T}_{4} \mathrm{KU} / \mathrm{T}_{4} \mathrm{KQ} / \mathrm{T}_{3} \mathrm{KU} / \mathrm{T}_{3} \mathrm{KQ}$ - These sequences involve a transient with failure to scram followed by either failure of boration or a stuck-open PORV. The core melts, because power continues to be generated or because pressure stays too high for successful HPSI makeup to the RCS. Containment fails by hydrogen burn and/or overpressure. These sequences contribute $13 \%$ of the total CMF and leads to early, high pressure failure of the RPV and early failure of containment.

C-7 $\mathrm{T}_{4} \mathrm{ML}$ - A transient is followed by loss of the PCS and AFW systems. The reactor scrams and containment systems function. Because of the loss of secondary heat sink, the RCS boils off through the PORVs and core melt ensues. Containment fails eventually duc to hydrogen burn or overpressurc. This sequence contributes 5\% of the CMF and leads to early, high pressure failure of the RPV and early or cventual failure of containment.

C-8 $\mathrm{T}_{1} \mathrm{QD}^{n} \mathrm{CC}^{\prime}$ - Loss of offsite power followed by a transient-induced LOCA; AFW works but HPSI and the containment systems fail. The core melts due to lack of RCS makeup; containment is expected to fail due to overpressurc. This sequence contributes $4 \%$ of the total CMF and leads to early, high pressure failure of the RPV and carly containment failure.

C-9 $T_{1} L$ - Loss of offsite power followed by failure of AFW. Because of the loss of secondary heat sink the RCS boils off through the PORVs. Containment fails duc to overpressure and/or hydrogen burn. This sequence accounts for $4 \%$ of the CMF and leads to early, high pressure failure of the RPV and cventual faiture of containment.

C-10 SBO - Station blackout followed by successful operation of the turbine driven AFW pump(s) until battery depletion some $4 \mathrm{~h}$ into the accident. RCS boiloff causes core melt; because of the station blackout no containment systems are available. Containment fails from overpressure. This sequence accounts for $3 \%$ of the CMF and leads to late, high pressure failure of the RPV and tate failure of containment.

C.11 $T_{3}$ ML - A transient requiring pressure relief is followed by loss of the PCS and AFW. The reactor scrams and containment systems succeed. Loss of secondary heat sink causes boiloff of the RCS through the PORVs. Containment fails due to hydrogen burn and/or overpressurc. This sequence contributes $1 \%$ of the CMF and leads to early, high pressure failurc of the RPV and eventual failure of containment.

C.12 $\mathrm{S}_{2} \mathrm{D}^{\prime \prime}$ - A small-small-break LOCA followed by loss of HPSI and cventual core melt duc to no RCS makeup during the injection phase of the accident. Containment systems succeed but containment eventually fails due to overpressure and/or hydrogen burn. This sequence accounts for $1 \%$ of the CMF and leads to high pressure failure of the RPV and eventual failure of containment.

C.13 T, TCC - A loss of offsite power followed by failure of AFW and the containment systems. The RCS inven16ry boils off through the PORVs due to loss of the secondary heat sink. Containment fails duc to overpressurc. This sequence accounts for $1 \%$ of the CMF and leads to early, high pressure failure of the RPV and eventual failure of containment. 


\section{C.1.2 Public Risk}

Using data from Table 8.3 of the CC.1 PRA, NUREG/CR-3511, Vol. 1, the most significant contributors to public risk are those sequences dominating the probability of early containment failures leading to large releases.

NUREG/CR-3511 indicates that the probability of containment failure due to stcam explosion is dominated by two sequences:

C-3, S2H, Small-small-break LOCA with loss of recirculation injection.

C-4, S2HF, Sequence C-3 with additional failure of containment spray.

The probability of early failures due to overpressure or hydrogen burn is dominated by five sequences:

C.-1, ATWS(PCS), ATWS with immediate RPV failure.

C-2, TDCL, Loss of DC bus 11 followed by loss of AFW.

C-3, S2H, Small-small-break LOCA with loss of recirculation injection.

C-4, S2HF, Sequence C-3 with additional failure of containment spray.

C-6, misccllaneous ATWS sequences without early RPV failure.

In addition to the sequences noted above, the following two sequences arc considered significant to public risk:

C-14 Event V (interfacing system LOCA) followed by additional failures resulting in core damage.

C-15 SGTR followed by additional failures resulting in core damage.

\section{C.1.3 Challenges to SaPety Functions}

In the Combustion Engineering Owners Group EPGs, CEN-152, there are ten safety functions identified as necessary to mitigate events and contain radioactivity. These safety functions are divided into four classes as follows:

(1) Anti-Core Melt Safety Functions.

(a) Reactivity control.

(b) RCS inventory control.

(c) RCS pressure control.

(d) Core Heat Removal.

(c) RCS Heat Removal. 
Appendix C

(2) Containment Integrity Safety Functions.

(a) Containment isolation.

(b) Containment temperature and pressure control.

(c) Combustible gas control.

(3) Indirect Radioactivity Releasc Control.

(4) Maintenance of Vital Auxiliaries.

The proviously cnumerated sequences, all of which result in corc damage and perhaps containment failure, involve chaltenges to one or morc safety functions. Other sequences that challenge safety functions are:

C-16 PTS challenges RPV integrity.

C-17 Excessive heat transfer from primary system to the sccondary system due to SG sheil side depressurization challenges reactor subcriticality, RPV integrity, and eventually other safely functions.

C-18 Pressurizer flooding (i.e., solid primary coolant system) challenges primary system and RPV integrity.

\section{C.1.4 Threats to Safety Systems}

The most significant threat to safcty systems is the station blackout, sequence $\mathrm{C}$-10. It eliminates all safety injection (except for the accumulators), the charging pumps, containment spray and heat renoval, RCP seal injection and seal cooling, two trains of AFW, all pumps, and all motor- operated valves.

Also significant for Calvert Cliffs is the loss of DC bus 11, sequence C-2, causing a plant trip, failure of the PCS and the AFW motor-Uriven pump 13, with degradation of the safety systems. Failure of DC bus 21 has similar, although not quitc as scrious, consequences.

Additional scquences threatening safety systems are:

C-19 Failure of service water system train 12 causes loss of main feedwater pump lube oil cooling and condensate booster pump lube oil cooling, resulting in a plant trip. Safety systems affected by train 12 failure are the conlainment air coolers 13 and 14 and DG 12.

C-20 The salt water system provides secondary (shell-sidc) cooling of the CCW system and the service water system and cooling for the ECCS pump room coolers.

Finally, scismic cvents, fires, and internal looding all threaten safety systems.

\section{C.2 CEN-152 Coverage of the Critical Accident Sequences}

The critical accident sequences identificd in the preceding section were evaluated to determine if they were adequately covered by the CEN-152 guidelines. CEN-152 contains Optimal Recovery Guidelincs (ORGs) and Functional 
Recovery Guidelines (FRGs). The ORGs are event-based and require operator diagnosis of the event; the FRGs are symptom-based and are entered if operators oar unable to diagnose the event or if the appropriate ORG does not successfully manage the event.

This review verified that the generic procedural steps of CEN-152 act to mitigate many of the dominant severe accidents sequences for Calvert Cliffs-1. However, the Introduction to CEN-152 notes: "... guidance for the management of degraded core conditions is not included. There is insufficient analytical base for this guidance."

Maintenance of vital auxiliaries is listcd as the last class of safety functions; however, loss of offsite power was fourth out of seven items in the dominant sequence list. Also the loss of DC bus 11 (special transient initiator) was third on the list. This could be construed to imply that not enough attention is placed on maintenance of vital auxiliaries in CEN-152. In actual practice, maintenance of vital auxiliaries is considered immediately after reactivity control and then concurrently with each safety function.

Specific information regarding the coverage of the numbered sequences: (alt page and section references are from CEN-152, Rev. 3, unless otherwise indicated)

Sequence C-1 (ATWS causing primary system failure)

Sequence C-6 (Other ATWS sequences)

The CEN-152 Functional Recovery Guideline (FRG) on REACTIVITY CONTROL (pp. 10-50 to 10-75) directs the opcrator to take the reactor subcritical by attempting (in the order given):

(1) Manual insertion of the control rods.

(2) Boration of the RCS using the chemical volume and control system.

(3) Boration using the safcty injection system.

(4) Control clement assembly drive down (manually energize control using normai control rod insertion mechanisms).

assemblics and drive them in to the core

The FRG stresses the importance of continuing to attempt to establish subcriticality.

Sequence C-2 (Loss of DC bus 11 with loss of secondary heat sink)

Sequence C.5 (Loss of secondary heat sink)

Sequence C.7 (Loss of secondary heat sink)

Sequence C-9 (Loss of offsite power followed by loss of secondary heat sink)

Sequence C-11 (Transient requiring pressure telief followed by loss of secondary heat sink)

Sequence C-13 (C-9 with additional loss of containment systems) 
Appendix C

The EPG on LOSS OF FEEDWATER RECOVERY (pp. 8-1 to 8-20) provides instructions for re-cstabiishment of fcedwater flow and appears through the associated safety function status check to be able to lead the operator into setting up feed and bleed cooling, when necessary.

Sequence C-3 (Small-break LOCA with recirculation failure)

Sequence C-4 (C-3 with additional containment spray failure)

Sequence C-12 (Smali-break LOCA with loss of HPSI)

The EPG on LOCA RECOVERY (Pp. 5-1 to 5.30), Step 46, directs the operator to verify automatic switchover to recirculation flow and to manually initiate recirculation if automatic switchover fails. It provides no guidance in the event both automatic switchover and manual initiation fail. The FRG on containment temperature and pressure control contains instructions for the use of the containment fan coolers in cither normal or emergency mode, but no specific instructions on what to do if containment spray fails.

Sequence C-8 (Loss of offsite power with induced LOCA, followed by HPI and containment systems failures)

CEN-152 provides no generic guidance on the maintenance of vital auxiliaries, indicating instead that plant-specific guidance is needed. The EPG on recovery of a LOCA and the FRGs are intended to help the operator diagnose and respond to the inadequate core cooling that results from the failure of the HPI system.

Sequence C.10. (Station blackout)

CEN-152 provides no explicit guidance for station blackout situations, rather indicating that restoration of vital AC and DC power require plant- specific actions and criteria. CEN-152 guidelines for LOSS OF FEEDWATER RECOVERY (Ch. 8) and LOSS OF FORCED CIRCULATION RECOVERY (Ch. 9) both assume availability of electrica! power.

Sequence C-14 (lnterfacing system LOCA)

The break identification chart (p. 5-23) provides the logic for identifying a LOCA oulsidc containment; procedural control stays with the EPG on recovery of a LOCA (Section 5 of CEN-152). Most of the subsequent steps assume a hreak in containment; in particular, Step 46, which initiates the switch over to recirculation flow, does not caution against initiating recirculation flow when the LOCA is outside containment.

Sequence C-15 (SGTR)

The EPG on recovery of a SGTR (Section 6 of CEN-152) provides specific guidance for this event.

Sequence C-16 (PTS)

Section 1.7.1 of CEN-152 provides guidance on PTS. 
Sequence C-17 (Excessive primary-to-secondary heat transfer)

The EPG on recovery of an excess stearn demand event (Section 7 of CEN-152) provides guidance for these overcooling or steamline break events.

Sequence C-18 (Pressurizer flooding)

Most of the ORGs and the FRGs contain specific guidance on the maintenance of appropriate pressurizer level.

Sequence C-19 (Failure of service water system train 12) Sequence C-20 (Failure of the sait watcr system)

CEN-152 contains no guidance on maintenance of vital auxiliaries, indicating that such guidance should be plantspecific.

\section{C.3 CEN-152 Coverage of the "A" Strategies}

Strategy 2.1 (Reduce Containment Spray Flow Rate to Conserve Water for Core Injection)

Specific guidance provided only to reduce or terminate flow upon pressure drop in containment.

Strategy 2.2 Enable Early Detection, Isolation, or Otherwise Mitigate the Effects of an Interfacing Systems LOCA)

More guidance is needed in the EPG to make the strategy successful. As noted in the Section C.4.2 summary of EPG coverage of Sequence C-14, the break identification chart provides togic for identifying and Interfacing Systems LOCA, but the EPG on LOCA RECOVERY (Ch. 5) assumes the break is in containment.

Strategy 2.3.2 (Refill Refueling Water Storage Tank with Borated Water)

Not covered in the EPGs.

Strategy 2.4 (Ensure Appropriate Recirculation Switchover and Manual Intervention Upon Failure of Automatic Switchover)

EPG guidance is adequate. The LOCA RECOVERY ORG (Ch. 5), Step 46, has the operator:

(1) continuously monitoring RWT level,

(2) verifying initiation of recirculation if the level falls to $10 \%$, and

(3) manually initiating recirculation, if necessary. 
Appendix C

Strategy 2.5 (Ensure Adequate Plant Heat Removal Capability by Emergency Connection(s) of Existing or Alternate Water Sources)

The EPGs do not provide adequate guidance.

Strategy 3.2.1 (Enable Emergency Bypass or Change of Protective Trips for Injection Pumps)

The EPGs do not provide adequate guidance.

Strategy 3.3.2 (Use Non-Safety Related Charging Pumps for Core Injection)

EPG guidance is adequate.

Strategy 3.4 (Use Alternate Seal Injection (e.g., Hydrotest Pump) When Reactor Coolant Pump Seat Cooling is Lost)

The EPGs do not provide any guidance

Strategy 3.5 (Use Condensate Pumps or Startup Feedwater Pumps for Steam Generator Injection)

No guidance is provide for recovery of feedwater using Condensate pumps or Startup Feedwater Pumps.

Strategy 4.1 (Conserve Battery Capability by Shedding Non-Essential Loads)

Strategy 4.2 (Use Portable Battery Chargers or Other Power Sources to Recharge Station Batteries)

Strategy 4.3 (Enablc Emergency Replenishment of the Pncumatic Supply for Safety Related Air Operated Components)

Strategy 4.4 (Enable Emergency Bypass or Change of Protective Trips for Emergency Dicsel Generators)

Strategy 4.5 (Enable Emergency Crosstic of AC Power Between Two Units or to an Onsitc Gas Turbine Generator)

CEN-152 provides no guidance for these five strategies, but rather indicates that plant-specific actions and criteria are required.

Strategy 4.7 (Use Diesel-Driven Firewater Pump for ... Steam Generator Injection or Containment Sprays)

The EPGs do not provide any guidance.

NUREG/CR-5856

C.8 
Appendix C

Strategy 5.1 (Reopen Main Steam Isolation Valves and Turbine Bypass Valves to Regain the Main Condenser as a Heat Sink)

Guidance is provided in the CEN-152 LOF guideline, but not in as much depth as in the Combustion Engineering Advanced Technology Manual.

Strategy 6.1 (Provide Additional Supply of Borated Makeup Water for Long-Term Accident Control)

The EPGs do not provide any guidance. 

Appendix D

Babcock \& Wilcox Large, Dry Containment - Oconee 3 


\section{Appendix D}

\section{Babcock \& Wilcox Large, Dry Containment - Oconee 3}

Critical accident sequences for the Babcock \& Wilcox (B \& W) large, dry containment plant were determined using the information contained in the Oconec PRA (NSAC-60), which documents the probabilistic risk assessment performed on Oconec Unit 3. Additional information was inferred from the Abnormal Transient Operating Guidelines (ATOGs) and the Emergency Operating Procedures Technical Bases Document.

Oconee Unit 3 has two unique, plant-specific features that directly impact the determination of critical sequences. One fcature is the standby shutdown facility (SSF), which is a separate, bunkered installation that provides a secure means for attaining and maintaining hot shutdown conditions for all threc Oconee units. The SSF was primarily designed to provide core cooling for incidents of industrial sabotage, fires, and flooding but can also be used to providc an alternative means of cooling after other types of events. The SSF can provide a backir supply of fecdwater to the steam generators for secondary-side heat removal and can inject and maintain sufficient inventory in the reactor coolant systcm (RCS) to sustain natural circulation and cool the reactor coolant pump (RCP) seals. The SSF also has its own electrical power system, with a dedicated diesel generator. This facility provides an additional level of backup 10 numcrous safety functions, not found at mosi plants, and thus affects the probability of a core melt event occurring for many sequences.

The other unique feature is the emergency power sources for Oconee: the Kcowec Hydroelectric Station and the Lee Stcan Station combustion turbines. Power from Kcowee is provided by an overhead path, which connects onc of the two Keowee units to the Keowee main stepup transformer, which in turn is connected to the 230-kV switchyard to provide power through the Oconce Unit 3 startup transformers (CT3). If the overhead path is unavailable, either Keowec unit can be connected to a 13.8-kV underground path that provides power to Oconce transformer CT4. These sources of emergency electrical power were determined in the Oconce PRA to be more reliable than a diesel generator set. However, should both Keowee units be unavailable for emergency power generation, either of two Lec Stcam Station combustion turbines can provide power to Oconce transformer CT5 via a $100-\mathrm{kV}$ overhead path. This level of redundancy and diversity in the emergency clcctrical power system is uncommon and results in a highly reliable emergency power source. Thercfore, the impacts of a loss of offsite power (and the probability of a station blackout) arc grcally diminished in the Oconee PRA.

\section{D.1 Critical Accident Sequences}

\section{D.I.I Core Melt Risk}

Ten accident sequence groups account for approximately $89 \%$ of the corc melt risk calculated in the Oconee PRA:

O-1 $\mathrm{T}_{12} \mathrm{BU}$ - The normally operating low-pressure service water (LPSW) system fails to provide cooling to the HPI pumps, which provide RCP seal injection, and to the CCW system, which provides RCP seal cooling. The RCP seal injection/cooling recovery actions that fail include:

(1) Using the LPSW sysicm, by cross-connecting it with either the high-pressure service water (HPSW) systent or the L.PSW system of another Oconee unit. 
(2) Opening the locat HPI pump LPSW discharge piping and cycling the HPI pumps to prevent pump overheating.

(3) Initiating the SSF, which can provide RCP seal injection, in time (within 30 minules of HPI failure as at resuit of HPI pump motor eooling failure) to prevent RCP seal lcakage.

Thus, the operations staff fails to reestablish a source of cooling prior to the initiation of RCP seal leakage, without the ability to make up the loss of inventory since the HPI systcm relies upon LPSW cooling. This sequence accounts for $28 \%$ of the core melt risk from intcrnal initiators.

O-2 $\mathrm{AX}_{\mathrm{A}}$ - A large-break LOCA is followed by success of the LPI system and the core flood tanks, but the operations staff either fails to implement low-pressure recirculation from the cmergency sump within 30 minutes or fails to throttle the high flow conditions that may develop during recirculation, thus causing the LPI pumps to cavitate. These sequences account for $15 \%$ of the core melt risk from internal initiators.

O-3 TWS - In these sequences the turbinc trips, but (because an insufficient number of control rods drop into the core to render the reactor subcritical) the reactor fails to shutdown. At this point one of two sequences can occur that result in core melt:

(1) The main fcedwater system fails to continue supplying the steam generators and either borated water is not injected to render the reactor subcritical in time to initiate a stable cooled state or a long-term stable cooling mode is not maintained.

(2) The reactor core is within a certain regime, with respect to core life and its effect on moderator temperature coefficien1 (cocfficient less than 95\%), such that a pressurc transicnt large enough to cause a RCS LOCA occurs and cither the injection systems fail to provide inventory makeup or the long-term stable cooling mode is not maintained.

These sequences account for $11 \%$ of the core melt risk from internal initiating events.

O-4 $\mathrm{SY}_{\mathrm{S}} \mathrm{X}_{\mathrm{S}}$ - A smatl-break LOCA is followed by successful HPI. The small-break LOCA also causes the initiation of the reactor building sprays, whose operation is not terminated after they are automatically actuated and the reactor buitding pressurc is reduced. Eventually (in $2 \mathrm{~h}$ ) the reactor building sprays deplete the borated water storage tank (BWST) injection-water inventory. High-pressure recirculation from the emergency sump fails duc primarily to operations staff error. This sequence accounts for $9 \%$ of the core melt risk from internal initiators.

O-5 $\mathrm{T}_{10} \mathrm{BU}$ - A large feedwater or condensate line break results in a loss of main and emergency feedwater because the main and emergency feedwater share water sources. The operations staff then fails to implement HPJ cooling (i.c., feed and bleed) and entergency feedwater from the SSF is not initiated within 30 minutes. This sequence accounts for $9 \%$ of the core melt risk from internal initiators.

0-6 $\mathrm{T}_{6} \mathrm{BU}$ - A loss of instrument air occurs (as the initiating event, as a result of a loss of offsite power, or as a result of system faults after a reactor/(urbine trip). Main feedwater and the emergency feciwater system motor-driven pumps are not available because the instrument air is lost. The emergency feedwater system steam-driven jump, which can operate using remote manual actions, fails to continue opcration after deplction of the upper surge tank (i.e., another suction source is not provided by the operations stafi). The fecdwater systems are not recovered and neither HPI coofing nor emergency feedwater from the SSF is iniliated. This sequence accounts for grt: of the core melt risk from internal initiating events. 
0-7 $\mathrm{RU}_{\mathrm{R}}$ - A steam generator tubc rupture (SGTR) is followed by an HPI failure to maintain RCS inventory. The HPI failure is the result of operations staff crror or hardware faults associated with the HPl suction valves, the BWST itself, or the single BWST suction valve (LP-28). This sequence accounts for $2 \%$ of the core melt risk from internal initiators.

O-8 $\quad \mathrm{T}_{2} \mathrm{BU}$ - A loss of main feedwater occurs and the cmergency feedwater system fails as a result of operations staff errors or hardwarc failures (dominated by insufficient level in the upper surge tank for suction requirements). The operations staff then fails to initiate feed and biecd cooling or recover a source of feedwater by restoring main feedwater or providing a suction source from the other two Oconce units. This sequence accounts for $2 \%$ of the core melt risk from internal initiating events.

O-9 $\mathrm{RX}_{\mathrm{R}} \mathrm{O}$ - A steam generator tube rupture occurs. If a main steam relief valve on the affected steam generator fails to close, recirculation from the sump is not an option since the break is cffectively outside containment. In this scenario, long-term cooling fails because the injection-phasc inventory is not maintained by continually refilling the BWST so as to allow extended injection and decay heat removal using the low-pressure system. If the secondary-side rcmains intact (i.e., the main-steam rclief valve closes), core melt commences if low-pressure injection and recirculation fail to function during the recirculation or decay heat removal modes of operation. The LPI system can fail as a result of various hardware faults, operations staff errors, or failures of the LPSW system that cools the LPI pumps. These sequences account for $2 \%$ of the core melt risk from internal initiating events.

O-10 VR - This sequence is unique in that it is a singie event: a disruptive rupture of the reactor pressure vessel (RPV) by a failure mode that precludes core reflooding. Thus, none of the safety systerns are effective after the initiating event. This sequence accounts for $2 \%$ of the core melt risk from internal initiators.

All other sequences individually contribute less than $2 \%$ of the core melt risk from internal initiating events.

\section{D.1.2 Public Risk}

Sequences important from the public risk standpoint for Oconee include most of the sequences important to core melt risk. Sequence $\mathrm{O}-8$ is the only sequence that does not appear to make a contribution to public risk. This is primarily due to the fact that this sequence does not directly affect the performance of the containment systems. The following sequence also becomes important to public risk:

O-11 ISLOCA - The interfacing system LOCA occurs when an interface between the high-pressure RCS and the LPI system is breached. The resultant LOCA allows the RCS water and any water injected for makeup to flow out the reactor building, thus bypassing containment. Mitigation fails directly as a result of the breach (e.g., the LPI pumps are damaged) or fails tater because there is no water in the sump for recirculation. The dominant location for an interfacing system LOCA is at the suction line from the RCS.

\section{D.1.3 Challenges to Safety Functions}

The safety functions derived from the Oconce PRA and the abnormal transient operating guidelines are as follows:

(1) RCS integrity.

(2) RPV integrity.

(3) Reactor subcriticality.

(4) RCS heat removal (via secondary system). 
(5) RCS pressure relief.

(6) Core heat removal.

(7) RCS makcup,

(8) Long-term heat removal.

(9) Reactor building cooling (heat removal).

All of the enumerated sequences, resulting in core melt and perhaps containmenı failure and public risk, involve challenges to one or more of these safety functions.

\section{D.1.4 Threats to Safety Systems}

The most significant threat to safety systems at Oconee Unit 3 is the loss of LPSW, Sequence O-1, since numerous systems rely on this system for cooling, including:

(1) The motors of the pumps in the HPI, emergency feedwater, and reactor coolant systems.

(2) The heat cxchangers of the decay heat removal system.

(3) The heat exchangers of the CCW system.

Other sequences that threaten numerous safety systems include sequences $0-5$ and $0-6$. An additional sequence posing a threat to safecy systems is:

O-12 $\mathrm{T}_{5} \mathrm{QU}$ - A loss of offsite power is followed by tocal power failures, resulting in a loss of ail AC power (i.e., a station blackout). The only system available for RCS heat renoval is the steam-driven emergency feedwater pump, which faits through hardware faults or operations staff errors. Once all feedwater is lost, the safety relicf valves are challenged and eventually open to discharge liquid, after which one or more valves fail to reclose. The inúuced LOCA cannot be mitigated due to the loss of all AC power.

\section{D.2 ATOG Coverage of the Critical Accident Sequences}

The Abnormal Transient Operating Guidelines (ATOGs) are symptom-based guidelines and as such do not distinguish the events by their initiating events. Rather, the symptoms or plant conditions are used to guide the actions of the operations staff. The ATOG used in this study was developed prior to the full implementation of the SSF, therefore, there is no reference to the SSF in the ATOG.

Sequence O-1 (Loss of LPSW causing RCP scal lcakage without makeup)

A loss of LPSW event is not addressed directly in the ATOG. In the INADEQUATE CORE COOLING guideline a step instructs the operations siaff to trip a RCP if the LPSW is lost and not restored to the RCP motor within 30 minutes. The necd for RCP seal cooling is not clearly indicated in the guidance and the only reference to the reliance of numerous systems on the LPSW system is in the system auxiliary diagram (SAD) section; which lists the components required to support each of the systems.

Sequence O-2 (Large-break LOCA with failure of low-pressure recirculation)

A Jarge-break LOCA will probably resuls in an ovcrheating transicnt condition for which guidance is provided in the LACK OF HEAT TRANSFER guideline (guideline III-B). An indication of a large LOCA is that the RCS pressure drops and the corc flood tanks are discharging to the RCS. CP-10I provides instructions for long-term corc cooling following a major LOCA. There are instructions to align to the sump for recirculation if the BWST lo- lo level alarms 
(i.e., level Jrops to $6 \mathrm{ft}$ ) and also provides instruction to throttle LPI valves to prevent pump cavitation. Should lowpressurc recirculation fail, the opcrations staff will enter the INADEQUATE CORE COOLING guidance.

\section{Sequence O-3 (Transient without scram)}

The guidance related to transient without scram events deals primarily with the steps for control rod insertion and boration to shutdown the reaction. Should main feedwater fail, emergency feedwater would be actuated to cnsurc an overheating transient does not occur. In the case where both main feedwater and emergency feedwater fail, HPI cooling would be initiated as directed by the LACK OF HEAT TRANSFER guideline (guideline III-B) and the sequence is similar to sequence O-5. If a LOCA is induced, the same guideline is used and the scquence is similar to sequence $\mathrm{O}-2$.

\section{Sequence 0-4 (Small-break LOCA without high-pressure recirculation)}

The guidelines that address the potential for RCS inventory losses do not provide instructions for shutting down the I eactor building sprays to conserve the BWST inventory used by the HPI system to provide makcup to the RCS. Guidance is provided for initiating high-pressure recirculation, using the LPI system to provide pump suction. Should high-pressure recirculation fail, the operations staff will enter the INADEQUATE CORE COOLING guidelines. At this point, if failed systems cannot be recovered, the operations staff will attempt to decrease the pressure of the RCS by opening the PORV and high point vents in order to make the core flood tanks and LPI system available for core cooling.

Sequence O-5 (Large fcedwatcr/condensate line break with failure of HPI cooling)

A large focdwater line break, which fails both main focdwater and emergency feedwater, will result in an overheating transient (i.e., a lack of heat transfer, guidcline III-B). This event is addressed in the ATOG and is one of the scenarios discussed in depth in Part II of the ATOG. The guidance expects the loss of natural circulation to oceur for an extended loss of fcedwater. The corrcetive actions for a loss of all feedwater are to attempt to restore feedwater; failing to do so, starting HPl cooling. Dircetion is given to actuate two HPI pumps and run them at full capacity while manually opening the PORV. In audition, all but one RCP should be tripped, thus reducing the heat load while still maintaining forcel core cooling. Upon losing all subcooling margin, all RCPs are tripped. Upon failure of HPI cooling, the operations staff will enter the INADEQUATE CORE COOLING guidelines. At this point, if failed systems cannot be recuvered, the operations staff will attempt to decrease the pressure of the RCS by opening the PORV and high point vents in order to make the core flood tanks and LPI system available for core cooling.

Sequence O-6 (Loss of instrument air with failure of primary or secondary cooling)

The toss of instruntent air results in a reliance on the emergency feedwater system steam-driven pump for secondaryside heat removal. Upon failure of this pump, the sequence and guidance is essentially the same as the loss of alt feedwater, described in $\mathrm{O}-5$ as an overheating transient.

Sequence O-7 (SGTR with failure of HPI)

There is a specific guideline (guideline III-D) for the occurrence of a SGTR and the SGTR scenario is discussed in detail in Part Il of the ATOG. Identification of the tube rupture is probably from the steam line or condenser air cjector radiation alarm. If the primary-to-secondary heat transfer is excessive, the operations staff is directed to follow EXCESSIVE HEAT TRANSIFE, guideline III-C, as expeditiously as possible and then to return to the SGTR guideline after heat transfer is stabilized. Guideline IH-C results in the isolation of the faulted stcan generator and the use of the funcrioning steam generator for secondary-side heat removal. Upon return to the SGTR guideline, the 
operations staff begins to cooldown and depressurize. If the HPI system fails, the operations staff will enter the INADEQUATE CORE COOLING guidance. At this point, if failed systems cannot be recovered, the operations staff will attempt to decrease the pressure of the RCS by opening the PORV and high point vents in order to make the core flood tanks and LPI system available for core cooling.

Sequence O-8 (Loss of MFW with faiłure of primary or secondary cooling)

A loss of main and emergency feedwater will result in an overheating transient. This scquence and related guidance is essentially the same as that given for 0.5 .

Scquence O-9 (SGTR with failure of long-term heat removal)

Therc is a specific guideline for the occurrence of a steam generator tube rupture, which is one of the scenarios discussed in detail in Part II. Indication of an SGTR is probably given by the steam line or condenser air ejector radiation alarm. If the primary-to-secondary heat transfer is excessive, which would be the case if a main steam relicf valve is stuck open, the operations staff is directed to follow EXCESSIVE HEAT TRANSFER, guidelinc III-C, as expeditiously as possible and then to return to the SGTR guidcline after heat transfer is stabilized. Guideline III-C results in the isolation of the faulted stcam generator and the use of the functioning steam generator for secondary-side heat removal. Upon return to the SGTR guideline, the operations staff begins a rapid cooldown if the SGTR leak rate is greater than the capacity of one normal makeup pump. There is no guidance mentioned in Parl I of the ATOG to continually replenish the BWST to avoid entering the recirculation phase if the main steam relief valve is stuck open; it is, however, recognized in Part II of the $A T O G$ that recirculatiou from the sump during a SGTR is not possible and means to replenish the BWST may need to be established. If long-term heat removal fails, the operations staff will enter the INADEQUATE CORE COOLING guidance. At this point, if failed systems cannot be recovered, the operations staff will attempt to decrease the pressurc of the RCS by opening the PORV and high point vents in order to make the core flood tanks and LPI systcm available for core cooling.

Sequence O-10 (RPV rupturc)

Duc to the catastrophic nature of this event no actions can be taken to mitigate the accident or release. The ATOG does not address this event since therc are no mitigating actions that could be rakeu. Actions to limit the potential for this type event arc implied by trying to avoid thermal shock and britle fracture operational regimes. Steps include throttling the HPI tow when subcooling margin is restorcd and restarting a RCP. Startiug the RCP will mix the HP] water with reactor coolant, thus raising the temperature of the water and preventing britle fracture.

\section{D.3 ATOG Coverage of the "A" Strategies}

\section{Strategy 2.1 (Reduce Containment Spray Flow Rate to Conserve Water for Core} Injection)

The AIOG does not recommend a strategy to reduce or terminate the reactor building sprays to conserve the water available to the core injection systems from the BWST. The need to provide for replenishing the BWST is referted to in the casc of a SGTR, where the RCS inventory does not reach the sump. The ATOG emphasizes being in the decay heat removal mode before depleting the BWST. 
Strategy 2.2 (Enablc Early Detection, Isolation, or Otherwise Mitigate the Effects of an Interfacing Systems LOCA)

The ATOG provides direct guidance on identifying and isolating various types of LOCAs. For isolatabic LOCAs, the locating symptoms and isolating valves are identified. Five LOCAs are identified as non-isolatable: SGTR, open pressurizer safety valves, HPI injection line break, RCP pump seal LOCA and RCS instrumentation line brcak. For these, locating symptoms are provided. Specific guidance is provided for the oceursence of a SGTR.

\section{Strategy 2.3.2 (Refill Refueling Water Storage Tank with Borated Water)}

The ATOG recognizes the need to replenish the BWST in situations where thcre is not adequate inventory in the sump. This is directly addressed for the case of SGTRs, though the source(s) of this additionat borated water is not identified.

Strategy 2.4 (Ensure Appropriatc Recirculation Switchover and Manual Intervention Upon Failure of Automatic Switchover)

The ATOG recognizes the need to verify that the switch over to recirculation is achieved. Two general causes of recirculation failure arc identified: loss of sump water and loss of both suction paths from the sump. The loss of sump water can occur because the RCS inventory does not accumulate in the sump (e.g., during a SGTR) or the sump water is diluted from a non-borated source, which requires the sump water to be borated and the dilution to be terminated. The loss of both suction paths can occus as a result of clogging or if both sump valves fail to open. The clogged valves may be cleared by back flushing the line. If the valves fail to open, local manual operation of the valves is suggested. However, it is recognized that local attempts to open these valves may not be possible because the radiation levels may be too high.

Strategy 2.5 (Ensure Adequate Piant Heat Removal Capability by Emergency Connection(s) of Existing or Alternate Water Sources)

The Oconee SSF can providc a backup supply of feedwatcr to the steam generators for secondary-side heat removal and can inject and maintain sufficient inventory in the RCS to sustain natural circulation and cool the RCP seals. The SSF also has its own electrical power system, with a dedicated diesel generator. This facility provides an additional level of backup to numerous important safety systems. The ATOG used in this study does not identify this backup systern because the SSF was not fully implemented at Oconee at the time the ATOG was developed.

\section{Strategy 3.2.1 (Enable Emergency Bypass or Change of Protective Trips for Injection Pumps)}

This strategy is not discussed in the ATOG.

\section{Strategy 3.3.2 (Use Non-Sately Related Charging Pumps for Core Injection)}

The ATOG specific rules for initiating HPI state that if one HPI pump fails to start then the makcup pump is put into service, taking suction from the BWST. In addition, the SSF also provides an independent backup to the HPI system.

\section{Strategy 3.4 (Use Aliernatc Seal Injection (c.g., Hydrotest Pump) When Reactor Coolant Pump Seal Cooling is} Losi)

If RCP seal cooling is lost, the operations staff will trip the RCPs and attempt to recover seal cooling. The SSF provides a backup to this function and essentially implements the strategy at the Oconee Nucicar Station. 
Appendix D

Stratcgy 3.5 (Use Condensate Pumps or Startup Feedwater Pumps for Steam Generator Injection)

At Oconec, this strategy is essentially implemented since the SSF can be used to provide feedwater to the stcam igencr. ators for sccondary-side heat removal. Since the SSF has a dedicated diesel generator, this feedwater source is not dependent on site AC power.

Sirategy 4.1 (Conscrve Batiery Capability by Shedding Non-Essential Loads)

This strategy is not discusscd in the ATOG.

Strategy 4.2 (Use Portabic Battery Chargers or Other Power Sources to Recharge Station Batteries)

This stratcgy is not discussed in the ATOG.

Strategy 4.3 (Enable Emergency Replenishment of the Pneumatic Supply for Safety Related Air Operated Components)

This stralcgy is not discussed in the ATOG.

Srategy 4.4 (Enable Emergency Bypass or Change of Protective Trips for Emergency Diesel Generators)

This strategy does not apply since the Keowee Hydroelectric Station is the emergency AC power source for the Oconee Nuclear Station.

Strategy 4.5 (Enable Emergency Crosstie of AC Power Between Two Units or to an Onsite Gas Turbine Generator)

The emergency power source for all three Oconce units is the Keowee Hydroelectric Station, which supplies power via a $230-\mathrm{kV}$ line to the Oconee suitchyard. In addition, the Lee Steam Station combustion turbines can provide backup emergency AC power if the Keowec Hydroelcetric Station is unavailablc. A crosstie between Oconee units is thus not necessary.

Strategy 4.7 (Use Diesel-Driven Firewater Purnp for ... Steam Generator Injection or Containment Sprays)

The strategy for using a pump that is indepcndent of oasite AC power for steam generator injection is essentially implemented at Oconec since the SSF can be used to provide the fecdwater and has its own dedicated diesel genetator. The ATOG does not discuss the use of au independent source for reactor building sprays.

Strategy 5.1 (Reopen Main Steam Isolation Valves and Turbinc Bypass Valves to Regain the Main Condenser as a Heat Sink)

This strategy is not discussed in the ATOG.

Strategy 6.1 (Provide Addjtional Supply of Borated Makeup Watcr for Long-Term Accident Control)

This strategy is similar to the strategy involving replenishing the BWST borated water inventory. 
Appendix E

Table of Acronyms 


\section{Appendix E}

\section{Table of Acronyms}

\begin{tabular}{|c|c|}
\hline $\mathrm{AC}$ & alternating current \\
\hline $\mathrm{AFW}$ & auxiliary feedwater \\
\hline $\mathrm{AI}$ & artificial intelligence \\
\hline ANN & artificial neural network \\
\hline AOP & Abnormal Operating Procedures \\
\hline ASWS & Auxiliary Service Water system \\
\hline ATOG & Abnormal Transient Operating Guidelinc \\
\hline ATWS & anticipated transicnt without scram \\
\hline $\mathrm{B} \& \mathrm{~W}$ & Babcock \& Wilcox \\
\hline BNL & Brookhaven National Laboratory \\
\hline BWST & Borated Water Storage Tank \\
\hline $\mathrm{CC}-1$ & Calver: Clifis-1 \\
\hline $\mathrm{CCP}$ & centrifugal charging pumps \\
\hline $\mathrm{CCW}$ & Component Cooling Water system \\
\hline CE & Combustion Engineering \\
\hline CEOG & Combustion Engineering Owners Group \\
\hline CET & corc exit thermocouple \\
\hline CFT & core flood tank \\
\hline $\mathrm{DC}$ & direct current \\
\hline $\mathrm{DCH}$ & direct containment heating \\
\hline DG & diesel generator \\
\hline DST & demineralized water storage tank \\
\hline $\mathrm{ECCS}$ & emergency core cooling system \\
\hline EDG & emergency diesel generator \\
\hline EOP & Emergency Operating Procedure \\
\hline EPG & Emergency Procedures Guideline \\
\hline $\mathrm{ERG}$ & Emergency Response Guideline . \\
\hline FCI & fuel-coolant interaction \\
\hline FP & Fire Protection system \\
\hline FR & Funetional Restoration \\
\hline FRG & Functional Recovery Guideline \\
\hline FSAR & Final Safety Analysis Report \\
\hline $\mathrm{FY}$ & fiscal year \\
\hline HJTC & heated junetion thermocouple \\
\hline HPI & high-pressure injection \\
\hline
\end{tabular}

\begin{tabular}{|c|c|}
\hline HPME & high-pressure melt ejection \\
\hline HPSI & high-pressure safety injection \\
\hline HPSI/R & $\begin{array}{l}\text { high-pressure safety injection/recirculation } \\
\text { mode }\end{array}$ \\
\hline HPSW & high-pressure servicc water \\
\hline $\mathrm{ICC}$ & inadequate core cooling \\
\hline IPE & Indivjdual Plant Evaluations \\
\hline IREP & Interim Reliability Evaluation Program \\
\hline IRM & Interruption and Resumption Mode \\
\hline JPA & job performance aid \\
\hline kVA & kilovolt amp \\
\hline LOCA & loss of coolant accident \\
\hline LOF & loss of feedwater \\
\hline LOFT & Loss-of-Fluid Test \\
\hline LOSP & Loss of Offsite power \\
\hline LPI & Low Pressure injection \\
\hline LPSW & Low Prcssure Service Water system \\
\hline MAAP & Modular Accident Analysis Code \\
\hline MFW & Main Feedwater \\
\hline MOV & motor-operated valve \\
\hline MSIV & Main Steam Isolation VaIve \\
\hline $\mathrm{NRC}$ & Nuciear Rcgulatory Commission \\
\hline NRCRES & Oflice of Nuclear Regulatory Research \\
\hline NSAC & Nuclear Safety Analysis Center \\
\hline ORG & Optimal Recovery Guideline \\
\hline OTSG & once-through steam generator \\
\hline PCS & Power Conversion System \\
\hline PNL & Pacific Northwest Laboratory \\
\hline PORV & Pilot (or Power) Operated Relief Valve \\
\hline PRA & probabilistic risk assessment \\
\hline PTS & pressurized thermal shock \\
\hline PWR & pressurized water reactor \\
\hline
\end{tabular}


Appendix E

$\begin{array}{llll}\text { RCP } & \text { Reactor Coolant Punp } & \text { SPND } & \text { self-powered neutron detcctor } \\ \text { RCS } & \text { Reactor Coolant System } & \text { SRV } & \text { safety relicf valve } \\ \text { RCVCS } & \text { Rcactor Coolant Volume Control System } & \text { SSF } & \text { Standby Shutdown Facility } \\ \text { RHR } & \text { Residual Heat Removal systern } & \text { SSF } & \text { Standby Shutdown Facility } \\ \text { RPV } & \text { Reactor Pressure Vessel } & \text { SW } & \begin{array}{l}\text { Service Water system } \\ \text { Service Water system }\end{array} \\ \text { RVLIS } & \begin{array}{l}\text { Reactor Vessel Lcvel instrumentation } \\ \text { system }\end{array} & \text { SWS } & \\ & & \text { TBV } & \text { Turbine Bypass Valvc } \\ \text { RWST } & \text { Refucling Water Storage Tank } & \text { TMI-2 } & \text { Three Mile Island, Unit 2 } \\ \text { RWST } & \text { refueling water storage tank } & & \\ & & \text { U-235 } & \text { uranium-235 isotope } \\ \text { SAD } & \text { system auxiliary diagram } & \text { UPS } & \text { uninterruptible power system } \\ \text { SBO } & \text { station blackout } & \text { USNRC } & \text { U.S. Nuclear Regulatory Commission } \\ \text { SCRAM } & \text { scram, a rapid shutdown of the reactor } & & \\ \text { SG } & \text { steam generator } & \text { W } & \text { Westinghousc } \\ \text { SGTR } & \text { steam generator tube rupturc } & \text { WOG } & \text { Westinghouse Owners Group } \\ \text { SI } & \text { safety injection } & & \end{array}$


NUREG/CR-5856

PNL -8022

\section{OISTRIBUTION}

No. of

Copies

OFFSITE

Gary Bair

Portland General Electric

Trojan Nuclear Power Plant

71760 Columbia River Highway

Rainier, OR 97048

Peter Cybulskis

Battelle Memorial Institute

505 King Avenue

Columbus, $\mathrm{OH} 43201$

Dr. Richard Denning

Battelle Memorial Institute

$505 \mathrm{King}$ Avenue

Columbus, OH 43201

Dr. Vijay Dhir

Univ. of California, Los Angeles

Mechanical, Aerospace, and Nuclear Engineering Department

405 Hilgard Ave.

Los Angeles, CA 90024-1957

5 Donald G. Harrison

Jason Associates

255 B Street, Suite 203

Idaho Falls, ID 83402

Dr. William Kastenberg

Univ. of California, Los Angeles

Mechanical, Aerospace, and Nuclear Engineering Department

405 Hilgard Ave.

Los Angeles, CA 90024-1957
No. of

Copies
Dr. Pui Kuan

EG\&G Idaho, Inc.

P.0. Box 1625

Idaho Falls, ID 83415-1576

Dr. Sudarshan K. Loyalka

Dept. of Nuclear Engineering

$U$ of Missouri-Columbia

Columbia, MO 65201

Dr. Norm McCormick

Dept. of Mechanical Engineering

Univ of Washington

Seattle, WA 98195

5 Mike Morgenstern

Battelle HARC

P.O. Box 5395

4000 N.E. 41 st Street

Seattle, WA 98105-5428

Walter Scott

2537 Cordova Court

Richland, WA 99352

ONSITE

25 Pacific Northwest Laboratory

Francis Buck

Dr. Spencer H. Bush

Laurin Dodd

James Dukelow (10)

Dr. Bryan Gore (3)

Jim Jamison

James Livingston

Tim Mitts

Robert Moffitt

Dr. Billy Shipp

Eric Schmieman

Larry Sherfey

Rollie Warner

Kevin Winegardner 



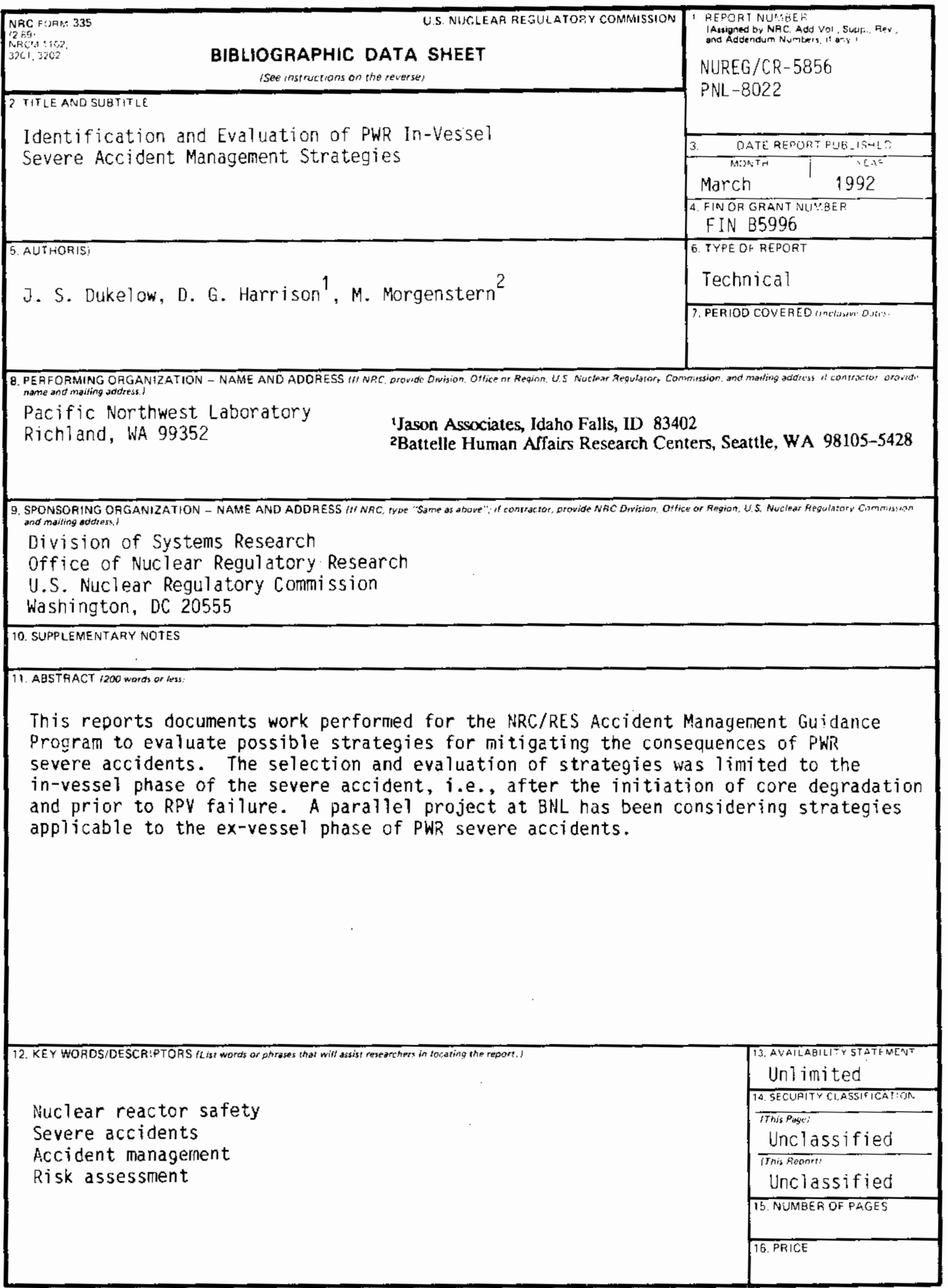


THIS DOCUMENT WAS PRINTED UGING RECYCLED PAPER 